CENTRO UNIVERSITÁRIO FEI

MOISÉS SANTANA PEREIRA

PREDIÇÃO DO CONSUMO DE ENERGIA ELÉTRICA EM SISTEMAS JOB SHOP UTILIZANDO TÉCNICAS DE APRENDIZADO DE MÁQUINA

São Bernardo do Campo 

MOISÉS SANTANA PEREIRA

\title{
PREDIÇÃO DO CONSUMO DE ENERGIA ELÉTRICA EM SISTEMAS JOB SHOP UTILIZANDO TÉCNICAS DE APRENDIZADO DE MÁQUINA
}

\author{
Dissertação de Mestrado, apresentada ao Centro \\ Universitário da FEI para obtenção do título de Mes- \\ tre em Engenharia Mecânica. Orientado pelo Prof. \\ Dr. Fábio Lima.
}

São Bernardo do Campo 


\section{Pereira, Moises Santana.}

Predição do consumo de energia elétrica em sistemas job shop utilizando técnicas de aprendizado de máquina / Moises Santana Pereira. São Bernardo do Campo, 2019.

117 p. : il.

Dissertação - Centro Universitário FEI.

Orientador: Prof. Dr. Fábio Lima.

1. eficiência energética. 2. sistemas job shop. 3. redes neurais artificiais. I. Lima, Fábio, orient. II. Título.

Elaborada pelo sistema de geração automática de ficha catalográfica da FEI com os dados fornecidos pelo(a) autor(a). 
Aluno: Moisés Santana Pereira

Título do Trabalho: Predição do consumo de energia elétrica em sistemas job shop utilizando técnicas de aprendizado de máquina.

Área de Concentração: Produção

Orientador: Prof. Dr. Fábio Lima

Data da realização da defesa: 28/02/2019

ORIGINAL ASSINADA

Avaliação da Banca Examinadora:

São Bernardo do Campo,

\section{MEMBROS DA BANCA EXAMINADORA}

Prof. Dr. Fábio Lima

Prof. Dr. Alexandre Augusto Massote

Prof. Dr. Ivan Nunes da Silva
Ass.:

Ass.:

Ass. :

A Banca Julgadora acima-assinada atribuiu ao aluno o seguinte resultado:

APROVADO \ REPROVADO

\section{VERSÃO FINAL DA DISSERTAČ̃̃O}

APROVO A VERSÃO FINAL DA DISSERTAÇÃO EM QUE FORAM INCLUÍDAS AS RECOMENDAÇÕES DA BANCA EXAMINADORA
Aprovação do Coordenador do Programa de Pós-graduação

Prof. Dr. Rodrigo Magnabosco 

Dedico este trabalho à minha amada avó Afra (in memoriam), uma mulher de origem simples, mas extremamente sábia, altruísta e de muita fé. 



\section{AGRADECIMENTOS}

Primeiramente, agradeço à Deus, que sempre me abençoou com sabedoria e paixão para lutar pelos meus objetivos, mesmo diante das dificuldades e peças que a vida nos prega.

Aos meus queridos pais, João e Iraci, por todos os valores transmitidos e ensinamentos de que sempre podemos alcançar aquilo que sonhamos.

À minha amada esposa Janaína, por sempre acreditar em mim, me motivar na busca dos meus sonhos, apoiar minhas decisões, dar suporte nos momentos de angústia e, principalmente, pelos sacrifícios e concessões realizados.

Ao exímio Prof. Aguinaldo Prandini Ricieri, por jogar luz em meu caminho na busca por novos conhecimentos.

Aos ilustres Prof. Dr. Alexandre Massote e Prof. Dr. Rodrigo Filev, pelas imprescindíveis contribuições dadas durante a etapa de qualificação deste projeto.

Ao Prof. Dr. Fábio Lima, por acreditar neste trabalho desde o início, pelo incentivo, pela amizade, pela orientação e disponibilidade durante toda a execução.

Ao Centro Universitário Fei, por todo o suporte e assistência prestada desde a minha graduação.

À todos os demais colegas que, direta ou indiretamente, contribuíram para a execução deste trabalho. 

"Não permita que nenhum obstáculo o detenha.

Onde há obstáculos há também grandes oportunidades"

Dorothy Herman 



\section{RESUMO}

A eficiência energética se tornou um grande desafio para as empresas de manufatura. Embora seja possível melhorar a eficiência energética aplicando novas máquinas mais eficientes, os tomadores de decisão tendem a buscar por alternativas mais baratas. Neste contexto, a adoção de estratégias mais eficientes durante o planejamento e programação da produção permitem a redução no consumo de energia e emissões associadas a ela. Além disso, a realidade atual das empresas de manufatura, trazida pelos conceitos da Indústria 4.0, requer maior flexibilidade dos sistemas de produção e, assim, aumentando a complexidade para a programação das máquinas de tal forma que não sejam comprometidos os aspectos sustentáveis. Desta forma, este trabalho propõe um método para estimação do consumo de energia em sistemas do tipo job shop aplicando técnicas de aprendizado de máquina (machine learning). Diferentes programações podem resultar em diferentes tempos de processamento e taxas de consumo de energia. Contudo, estimar o consumo total de energia pode exigir análises sistemáticas ou a aplicação de ferramentas de simulação, por exemplo. Sendo assim, uma rede neural artificial é aplicada para uma rápida estimação da energia total consumida neste tipo de sistema. A fim de validar o modelo, experimentos computacionais utilizando ferramentas de software de manufatura digital foram realizados em diferentes configurações de um sistema job shop, para demonstrar a eficiência do modelo proposto.

Palavras-chave: Eficiência energética. Sistemas job shop. Redes neurais artificiais. 



\begin{abstract}
Energy efficiency has become a great challenge for manufacturing companies. Although it is possible to improve efficiency applying new and more efficient machines, decision makers tend to look for some less expensive alternatives. In this context, the adoption of more efficient strategies during the production planning can allow the reduction in energy consumption and associated emissions. Furthermore, the current reality of manufacturing companies, brought by Industry 4.0 concepts, requires more flexibility of production systems, thus, increasing complexity for machine rescheduling without compromising sustainable requirements. Thus, this work proposes a method to predict total energy consumption in job shop systems applying machine learning techniques. Different schedules may result in different consumption rates. However, to estimate the total energy consumption might require systematic analyses or the application of simulation tools, for example. In order to validate the model, computational experiments, using digital manufacturing software tools, are performed on different job shop configurations to show the efficiency of the proposed model.
\end{abstract}

Keywords: Energy efficiency. Job shop system. Artificial neural networks. 



\section{LISTA DE ILUSTRAÇÕES}

Figura 1 - Proposta de evolução dos atributos decisórios da manufatura . . . . . . . . . 32

Figura 2 - Níveis de análise da eficiência energética . . . . . . . . . . . . 35

Quadro 1 - Comparativo entre diferentes abordagens de classificação dos níveis de análise da eficiência energética na manufatura . . . . . . . . . . . 36

Figura 3 - Comparação qualitativa entre o número de indicadores propostos na literatura (a) e o número necessário (b) para cada nível de agregação. . . . . . . . . . . 41

Figura 4 - Classificação dos modelos de planejamento da produção. . . . . . . . . . . . 42

Figura 5 - Possíveis estados de energia de máquinas e equipamentos . . . . . . . . 44

Figura 6 - Vínculos entre os estados produtivos e energéticos . . . . . . . . . . 44

Figura 7 - Representação do modelo matemático de um neurônio artificial . . . . . . . 58

Figura 8 - Exemplo de rede neural do tipo feed-forward . . . . . . . . . . 60

Figura 9 - Exemplo de rede neural do tipo recorrente . . . . . . . . . . . . . 60

Quadro 2 - Principais métricas de desempenho de RNA identificadas na literatura . . . 63

Figura 10 - Exemplo de um sistema do tipo job shop . . . . . . . . . . . . . 65

Figura 11 - Aplicação do operador de crossover . . . . . . . . . . . . . . 68

Figura 12 - Estrutura básica do Algoritmo Genético . . . . . . . . . . . . . . . 70

Figura 13 - Operador GOX - Cromossomo "Pai" . . . . . . . . . . . . . . . 71

Figura 14 - Operador GOX - Cromossomo "Mãe" ～. . . . . . . . . . . . . . . . . . . 71

Figura 15 - Operador GOX - Cromossomo "Pai"adequado . . . . . . . . . . . . . . 71

Figura 16 - Operador GOX - Cromossomo "Filho" . . . . . . . . . . . . . . . . . 71

Figura 17 - Análise energética no nível da linha de produção . . . . . . . . . . . 73

Figura 18 - Modelo de simulação do sistema job shop . . . . . . . . . . . . . . . . . 75

Figura 19 - Exemplo de decodificação do vetor de entrada . . . . . . . . . . . . . . 77

Quadro 3 - Equivalência entre os parâmetros utilizados no modelo e os disponíveis no software .............................. 80

Figura 20 - Janela de configuração dos parâmetros de energia da máquina . . . . . . . . 81

Figura 21 - Gráfico do consumo de energia por estado de cada máquina . . . . . . . 82

Figura 22 - Gráfico de consumo total de energia . . . . . . . . . . . . . . . . 83

Figura 23 - Exemplo do cálculo da nuance fator de prioridade . . . . . . . . . . . 84 
Figura 24 - Mapeamento das variáveis de entrada e saída

Figura 25 - Gráfico de acompanhamento do erro de treinamento e validação do módulo

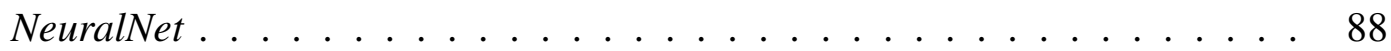

Figura 26 - Ciclo de geração do banco de treinamento . . . . . . . . . . . . . . . . . . 92

Figura 27 -Erro de treinamento para o experimento $1 \ldots \ldots$. . . . . . . . . 93

Figura 28 - Erro de treinamento para o experimento $2 \ldots \ldots$. . . . . . . . 93

Figura 29 - Erro de treinamento para o experimento $3 \ldots \ldots$. . . . . . . . . . 94

Figura 30 - Erro de treinamento para o experimento $4 \ldots \ldots$. . . . . . . . . 94

Figura 31 - Erro de treinamento para o experimento $5 \ldots \ldots$. . . . . . . . 95

Figura 32 - Erro de treinamento para o experimento $6 \ldots \ldots$. . . . . . . 95

Figura 33 - Erro de treinamento para o experimento $7 \ldots \ldots$. . . . . . . . 96

Figura 34 - Erro de treinamento para o experimento $8 \ldots \ldots$. . . . . . . 96

Figura 35 - Atuação do algoritmo de reinicialização da Rede Neural Artificial (RNA) para o experimento $2 \ldots \ldots \ldots \ldots$

Figura 36 - Integração entre o modelo de simulação e o algoritmo de otimização. . . . . 101

Figura 37 - Comparativo entre o valor alvo e a saída da RNA . . . . . . . . . . . 106

Figura 38 - Histograma do erro de estimação da RNA . . . . . . . . . . . . . . . . 107

Figura 39 - Mapa de calor da correlação entre as variáveis . . . . . . . . . . . . . . . . 109

Figura 40 - Erros de estimação antes da normalização . . . . . . . . . . . . . . . 111

Figura 41 - Erros de estimação após a normalização . . . . . . . . . . . . . . . . . . . 111

Figura 42 - Erros de estimação para função de ativação identidade . . . . . . . . . . . 112

Figura 43 - Desempenho da RNA para diferentes conjuntos de treinamento . . . . . . 113

Figura 44 - Erros de estimação para o conjunto de treinamento $M L$. . . . . . . . . . . 114

Figura 45 - Erros de estimação para o conjunto de treinamento $S T$. . . . . . . . . . . 114

Figura 46 - Erros de estimação para o Grupo 1 Individual $(M L+N u m J o b s) ~ \ldots . . \ldots 115$

Figura 47 - Erros de estimação para o Grupo 2 Individual $(F P) \ldots \ldots$. . . . . . . . . 116

Figura 48 - Erros de estimação para o Grupo 3 Individual $(S T+E T)$. . . . . . . . . 116

Figura 49 - Erros de estimação para o Grupo 1 Acumulado $(M L+N u m J o b s)$. . . . . . . 116

Figura 50 - Erros de estimação para o Grupo 2 Acumulado $(F P+M L) \ldots \ldots \ldots$. . . . 117

Figura 51 - Erros de estimação para o Grupo 3 Acumulado $(F P+M L+N u m J o b s+S T+E T) \quad 117$

Figura 52 - Algoritmo para o cálculo dos instantes de início e término das máquinas . . . 130 
Figura 53 - Algoritmo para o cálculo do Fator de Prioridade . . . . . . . . . . . . . 132 



\section{LISTA DE TABELAS}

Tabela 1 - Exemplo de tabela de sequenciamento e tempos das operações . . . . . . . . 64

Tabela 2 - Tabela de sequenciamento e tempos das operações de cada job . . . . . . . 78

Tabela 3 - Potência consumida pelas máquinas . . . . . . . . . . . 80

Tabela 4 - Resumo dos resultados para cada configuração da RNA . . . . . . . . . . . 97

Tabela 5 - Desempenho da RNA para diferentes coeficientes de momento . . . . . . . 99

Tabela 6 - Estimativa de consumo de energia para ordens de produção pós algoritmo heurístico . . . . . . . . . . . . . . . . . . 102

Tabela 7 - Melhor valor de $\mathrm{R}^{2}$ para cada um dos grupos de variáveis . . . . . . . . 115 



\section{LISTA DE ABREVIATURAS}

AG Algoritmo Genético.

BP Back-Propagation.

CPS Cyber Physical System.

DRC Dual Resource Constrained.

EnPIs Energy Performance Indicators.

GAEJP Genetic Algorithm Electricity Saving in Job Shop.

GOX Generalization of Order-Crossover.

LS Local Search.

LTF Long Term Forecasting.

MEM Methods Energy-Measurement.

MKS Tempo Total de Processamento.

MTF Medium Term Forecasting.

NARX Nonlinear AutoRegressive with eXogenous.

NNGA Neural Network based Genetic Algorithm.

NNPSO Neural Network based Particle Swarm Optimization.

NSGA-II Nondominated Sorting Genetic Algorithm II.

ONU Organização das Nações Unidas.

PIB Produto Interno Bruto.

PMC Perceptron de Múltiplas Camadas.

RBF Radial Basis Function.

RNA Rede Neural Artificial.

SPEA-II Strength Pareto Evolutionary Algorithm II.

SPT Shortest Process Time.

STF Short Term Forecasting.

SVM Support Vector Machine.

SWBP Small-World BP.

TEC Energia Total Consumida.

TLBO Teacher-Learning-Based Optimization.

VSTF Very Short Term Forecasting.

WEC Energia Total Não Produtiva. 



\section{SUMÁRIO}

INTRODUÇÃ̃O . . . . . . . . . . . . . . . . . . 25

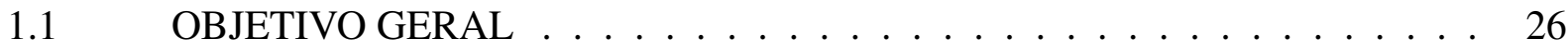

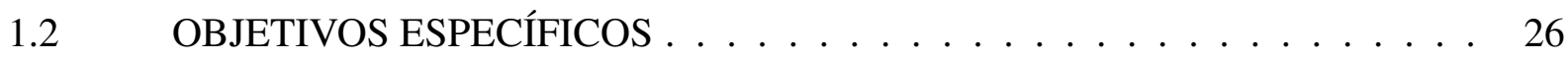

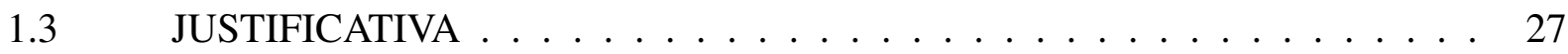

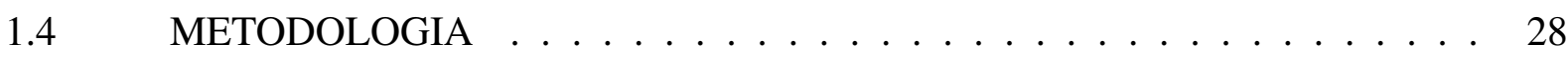

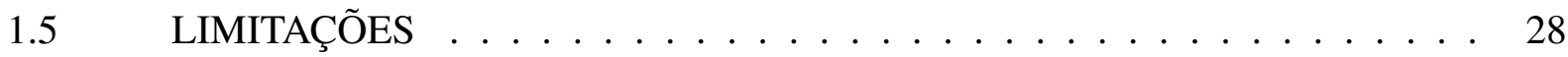

$1.6 \quad$ PRINCIPAIS TERMOS . . . . . . . . . . . . . . . . . 29

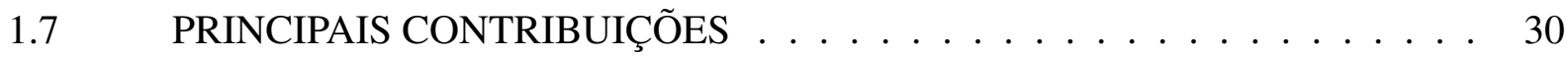

2 REVISÃO DA LITERATURA . . . . . . . . . . . . . . . . . 31

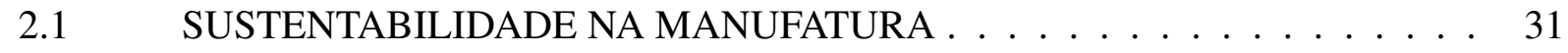

2.2 EFICIÊNCIA ENERGÉTICA NO CONTEXTO DA MANUFATURA . . . . . 33

2.3 CLASSIFICAÇÃO DOS NÍVEIS DE ANÁLISE DA EFICIÊNCIA ENERGÉ-

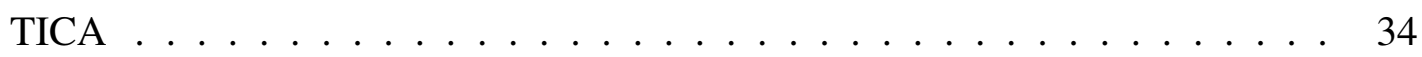

$2.4 \quad$ EFICIÊNCIA ENERGÉTICA EM LINHA DE PRODUÇÃO . . . . . . . . . . 35

2.5 PROGRAMAÇÃO DA PRODUÇÃO ORIENTADA À EFICIÊNCIA ENERGÉTICA ............................. 40

2.6 EFICIÊNCIA ENERGÉTICA EM SISTEMAS DO TIPO JOB SHOP . . . . 42

2.7 REDES NEURAIS ARTIFICIAIS NA PROGRAMAÇÃO DA PRODUÇÃO 46

$2.8 \quad$ REDES NEURAIS APLICADAS À ANÁLISE ENERGÉTICA . . . . . . . . 49

2.8.1 Análise comparativa do desempenho energético entre diferentes plantas, indústrias ou nações . . . . . . . . . . . . . . . . . . . . . 50 50

2.8.2 Previsão da produção de energia em usinas geradoras . . . . . . . . . . . . . 51

2.8.3 Previsão de carga para o gerenciamento de demanda e balanceamento de rede de energia $\ldots \ldots \ldots \ldots$

2.8.4 Previsão do consumo de energia para plantas industriais, transportes e instalações prediais . . . . . . . . . . . . . . . . . . . 54

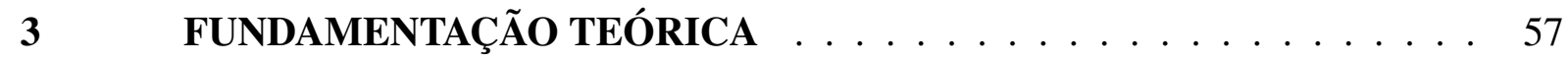

$3.1 \quad$ REDES NEURAIS ARTIFICIAIS . . . . . . . . . . . . . . . 57

3.1.1 Representação básica de uma rede neural . . . . . . . . . . . . . . . . . 57 
3.1.2 Classificação das redes neurais artificiais $\ldots \ldots \ldots \ldots$

3.1.3 Rede Perceptron de Múltiplas Camadas . . . . . . . . . . . . . . . . . . . 61

3.1.4 Treinamento e validação da rede . . . . . . . . . . . . . . . . . . . . 62

$3.2 \quad$ SISTEMAS JOB SHOP $\ldots \ldots \ldots \ldots \ldots \ldots \ldots$

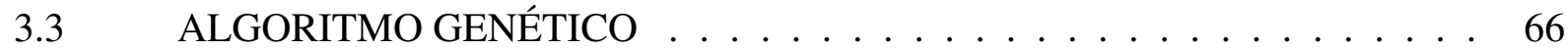

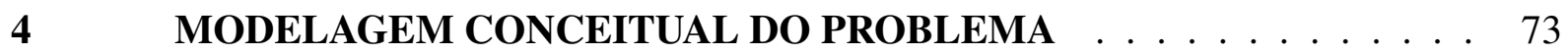

$4.1 \quad$ DESCRIÇÃO GERAL DO MODELO . . . . . . . . . . . . . . . . . . 74

4.2 CONFIGURAÇÃO GERAL DO SISTEMA SIMULADO . . . . . . . . 76

4.3 CONJUNTO DE TREINAMENTO PARA ESTIMAÇÃO DA ENERGIA TO-

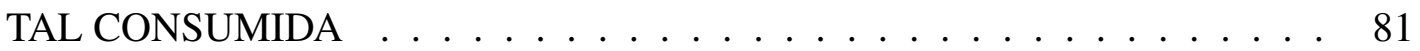

4.3.1 Nuance 1 - Fator de Prioridade f . . . . . . . . . . . . . . . . . . 82

4.3.2 Nuance 2 - Instante de Início . . . . . . . . . . . . . . . . . . . . . . . 84

4.3.3 Nuance 3 - Instante de Término . . . . . . . . . . . . . . . . . . . . . . 84

4.3.4 Nuance 4 - Carga de máquina $\ldots \ldots \ldots$

4.3.5 Nuance 5 - Quantidade de jobs . . . . . . . . . . . . . . . . . 85

4.4 CAPTURA DE DADOS PARA O TREINAMENTO DO MODELO . . . . . 85

4.5 IMPLEMENTAÇÃO DA RNA NO MODELO DE SIMULAÇÃO . . . . . . . 86

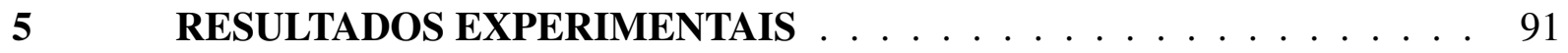

$5.1 \quad$ ARQUITETURA DA REDE NEURAL . . . . . . . . . . . . . . . . 91

5.2 ESTIMAÇÃO DO CONSUMO DE ENERGIA PARA ORDENS DE PRODUÇÃO DE TAMANHOS VARIADOS . . . . . . . . . . . . . . . . 100

5.3 ANÁLISE DA INFLUÊNCIA DAS VARIÁVEIS . . . . . . . . . . . . 108

5.3.1 Análise de Correlação das Variáveis . . . . . . . . . . . . . . . . . . 108

5.3.2 Análise empírica do conjunto de variáveis f . . . . . . . . . . . . 110

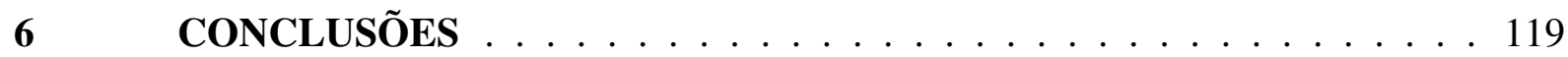

REFERÊNCIAS . . . . . . . . . . . . . . . . . 121

APÊNDICE A - Algoritmo para o cálculo dos instantes de início e término de uso das máquinas . . . . . . . . . . . . . . . . . . . . . . . . 129 APÊNDICE B - Algoritmo para o cálculo do Fator de Prioridade . . . . . 131 


\section{INTRODUÇÃO}

Empresas de manufatura que se baseiam em sistemas clássicos de produção, têm seus modelos de negócio orientados à fabricação de produtos de alta qualidade e baixo custo. No entanto, observa-se uma mudança no comportamento do mercado onde as estratégias com foco apenas no baixo custo do produto vêm perdendo espaço, deixando de ser tão efetivas como antigamente (MAY; KIRITSIS, 2017). Isso fez com que emergissem novas estratégias de negócios ao longo das últimas décadas, que buscam permitir às empresas manter, e até aumentar, seus níveis de competitividade a partir da migração de uma perspectiva baseada no custo, para estratégias voltadas à disponibilização de serviços e aumento da eficiência de seus processos. Neste contexto, destacam-se as discussões sobre os temas Sistema Produto-Serviço (REIM; PARIDA; ORTQVIST, 2015) e a Indústria 4.0 (DRATH; HORCH, 2014; JIN et al., 2017).

A Indústria 4.0, como é chamada a manufatura avançada pela Alemanha, visa a utilização de novas tecnologias de hardware e de sistemas de informação e comunicação para melhorar, não somente a competitividade econômica individual dos fabricantes, mas também a sustentabilidade do setor industrial de maneira geral (JIN et al., 2017). Estima-se que o setor industrial é responsável pelo consumo de cerca de $154 \mathrm{EJ}$, o que equivale a $36 \%$ do total de energia consumida mundialmente (IEA, 2017). Com isso, diversos estudos estão sendo concentrados no desenvolvimento de técnicas e modelos que permitam aumentar a eficiência energética dos sistemas de manufatura. Neste sentido, três principais fatores permitem explicar o crescente interesse pelo tema: o aumento de custo das tarifas de energia, o aumento no número de regulamentações ambientais, cada vez mais restritivas, e a mudança comportamental dos consumidores, que buscam cada vez mais por produtos e serviços ecologicamente corretos (BENEDETTI et al., 2016). Além disso, Herrmann et al. (2011) estimam haver um potencial de melhoria no consumo de energia entre 10 e $30 \%$, apenas aplicando tecnologias já existentes atualmente.

Com a adoção dos Sistemas Ciber-Físicos (CPSs) proposta pela manufatura avançada, espera-se que os dados sobre os ciclos de produção estejam disponíveis em tempo real, permitindo assim ampliar o uso de técnicas de aprendizado de máquina (machine learning) para a melhor tomada de decisão na manufatura. Tais ações poderão ser voltadas à melhoraria dos aspectos sustentáveis de entrada do sistema, como o consumo de energia elétrica e matériaprima, redução dos aspectos de saída, como a emissão de poluentes e sobras, e até mesmo 
uma abordagem mista que contemple ambos os aspectos (GIRET; TRENTESAUX; PRABHU, 2015).

Recentemente, Jin et al. (2017) apresentaram uma visão geral sobre o impacto da manufatura avançada na sustentabilidade. Naquele trabalho foram identificados os principais temas que visam maximizar seu potencial na redução do consumo de energia, de recursos naturais e da emissão de poluentes. Além disso, os autores destacam que o estudo sobre novas técnicas para facilitar a tomada de decisão na manufatura, sejam elas online ou offline com o sistema produtivo, carecem urgentemente do desenvolvimento de novas pesquisas.

Com base no contexto apresentado, o trabalho proposto visa o emprego de técnicas de aprendizado de máquina, um dos elementos habilitadores da manufatura avançada, para auxiliar o processo de programação da produção, com enfoque na estimativa e tomada de decisão baseada no aspecto da eficiência energética.

\subsection{OBJETIVO GERAL}

O objetivo geral deste trabalho está na apresentação de um modelo para a estimação do consumo total de energia em sistemas do tipo job shop utilizando técnicas de aprendizado de máquina, no qual poderá ser empregado no processo decisório durante a etapa de programação da produção.

\subsection{OBJETIVOS ESPECÍFICOS}

a) Contribuir para a redução do gap de pesquisa sobre sistemas job shop a partir da perspectiva da eficiência energética;

b) Avançar com o uso de técnicas de aprendizado de máquina, em particular as RNAs, na análise energética de sistemas de manufatura;

c) Disponibilizar um modelo que permita a substituição da ferramenta de simulação para a rápida estimação do consumo de energia durante a etapa de programação da produção de sistemas similares ao investigado neste trabalho. 


\subsection{JUSTIFICATIVA}

Cerca de um terço de toda a energia produzida no mundo é consumida pelo setor industrial (IEA, 2017). Contudo, dentro do contexto da manufatura avançada, a adoção de tecnologias já existentes tem um potencial de melhoria na eficiência energética entre 10 e 30\% (HERRMANN et al., 2011). A adoção de tecnologias e equipamentos mais eficientes certamente permite uma redução no consumo de energia. Contudo, pouca atenção tem sido dada nas oportunidades presentes na identificação do caminho de maior eficiência energética, durante o processo de sequenciamento das atividades em sistemas de manufatura (LI et al., 2017).

Nas últimas décadas, produtos e também seus respectivos processos produtivos, têm se tornado cada vez mais complexos. Isso ocorre devido ao incremento de funcionalidades, do emprego de diferentes disciplinas e tecnologias no projeto, da exigência dos clientes por customização, entre outros fatores. Isso implica no aumento da complexidade para o planejamento, análise e decisão sobre o sistema produtivo (HENNING; WOLFGANG; JOHANNES, 2013) e pode impactar diretamente no consumo de energia (WEINERT; CHIOTELLIS; SELIGER, 2011). Desta forma, o planejamento e programação da produção executa um papel significativo para a eficiência energética de um sistema de manufatura, onde os gestores devem ser capazes de planejar e tomar decisões, não somente considerando os custos, mas também considerando a eficiência energética dos processos (APOSTOLOS et al., 2013). O aumento da complexidade no planejamento, implantação e operação dos processos produtivos, somado aos desafios ecológicos e energéticos existentes, aumentam o número de variáveis dos sistemas de manufatura e trazem um grande desafio para a manufatura avançada.

Em particular, este trabalho busca contribuir com a redução do gap de pesquisa apontado por Ying Liu et al. (2014) e May et al. (2015), onde os autores indicam que, apesar do crescente número de pesquisas relacionadas ao aumento da eficiência energética na programação dos sistemas de manufatura, os trabalhos têm se concentrado em sistemas de única máquina ou naqueles onde fluxo de produção é contínuo (flow shop). Contudo, pouca atenção tem sido dada aos sistemas do tipo job shop, que representam a maioria dos sistemas encontrados nas indústrias de pequeno e médio porte (LIU, Y. et al., 2014). De maneira resumida, um sistema do tipo job shop possui múltiplas máquinas (i.e, recursos), onde os jobs (e.g., produtos) produzidos compartilham recursos com outros jobs processados simultaneamente. O sequenciamento de 
cadajob nas máquinas não são, necessariamente, os mesmos para os demais jobs. Com isso, a resolução de um problema do tipo job shop visa encontrar o melhor sequenciamento possível para melhorar alguma variável do sistema (e.g, reduzir o tempo de atravessamento, aumentar a eficiência energética, etc.). A definição formal do problema é apresentada na seção 3.2 deste trabalho.

\subsection{METODOLOGIA}

O presente projeto de pesquisa foi desenvolvido a partir de uma abordagem quantitativa do problema de estimação do consumo de energia elétrica em sistemas de manufatura do tipo job shop. Segundo (GIL, 2010), o objetivo principal das pesquisas exploratórias está no aprimoramento de ideias ou na descoberta de intuições sobre o problema estudado.

Para esta pesquisa, o método empregado foi a modelagem e simulação, cujo objetivo exploratório esteve na identificação de nuances a partir do vetor de entrada de sequenciamento das operações de um sistema do tipo job shop, que permitiram estimar o consumo total de energia para diferentes ordens de produção.

Inicialmente, partiu-se pelo levantamento bibliográfico preliminar de trabalhos anteriores relacionados ao tema de pesquisa. Esta etapa teve por objetivo proporcionar familiaridade ao tema pesquisado, bem como permitir a identificação de gaps na literatura e a delimitação do problema estudado. A revisão bibliográfica é desenvolvida no Capítulo 2 deste trabalho, onde buscou-se introduzir os conceitos de sustentabilidade e eficiência energética no contexto da manufatura. Em particular, o processo de triagem dos trabalhos anteriores focou na identificação de artigos que fazem uso de técnicas de aprendizado de máquina para a análise energética, em especial, os que fizeram uso de RNAs.

\subsection{LIMITAÇÕES}

Limita-se ao escopo deste trabalho o estudo de técnicas em aprendizado de máquina, em particular o uso de RNAs, na estimativa do consumo de energia elétrica em sistemas de manufatura do tipo job shop. O método proposto visa auxiliar o processo decisório, quando levado em conta o aspecto da sustentabilidade no sistema de manufatura. 
Está fora do escopo deste projeto a estimativa de consumo de outras fontes de energia que podem ser empregadas neste tipo de sistema produtivo, bem como o emprego de outras políticas energéticas que diferem da adotada neste trabalho.

\subsection{PRINCIPAIS TERMOS}

Para uniformizar os termos e facilitar a compreensão durante a leitura deste trabalho, a seguir são apresentados os principais termos utilizados referentes ao sistema de produção do tipo job shop:

a) Sistema Job Shop: refere-se a um tipo de sistema de produção, onde $N$ diferentes jobs são processados por $M$ diferentes máquinas. Para mais informações, a Seção 3.2 traz a fundamentação teórica sobre este tipo de sistema.

b) Job: os jobs referem-se aos entregáveis finais resultantes do sistema job shop. A exata definição de um job dependerá da etapa na qual o sistema se encontra, podendo ser desde peças que serão utilizadas em processos posteriores, como até mesmo os produtos finais produzidos pela empresa. Neste trabalho, consideraremos um job como sendo um produto final do sistema.

c) Ordem de Produção: refere-se a um conjunto de jobs que precisa ser programado e produzido pelo sistema job shop.

d) Operação: refere-se à atividade realizada em um centro de trabalho (i.e., máquina. Para um job ser concluído, ele requer que todas as suas operações sejam realizadas. Vale ressaltar que as operações de um job são restritas a um sequenciamento de operações pré-definido.

e) Makespan: refere-se ao tempo total de processamento da ordem de produção pelo sistema. Seu valor é dado pela diferença entre o instante de término da última operação realizada, e o instante de início da primeira operação.

f) Programação da Produção: refere-se ao detalhamento de execução de cada operação por cada máquina, onde questões relacionadas à prioridade de execução das operações por cada máquina são observadas. Como resultado, a programação da produção resultará em um sequenciamento de execução, contemplando a ordem das operações realizadas por cada máquina. 


\subsection{PRINCIPAIS CONTRIBUIÇÕES}

A metodologia empregada para a estimação do consumo de energia e os resultados obtidos, resultaram em um trabalho submetido e aprovado para a $44^{\mathrm{a}}$ Conferência Anual do IEEE, o IECON 2018, cuja publicação pode ser vista em Pereira e Lima (2018). 


\section{REVISÃO DA LITERATURA}

A seguir é apresentada a revisão da literatura, relacionando o problema de pesquisa apresentado e o conhecimento existente sobre o assunto. Conforme destacado por Gil (2010), a revisão da literatura deve esclarecer os pressupostos teóricos que fundamentam a pesquisa, bem como a indicação de trabalhos anteriores, apresentando um discussão crítica sobre o atual estado da arte. Desta forma, os temas que embasam o presente trabalho são apresentados e discutidos a seguir.

\subsection{SUSTENTABILIDADE NA MANUFATURA}

O conceito de sustentabilidade tem suas primeiras raízes ainda na década de 1950, em um cenário pós-guerra, onde passou-se a discutir questões sobre a capacidade do planeta em suportar o rápido crescimento populacional. Posteriormente, discussões sobre o impacto das ações do homem sobre o meio-ambiente e a criação de legislações específicas, levou a Organização das Nações Unidas (ONU) a definir o termo "sustentabilidade", ainda na década de 1970 (KIDD, 1992). Já na década de 1980, a expressão "desenvolvimento sustentável"foi apresentada como sendo o "desenvolvimento que atende às necessidades do presente sem comprometer a habilidade das gerações futuras em atender suas próprias necessidades"(BRUNDTLAND, 1987). Já um sistema de manufatura pode ser definido como a combinação de esforços de humanos, máquinas e equipamentos, conectados por meio da transformação das entradas (e.g. matériaprima, energia, demanda de clientes) em saídas (e.g. produtos acabados, sobras, indicadores de desempenho) (CHRYSSOLOURIS, 2006).

Desde então, o aspecto da sustentabilidade tem se tornado cada vez mais um requisito presente nos sistemas de manufatura. Haja vista ao maior enfoque dado às questões como a diminuição dos recursos não renováveis, o surgimento de novas legislações ambientais cada vez mais restritivas, o aumento das tarifas de energia elétrica, entre outras, diversos esforços têm sido demandados em busca de se obter sistemas de manufatura mais sustentáveis (GIRET; TRENTESAUX; PRABHU, 2015). Contudo, a literatura clássica apresenta quatro principais classes de atributos que normalmente são levadas em consideração no processo decisório em sistemas de manufatura: custo; tempo; qualidade; e flexibilidade (CHRYSSOLOURIS, 2006). Para cada uma dessas classes, facilmente encontram-se métricas para a medição de seus de- 
sempenhos (SALONITIS; BALL, 2013). Entretanto, analisando o aspecto da sustentabilidade, mais especificamente o consumo de energia, raramente são empregados indicadores que permitam auxiliar no processo de tomada de decisão (WEINERT; CHIOTELLIS; SELIGER, 2011). Neste sentido, Salonitis e Ball (2013) sugerem a inclusão da sustentabilidade (figura 1) como um quinto atributo para o processo decisório em sistemas de manufatura, buscando realizar uma análise crítica sobre a ocorrência de uso desnecessário de recursos.

Figura 1 - Proposta de evolução dos atributos decisórios da manufatura
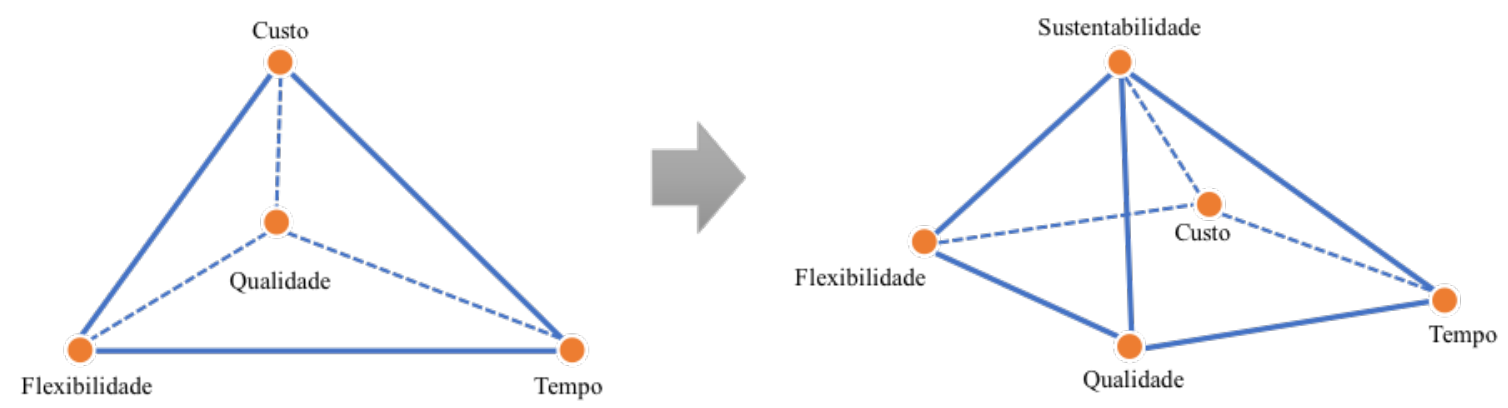

Fonte: Autor "adaptado de" Salonitis e Ball (2013), p. 635

A atividade industrial, mais especificamente os sistemas de manufatura, estão entre os grandes responsáveis pelas ações que geram impactos ao meio ambiente. Conforme apontado por Duflou et al. (2012), estes impactos vão desde o consumo de recursos materiais renováveis e não renováveis como a água, metais, combustíveis fósseis, etc., assim como o consumo de grandes quantidades de energia elétrica. O consumo de recursos citado é classificado por Giret, Trentesaux e Prabhu (2015) como aspectos de entrada da manufatura. Entretanto, os autores também destacam os aspectos de saída do sistema de manufatura, como por exemplo a emissão de carbono, rejeitos e sobras de materiais descartados. Neste sentido, os autores sintetizam o termo sustentabilidade no contexto da manufatura, a partir de dois pontos de vista:

a) Consumo, vinculado à redução dos aspectos de entrada, como a energia, matéria prima e ferramentas;

b) Emissões, vinculado à redução dos aspectos de saída, como os poluentes, rejeitos e a poluição. 


\subsection{EFICIÊNCIA ENERGÉTICA NO CONTEXTO DA MANUFATURA}

Estima-se que o setor industrial seja responsável por consumir cerca de 154 EJ (exajoules) de energia. Isso representa, aproximadamente, $36 \%$ de toda a energia produzida no mundo (IEA, 2017). Isso tem feito com que, ao longo dos últimos anos, questões relacionadas à eficiência energética em sistemas de manufatura recebam cada vez mais destaques no meio científico e também influenciem nos aspectos de competitividade entre as empresas. Segundo Benedetti et al. (2016) a maior relevância dada ao tema, está vinculada a três principais fatores: o aumento de custo das tarifas de energia, novas regulamentações voltadas à conservação do meio ambiente e recursos naturais, cada vez mais restritivas, e a mudança no comportamento dos consumidores, que têm buscado cada vez mais a aquisição de produtos "verdes". Shrouf, Ordieres-Meré e Miragliotta (2014) compartilham da mesma opinião e complementam que, além dos processos produtivos terem de ser mais energeticamente eficientes, os produtos resultantes também devem consumir menos energia quando em uso pelo usuário final.

Os termos eficiência e eficácia estão vinculados ao aspecto da sustentabilidade, mas, contudo, há diferenças significativas entre eles. Duflou et al. (2012) explicam que a eficiência está relacionada ao consumo de recursos necessários para se fazer algo. Assim, a eficiência é alcançada quando ocorre a eliminação de desperdícios dos recursos consumidos. Por outro lado, a eficácia está ligada às escolhas realizadas para a execução do processo, onde ela pode ser alcançada por meio da eliminação de etapas ou recursos durante a fabricação, que ao final, não impactam nas características do produto. Em resumo, a eficiência pode ser compreendida como o fazer as coisas corretamente (sem desperdícios) e a eficácia no fazer apenas as coisas corretas (consumir o que é realmente necessário). Neste contexto, a eficiência energética na manufatura pode ser definida como uma métrica utilizada na comparação entre diferentes configurações de um sistema produtivo, que ao final, permita selecionar aquele que produz mais com menos energia (FYSIKOPOULOS et al., 2014). Levando em consideração que produtos e processos têm se tornado cada vez mais complexos (HENNING; WOLFGANG; JOHANNES, 2013), avaliar diferentes configurações de um sistema de produção implica na adoção de técnicas e ferramentas mais sofisticadas por parte dos gerentes e planejadores da produção, que permitam a eles a tomada de decisão com base nos critérios de eficiência energética (MAY; KIRITSIS, 2017). 
Aumentar a eficiência energética em sistemas de manufatura tem chamado muito a atenção da comunidade científica e também das empresas. Muito se deve pelas oportunidades de novas pesquisas e dos potenciais ganhos econômicos com a redução no consumo de energia. Estima-se que o aumento da eficiência possível é de 10 a 30\%, somente empregando técnicas já existentes atualmente (HERRMANN et al., 2011). Para alcançar esses ganhos, diferentes abordagens são possíveis de serem realizadas, em níveis distintos de manufatura, conforme apresentado na próxima sessão.

\subsection{CLASSIFICAÇÃO DOS NÍVEIS DE ANÁLISE DA EFICIÊNCIA ENERGÉTICA}

Diversos aspectos podem ser analisados em busca de oportunidades para melhorar a eficiência energética na manufatura. Estas oportunidades estão distribuídas desde o nível das máquinas e ferramentas, até o nível corporativo (SALONITIS; BALL, 2013). Contudo, estudos recentes (HERRMANN et al., 2011; SALONITIS; BALL, 2013) apontam que, apesar de necessário o aumento da eficiência energética individual de cada máquina, uma perspectiva mais holística do sistema de manufatura é necessária para se maximizar as oportunidades de melhorias. Partindo desta perspectiva, Duflou et al. (2012) apresentam uma segregação do sistema de manufatura em cinco diferentes níveis, onde são discutidos os principais aspectos e oportunidades para cada nível. Já no trabalho apresentado por Fysikopoulos et al. (2014), os autores também propõem uma categorização do sistema de manufatura para a análise da eficiência energética, porém em quatro níveis. A figura 2 ilustra os níveis da divisão proposta. Neste trabalho, eles também sugerem que quanto mais alto for o nível da análise (camadas mais externas), novos fatores devem ser aglutinados, levando sempre em consideração os fatores das camadas internas.

O quadro 1 apresenta um comparativo entre ambas as propostas de segregação do sistema de manufatura apresentadas pelos autores. Apesar da similaridade entre os trabalhos, é possível observar que a abordagem proposta por Duflou et al. (2012) possui uma maior abrangência do sistema de manufatura, enquanto a proposta por Fysikopoulos et al. (2014) foca nas atividades desenvolvidas dentro de uma única planta, porém, fazendo distinção na análise em nível do processo de execução e de máquinas e periféricos. Contudo, ambas as abordagens 
Figura 2 - Níveis de análise da eficiência energética

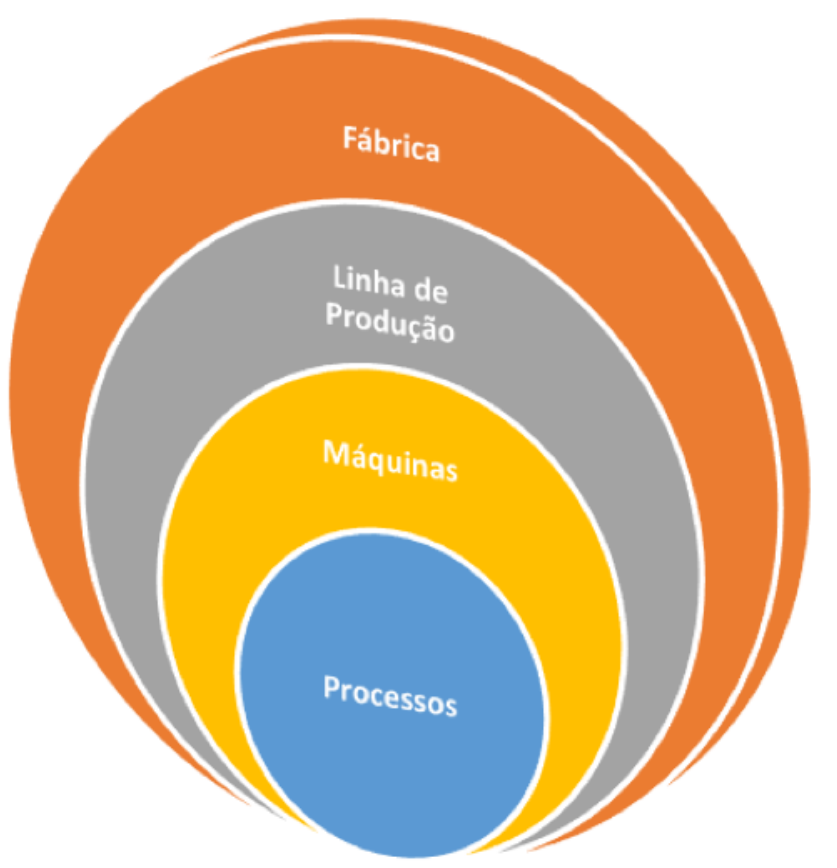

Fonte: Autor "adaptado de" Fysikopoulos et al. (2014), p.1439

coincidem nos níveis da linha de produção e no nível de fábrica, onde é fundamental o papel do planejamento e controle da produção.

Giret, Trentesaux e Prabhu (2015) ressaltam a importância de se considerar os aspectos da sustentabilidade em todos os níveis, desde o estratégico, até o nível tático e operacional, mas destacam que as etapas de planejamento são de grande importância, não apenas para produtividade e custos operacionais, mas também para a eficiência energética de um sistema de manufatura.

\subsection{EFICIÊNCIA ENERGÉTICA EM LINHA DE PRODUÇÃO}

Fysikopoulos et al. (2014) definem o nível de linha de produção para a análise da eficiência energética como sendo o local onde se encontra "um grupo de diferentes máquinas e quaisquer outros dispositivos periféricos que possam ser necessários para o correto funcionamento da linha de produção". Neste nível, destacam-se as tomadas de decisões quanto ao planejamento do sistema de manufatura, levando em consideração a dinâmica entre as máquinas. É neste nível também onde, normalmente, encontram-se os trade-offs entre a produtividade 
Quadro 1 - Comparativo entre diferentes abordagens de classificação dos níveis de análise da eficiência energética na manufatura

\begin{tabular}{|c|c|}
\hline Fysikopoulos et al. (2014) & Duflou et al. (2012) \\
\hline $\begin{array}{l}\text { Nível de processo: onde o foco da aná- } \\
\text { lise do dispêndio de energia é voltado aos } \\
\text { dispositivos e meios físicos que realizam o } \\
\text { processo (e.g. ferramentas de corte, bro- } \\
\text { cas, fresas, lasers, etc.). }\end{array}$ & \multirow[t]{2}{*}{$\begin{array}{l}\text { Nível do dispositivo/unidade de } \\
\text { processo: dispositivo individual ou } \\
\text { máquina dentro do sistema de manufatura. } \\
\text { Inclui equipamentos periféricos que dão } \\
\text { suporte a operação. }\end{array}$} \\
\hline $\begin{array}{l}\text { Nível de máquina: além de considerar os } \\
\text { aspectos do nível de processo, também são } \\
\text { avaliados os demais periféricos que permi- } \\
\text { tem o correto funcionamento do equipa- } \\
\text { mento. }\end{array}$ & \\
\hline $\begin{array}{l}\text { Nível da linha de produção: refere-se ao } \\
\text { grupo de diferentes máquinas e qualquer } \\
\text { outro tipo de periférico que pode ser solici- } \\
\text { tado para o correto funcionamento da linha } \\
\text { de produção. }\end{array}$ & $\begin{array}{l}\text { Nível da linha: célula ou múltiplas má- } \\
\text { quinas: organização lógica de equipamen- } \\
\text { tos de fabricação, que atuam em série ou } \\
\text { em paralelo para executar uma atividade } \\
\text { específica. Equipamentos periféricos que } \\
\text { apoiam a execução das atividades entre as } \\
\text { máquinas, como correias transportadoras, } \\
\text { estão inclusos neste nível. }\end{array}$ \\
\hline \multirow[t]{3}{*}{$\begin{array}{l}\text { Nível da fábrica: segue o mesmo raciocí- } \\
\text { nio acima, mas ao invés de máquinas, con- } \\
\text { sidera diferentes linhas de produção. }\end{array}$} & $\begin{array}{l}\text { Nível da fábrica: localidade física que } \\
\text { abriga múltiplos equipamentos e máqui- } \\
\text { nas, as quais podem ou não estarem conec- } \\
\text { tadas logicamente (linhas, células, etc.). } \\
\text { Inclui os equipamentos que habilitam a } \\
\text { operação no nível da fábrica, como gera- } \\
\text { dores e sistemas de climatização. }\end{array}$ \\
\hline & $\begin{array}{l}\text { Nível do sistema multi-fábricas: onde } \\
\text { a proximidade entre diferentes instalações } \\
\text { (fábricas) permite aproveitar possíveis si- } \\
\text { nergias entre elas, como o reaproveita- } \\
\text { mento de rejeitos. }\end{array}$ \\
\hline & $\begin{array}{l}\text { Nível organizacional e supply chain: sis- } \\
\text { tema completo de manufatura, contem- } \\
\text { plando todas as fábricas individuais, bem } \\
\text { como o sistema de transporte entre elas e as } \\
\text { externalidades da cadeia de suprimentos. }\end{array}$ \\
\hline
\end{tabular}

Fonte: Autor "adaptado de" Fysikopoulos et al. (2014) e Duflou et al. (2012)

e a sustentabilidade, como por exemplo o aumento do número de recursos para o cumprimento de prazos mais restritos (GIRET; TRENTESAUX; PRABHU, 2015).

A criação de um sistema de manufatura sustentável, em particular, o projeto de uma nova linha de produção, requer uma avaliação prévia do consumo de energia estimado para os processos. Para isso, é necessário o uso de técnicas e ferramentas que permitam estimar o 
consumo de energia. Neste contexto, destaca-se o uso das ferramentas de simulação, as quais habilitam a investigação das relações de causa e efeito, além de permitirem um entendimento mais profundo sobre a dinâmica do sistema (THIEDE, 2012). Contudo, a literatura atual se concentra na estimativa do consumo dos sistemas de manufatura quando já em produção, cujo o objetivo é melhorar a eficiência energética e auxiliar no planejamento do sistema já existente. Tendo em vista auxiliar a etapa de concepção da linha, Bornschlegl, Bregulla e Franke (2016) apresentam a metodologia Methods Energy-Measurement (MEM), que auxilia os planejadores e tomadores de decisões com base no aspecto de consumo de energia. Trata-se de um método que possibilita estimar o consumo potencial de energia para linhas de produção e células de manufatura de maior complexidade. O método consiste na identificação das etapas do processo previsto para a linha e análise do consumo de energia a partir de outras linhas existentes que executam processos similares, permitindo realizar uma estimativa baseada no consumo [Wh] ou na demanda de energia [W]. Ao final, o método permite realizar análises quanto aos custos de energia e também sobre os níveis de emissão de $\mathrm{CO}_{2}$.

Segundo Duflou et al. (2012), o consumo de energia e recursos de um sistema podem ser significativamente influenciados pelo planejamento e controle da produção. Aspectos como o tamanho dos lotes em processo, o sequenciamento de execução das ordens e a velocidade de produção, são alguns exemplos que, individualmente ou de forma combinada, influenciam na eficiência energética do sistema. Tendo em vista auxiliar o processo de planejamento e controle da produção, Weinert, Chiotellis e Seliger (2011) apresentam a metodologia chamada EnergyBlocks. Nesta metodologia, a proposta é descrever a energia consumida em cada equipamento da produção, a partir da discretização de seus estados operação (i.e. "desligado", "inicializando", "aquecendo", "stand by", "processando" e "parado"). Então, a energia e o tempo demandado em cada operação são separados em blocos de energia (EnergyBlocks) e registrados em uma base de dados. Com isso, é possível realizar o planejamento das etapas de produção a partir dos EnergyBlocks coletados, possibilitando uma análise conjunta do tempo de produção e consumo de energia, permitindo a tomada de decisão baseada no critério de eficiência energética. Apesar disso, o modelo limita-se a analisar um sequenciamento previamente definido, não apresentando métodos para a aumentar a eficiência energética.

O modelo apresentado anteriormente, pode ser complementado mediante ao uso de ferramentas de simulação. A simulação tem sido utilizada de forma crescente ao longo das últimas 
décadas na manufatura, como ferramenta de apoio ao planejamento e tomada de decisão (NEGAHBAN; SMITH, 2014; THIEDE, 2012; SMITH, 2003). Atualmente, ferramentas como os softwares Plant Simulation ${ }^{\circledR}$ e Eco3 ${ }^{\circledR}$, permitem analisar a eficiência energética dos sistemas de manufatura simulados. Um exemplo de aplicação da simulação de forma conjunta aos EnergyBlocks pode ser visto no trabalho de Kouki et al. (2017). Neste trabalho, os autores focaram em como realizar a adequação dos dados brutos de consumo de energia coletados experimentalmente, de tal forma a condicioná-los como parâmetros de entrada do modelo de simulação. Para os sistemas de manufatura de maior complexidade, onde o consumo de energia pode variar a cada ciclo de produção devido a fatores de influência externos (i.e., operadores, fenômenos físicos, etc.), os autores propuseram o desmembramento de cada equipamento em subsistemas, permitindo atribuir um EnergyBlock para cada uma das partes. Com isso, a aplicação sucessiva dos blocos de energia permitiu reproduzir com a simulação o comportamento do sistema, obtendo uma acurácia superior a 97\% para o estudo de caso apresentado.

Outro exemplo de aplicação da simulação em sistemas de manufatura é o trabalho apresentado por Antoniol e Lima (2016), onde os autores estudaram o comportamento de equipamentos com múltiplos estados de operação. Mediante ao uso da simulação, os diferentes estados foram avaliados, buscando oportunidades de redução no consumo de energia elétrica durante os períodos de ociosidade das máquinas. Já no estudo conduzido por Azmi, Mohd e Fadli (2016), os autores fazem uso da simulação na modelagem de um sistema de manufatura de cabos de transmissão de energia. Naquele trabalho, dois diferentes cenários foram avaliados, onde o primeiro priorizou o uso dos equipamentos mais energeticamente eficientes, e o segundo o agrupamento por máquina dos produtos com processos de fabricação similares. Ao final, os resultados foram comparados com o "melhor fluxo do processo" proposto por especialistas do departamento de produção da empresa. A simulação mostrou que, para o caso estudado, o agrupamento por similaridade possui um potencial de redução no consumo de energia elétrica da ordem de 3,2\%. Segundo Giret, Trentesaux e Prabhu (2015), os aspectos de entrada e saída da manufatura podem ser melhorados a partir de uma programação da produção mais eficiente. Enquanto os aspectos de entrada são normalmente utilizados como restrições para o modelo de programação da produção, os aspectos de saída podem ser consequências da programação realizada. Isso sugere que o planejamento e controle das atividades de produção impactam diretamente na eficiência energética do sistema de manufatura. 
Neste sentido, o trabalho apresentado por S. Wang et al. (2015) propõe uma abordagem sistemática para a programação das operações durante o processo de usinagem, em dois estágios. No primeiro, busca-se encontrar os melhores parâmetros de configuração do centro de usinagem, para cada item produzido. A qualidade de acabamento é considerada como uma restrição na modelagem, cuja função de múltiplos objetivos visa reduzir o consumo de energia e aumentar a produtividade do sistema. As variáveis consideradas para o primeiro estágio foram: velocidade de rotação, velocidade de corte, profundidade de corte e largura do corte. Devido a não linearidade entre as variáveis controladas e os objetivos do problema, RNAs foram empregadas para o cálculo dos indicadores referentes aos parâmetros de entrada selecionados. Em seguida, heurísticas foram aplicadas para encontrar os melhores parâmetros de entrada, sendo por fim registradas as melhores configurações de fabricação de cada peça em cada máquina. $\mathrm{O}$ segundo estágio faz uso dos melhores resultados obtidos no primeiro estágio, buscando identificar a combinação que maximiza a função objetivo de saída. Novamente, a função objetivo é normalizada, sendo ponderados os parâmetros de saída de energia consumida e tempo total de fabricação. A partir disso, as heurísticas são aplicadas para selecionar em qual máquina cada peça será fabricada, reduzindo o tempo de fabricação e melhorando a eficiência energética do sistema.

Outro trabalho de grande destaque relacionado à redução no consumo de energia durante o planejamento de operações em sistemas de manufatura é o apresentado por Shrouf et al. (2014). Nele, os autores propuseram uma modelagem matemática para a programação das operações de um sistema de única máquina, visando reduzir os custos com energia elétrica, considerando a variação contínua do preço da energia ao longo do dia. Apesar do objetivo inicial do trabalho ter sido a redução dos custos de produção, observou-se que o modelo permite a redução do consumo durante os períodos de pico, contribuindo assim para a diminuição dos impactos negativos devido a alta demanda do sistema de distribuição.

As etapas de planejamento e operação dos sistemas de manufatura sustentáveis, necessitam de conhecimento sobre o seu comportamento energético. Para isso, indicadores de desempenho e métodos que permitam identificar os estados de energia dos sistemas e seus subsistemas, são necessários. Seguindo este princípio, a literatura apresenta indicadores e métricas voltadas à eficiência energética, os quais Benedetti et al. (2016) os chamam de Energy Performance Indicators (EnPIs). Estes indicadores permitem que às empresas tenham uma visão geral 
e rápida sobre o atual estado do consumo de energia em suas plantas, auxiliando no processo de tomada de decisão nos diversos níveis hierárquicos.

Embora o uso dos EnPIs tenha como principal função auxiliar na redução do consumo de energia, seu uso pode entrar em conflito com outros indicadores utilizados na produção. Para isso, May et al. (2015) propõem um método para o desenvolvimento deste tipo de indicador nas empresas, que leva em consideração as sinergias e trade-offs com outros indicadores da manufatura, buscando oportunidades de redução no consumo de energia em diversas áreas da empresa. Inicialmente, o método proposto foi projetado para a aplicação dos indicadores considerando as máquinas individualmente (nível de máquina), onde segundo os autores, é o nível que mais possui oportunidades para a redução no consumo de energia (MAY et al., 2015). Entretanto, os autores sugerem que novos estudos sejam realizados em busca de indicadores de desempenho que possam ser aplicados aos demais níveis da manufatura.

Neste sentido, Benedetti, Cesarotti e Introna (2017) apresentam um método para gerenciar o desempenho energético, baseado na distribuição de responsabilidades e da clara definição de uma linha de base, que permita de forma rápida visualizar o status do sistema e a tomada de decisão no nível tático. O trabalho indica que as pesquisas vinculadas à criação de métricas de avaliação do desempenho energético, normalmente focam nos níveis estratégicos ou operacionais, sendo o nível tático raramente mencionado. Contudo, o nível tático é o responsável por vincular os outros dois níveis. Segundo os autores, o número de indicadores aplicados ao nível tático, deveria ser maior do que o número de indicadores de nível estratégico e menor do que os indicadores de nível operacional, formando uma estrutura piramidal. Entretanto, a investigação realizada indicou que o atual cenário da literatura segue uma estrutura de dupla pirâmide, conforme apresentado na figura 3. Esta interação entre os diferentes níveis também é destacada por Fysikopoulos et al. (2014), onde os autores ressaltam a existência de aspectos não triviais entre os níveis, sugerindo que os melhores resultados podem ser alcançados quando analisados os níveis de forma conjunta.

\subsection{PROGRAMAÇÃO DA PRODUÇÃO ORIENTADA À EFICIÊNCIA ENERGÉTICA}

Conforme já discutido nas seções anteriores, o aumento da eficiência energética pode ser alcançado a partir de diferentes níveis da manufatura, onde é possível observar uma série de 
Figura 3 - Comparação qualitativa entre o número de indicadores propostos na literatura (a) e o número necessário (b) para cada nível de agregação.

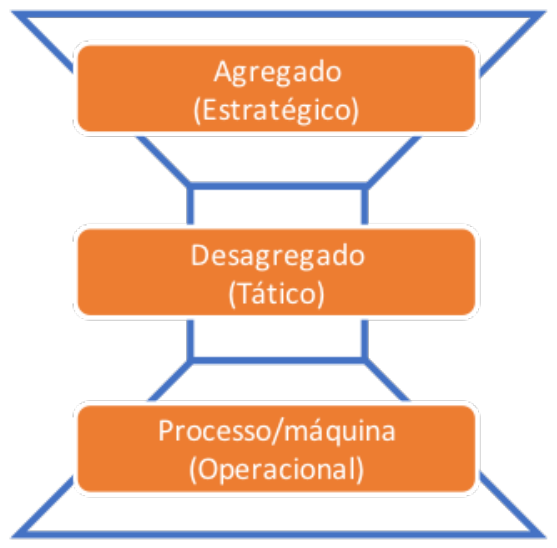

a) Estrutura atual

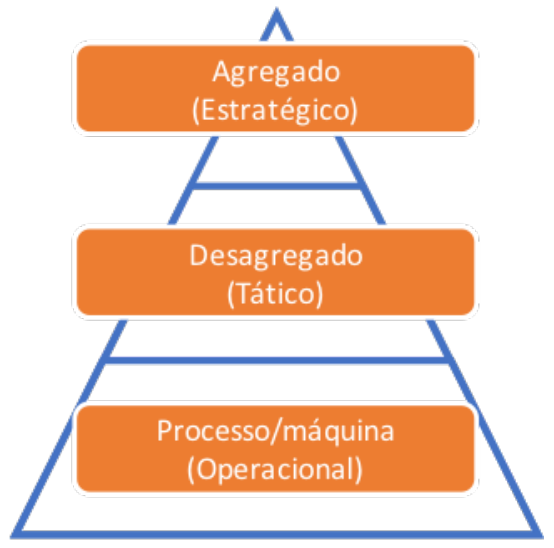

b) Estrutura ideal

Fonte: Autor “adaptado de” Benedetti, Cesarotti e Introna (2017), p. 1520

iniciativas na literatura para cada nível. De modo geral, observa-se que os trabalhos científicos relacionados a eficiência energética, podem ser agrupados em duas principais frentes (ZHOU et al., 2016; LI et al., 2017). Na primeira, encontram-se os estudos relacionados à redução do consumo de energia por meio da realização de melhorias tecnológicas, sejam elas em equipamentos ou nos processos de produção. Já a segunda, busca melhorar a eficiência energética por meio de ajustes nos parâmetros de gerenciamento, que influenciam direta ou indiretamente na eficiência do sistema. A primeira pode exigir altos investimentos para se obter a eficiência e, portanto, os tomadores de decisão tendem a seguir para a segunda opção, buscando melhorar o uso dos equipamentos existentes a partir do melhor planejamento e programação das operações executadas, a qual também possui potencial para a redução do consumo (ZHOU et al., 2016).

Neste contexto encontram-se as etapas de planejamento e programação da produção. Os trabalhos apresentados por Giret, Trentesaux e Prabhu (2015) e Biel e Glock (2016) revisam os principais modelos descritos na literatura, vinculados ao planejamento e programação da produção, que buscam melhorar o aspecto da sustentabilidade dos sistemas de manufatura. Em particular, Biel e Glock (2016) propõem a vinculação destes modelos às atividades clássicas executadas durante o planejamento da produção, conforme ilustrado na figura 4.

$\mathrm{Na}$ figura 4, os trabalhos referentes a alocação e sequenciamento de atividades recebem destaque, pois são os mais populares na literatura científica dentro do contexto apresentado. No trabalho de Biel e Glock (2016), os autores observaram que cerca de 57\% dos trabalhos identificados estavam focados em alocação e sequenciamento. Contudo, também foi possível observar 
a carência de estudos relacionados ao aumento da eficiência energética em sistemas caracterizados como do tipo job shop, já que, segundo os autores, é o tipo de sistema de manufatura que melhor representa a realidade da indústria. A percepção de que os sistemas do tipo job shop não têm sido bem investigado na perspectiva da redução do consumo de energia, também é compartilhada por Ying Liu et al. (2014). A seção seguinte traz uma apresentação deste tipo de sistema e discute os principais trabalhos que abordam a eficiência energética, identificados na literatura.

Figura 4 - Classificação dos modelos de planejamento da produção.

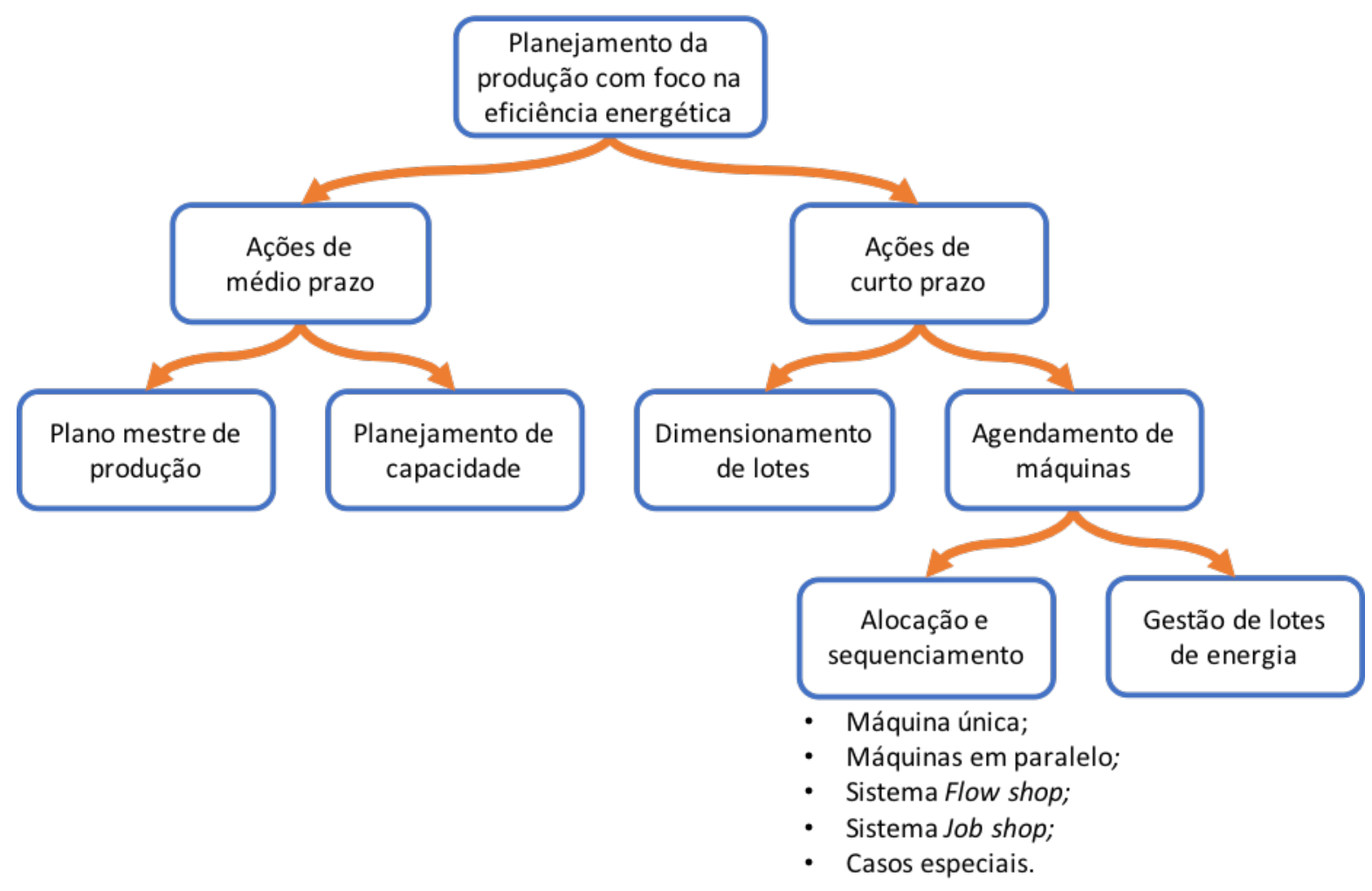

Fonte: Autor "adaptado de" Biel e Glock (2016), p. 247

\subsection{EFICIÊNCIA ENERGÉTICA EM SISTEMAS DO TIPO JOB SHOP}

O sistema de manufatura do tipo job shop clássico foi proposto ainda na década de 1960 (YAO; PAN, 2013). Trata-se de um problema de alto grau de dificuldade para a resolução, sendo classificado como do tipo NP-Complete (WILLEMS; BRANDTS, 1995; YAHYAOUI; FNAIECH, N.; FNAIECH, F., 2011). Contudo, por representar muito bem a realidade da maioria das empresas, principalmente as de pequeno e médio porte (LIU, Y. et al., 2014), o job 
shop se tornou um modelo largamente adotado pela indústria de manufatura. Este tipo de problema também se tornou muito popular na comunidade científica, onde diversas investigações utilizando heurísticas e métodos de otimização têm sido aplicadas (YAO; PAN, 2013).

De acordo com May et al. (2015), a programação de operações em sistemas job shop, ao longo das últimas décadas, tem sido largamente estudada a partir da perspectiva da produtividade do sistema. Contudo, assim como também apontado por Ying Liu et al. (2014) e Biel e Glock (2016), pouca atenção tem sido dada a análise do sistema, a partir da perspectiva da eficiência energética.

Neste sentido, May et al. (2015) realizaram um estudo comparativo entre diferentes políticas energéticas de utilização de máquinas em um sistema de manufatura do tipo job shop. A partir da definição dos estados de energia (figura 5) e da vinculação com os estados de operação das máquinas (figura 6), quatro políticas foram definidas e comparadas no estudo. A primeira política foi inspirada no modelo convencional encontrado na indústria, onde todas as máquinas são ligadas no instante inicial de produção do primeiro lote, e desligadas quando a última operação é concluída. A segunda política é similar à primeira, contudo as máquinas são ligadas uma a uma, na medida em que são demandadas. Já a terceira política de uso segue o descrito pela segunda, contudo é adicionada a possibilidade de desligar e religar o equipamento quando ele se encontra em estado de ociosidade e a energia total para desligar e religar o equipamento, seja menor do que a energia demandada caso o equipamento fosse mantido ocioso. Por fim, a quarta política adiciona o estado de espera (stand-by), seguindo a mesma lógica apresentada pela terceira política, onde há a opção de colocar o equipamento em um estado de menor consumo de energia, porém com mais agilidade para a voltar a operação.

Para a resolução do problema bi-objetivo apresentado acima, May et al. (2015) fizeram o uso combinado de dois métodos que correspondem ao estado-da-arte em algoritmos genéticos (Nondominated Sorting Genetic Algorithm II (NSGA-II) e Strength Pareto Evolutionary Algorithm II (SPEA-II)), tendo em vista melhorar ambos os aspectos produtivo e ambiental. Além disso, o algoritmo foi comparado com regras de despacho convencionais e outras heurísticas, avaliando os indicadores de Tempo Total de Processamento (MKS), Energia Total Consumida (TEC) e Energia Total Não Produtiva (WEC), a partir de testes realizados com problemas adaptados da literatura. Para problemas que envolvem apenas um objetivo, a heurística Local Search (LS) foi a que apresentou melhores resultados. Entretanto, quando avaliados os múltiplos ob- 
Figura 5 - Possíveis estados de energia de máquinas e equipamentos

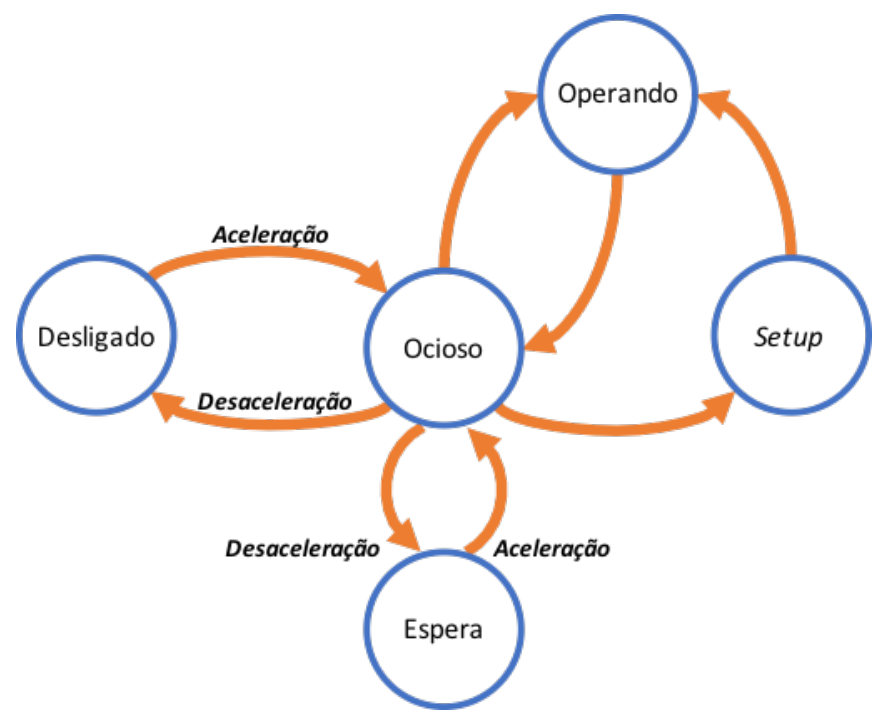

Fonte: Autor “adaptado de” May et al. (2015), p. 7073

Figura 6 - Vínculos entre os estados produtivos e energéticos

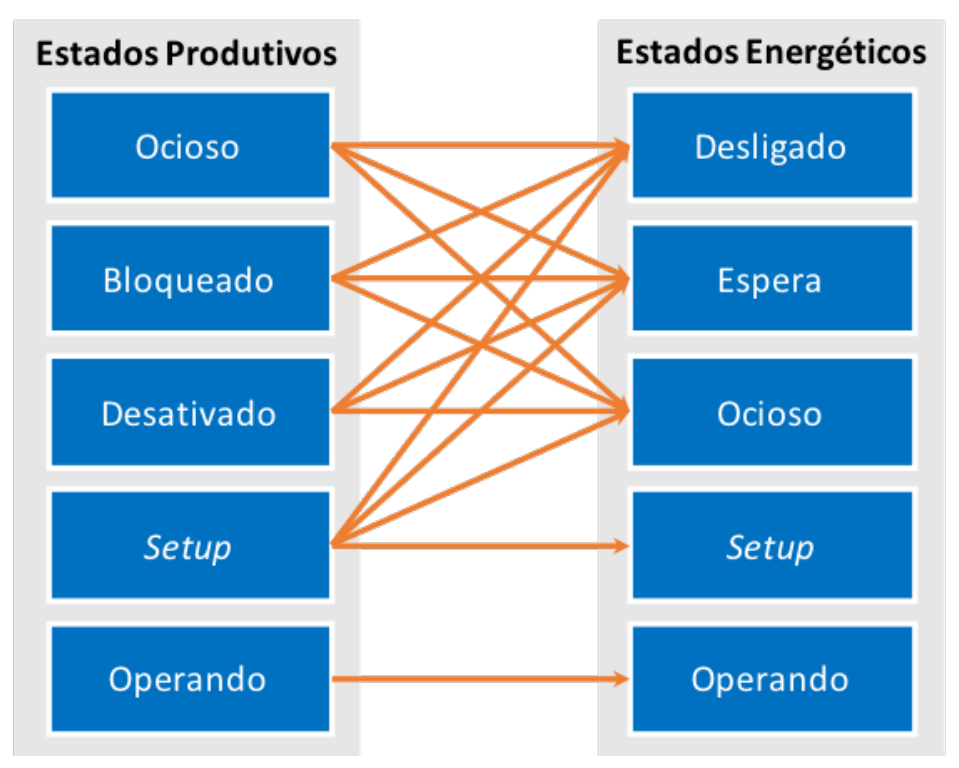

Fonte: Autor “adaptado de” May et al. (2015), p. 7073

jetivos, a heurística proposta no trabalho obteve resultados superiores. Ainda, com relação às políticas avaliadas, o algoritmo proposto se mostrou adequado para lidar com problemas de maior complexidade, como as políticas 3 e 4, onde se observou uma redução no indicador de energia elétrica consumida durante os estados não produtivos. Além disso, pelo fato do algoritmo ter seus objetivos relacionados à produtividade e aspectos ambientais, diferentes soluções da fronteira de Pareto foram obtidas, as quais representam os trade-offs entre os objetivos. 
Já em Ying Liu et al. (2015), uma investigação sobre os impactos da política energética adotada pelo governo chinês foi realizada. Neste trabalho, os autores realizaram um estudo sobre os efeitos das interrupções de fornecimento de energia sobre o planejamento de sistemas do tipo job shop, onde o custo total de energia foi considerado, além do consumo total de energia e dos atrasos nos prazos de entrega. A variável de custo energético foi adicionada ao estudo, uma vez que as empresas tendem a adotar o uso de geradores próprios a diesel para manter seus planejamentos e prazos de entrega. Entretanto, sistemas próprios de geração a diesel normalmente acarretam um maior custo e maiores níveis de emissões de $\mathrm{CO}_{2}$, quando comparados com o fornecimento convencional de energia. Neste sentido, os autores modelaram um problema triobjetivo, visando minimizar os custos com energia elétrica (uso de geradores), consumo total de energia e tempo total de fabricação dos lotes de produção. Os autores também fizeram uso do NSGA-II (DEB et al., 2002), além de proporem um novo método para a montagem da agenda de planejamento, levando em conta as janelas de restrições no fornecimento de energia. Como resultado, os experimentos realizados demonstraram um potencial de melhoria entre $60 \%$ e $70 \%$ nos prazos de entrega, além de permitir a redução de custo e consumo de energia de geração própria.

No estudo conduzido por Ying Liu et al. (2016), os autores apresentaram um modelo cujo o principal objetivo esteve em identificar oportunidades de desligamento das máquinas durante longos períodos de ociosidade. O modelo chamado de Genetic Algorithm Electricity Saving in Job Shop (GAEJP), também foi baseado no modelo NSGA-II (DEB et al., 2002), onde foram adicionadas duas etapas complementares para a redução do consumo de energia. Na primeira etapa, o modelo busca aumentar as janelas de ociosidade das máquinas, sem comprometer o tempo de atraso total da produção. Durante as janelas de ociosidade, é avaliada a viabilidade de desligar completamente os equipamentos, religando-os somente quando houver uma nova demanda, sem comprometer a programação da produção previamente definida pelo algoritmo NSGA-II. Na segunda etapa, as soluções obtidas durante a primeira são selecionadas seguindo os critérios de não dominância e elitismo, gerando famílias de soluções que permitiram observar a fronteira de Pareto para o problema. Como resultado, os autores observaram que o novo modelo proposto permite reduzir consideravelmente o consumo de energia elétrica, quando comparado com o trabalho anterior realizado pelos mesmos autores (LIU, Y. et al., 2014), sem comprometer o tempo total de atraso do sistema. 
O dia-a-dia das empresas de manufatura conta com diferentes fontes de interrupções na produção, como falhas em máquinas, cancelamento de ordens, atrasos de entrega, etc. Em alguns casos, a programação inicial das atividades pode absorver estas interrupções, quando menos significativas, sem gerar impactos ao tempo total de produção. Contudo, há casos onde ações de planejamento são necessárias para reestabelecer brevemente a programação original, minimizando os efeitos das interrupções. Neste sentido, Salido et al. (2017) sugerem uma nova técnica para reagendar as atividades de sistemas job shop após interrupções, a qual visou minimizar o consumo de energia para a retomada do cronograma original a partir da variação das velocidades de operação das máquinas. A variação da velocidade das máquinas afeta diretamente no consumo de energia e inversamente impacta no tempo de operação (FYSIKOPOULOS et al., 2014; SALIDO et al., 2017; ZHANG, R.; CHIONG, 2016). Com isso, os autores propuseram algoritmos para a identificação do tempo necessário na retomada do sistema, servindo este tempo como restrição para a geração de um novo cronograma. A nova programação das operações afetadas foi realizada a partir da combinação das heurísticas Algoritmo Genético (AG) e LS. A função objetivo do problema levou em conta os parâmetros de MKS e TEC, ponderadas por um coeficiente de sensibilidade, que permitiu avaliar o comportamento do trade-off entre o tempo de produção e o consumo de energia.

\subsection{REDES NEURAIS ARTIFICIAIS NA PROGRAMAÇÃO DA PRODUÇÃO}

A aplicação de RNAs na resolução de problemas práticos da manufatura tem sido largamente explorada, principalmente a partir da década de 1980 (HUANG, S. H.; ZHANG, H.-C., 1993). Dentre as principais aplicações, pode-se destacar seu uso para o controle de qualidade (YU; XI, 2009), no planejamento de layouts (AZIMI; SOOFI, 2017), no monitoramento e detecção dos estados de operação de equipamentos (LE et al., 2013) e na programação da produção (RATHORE; CHAUHAN, 2015). Esta diversidade de aplicações atribuídas às RNAs se dá pela sua capacidade de aprender a partir de padrões existentes, lidar com tarefas onde os dados de entrada são incompletos ou não precisos, e pela alta capacidade de abstração na resolução de problemas mal definidos (KALOGIROU, 2000). Contudo, para cada tipo de problema uma análise sobre a melhor topologia a ser empregada na resolução deve ser investigada. 
O modelo de Hopfield (HOPFIELD, 1982) é uma das principais topologias em redes neurais empregadas em problemas de programação da produção. Trata-se de uma rede neural recorrente, ou seja, cujas saídas são conectadas às entradas e defasadas no tempo (BRAGA; CARVALHO; LUDERMIR, 2014). A atualização dos neurônios é comumente feita de três diferentes formas (WILLEMS; BRANDTS, 1995; YAHYAOUI; FNAIECH, N.; FNAIECH, F., 2011):

a) Sequencialmente, onde a saída de cada neurônio é calculada a partir de uma ordem pré-determinada;

b) Aleatoriamente, onde o neurônio a ser atualizado é escolhido de forma randômica;

c) Simulação de processamento paralelo, onde aleatoriamente ou sequencialmente os neurônios têm suas saídas calculadas, contudo seus valores são temporariamente armazenados até que todos sejam calculados. Então, todos os neurônios têm suas saídas atualizadas simultaneamente.

Como característica, a rede de Hopfield permite ser empregada na resolução de problemas de otimização sujeitos a restrições. Neste contexto, os primeiros esforços para a aplicação do modelo na resolução de problemas de programação da produção podem ser vistos em Simon e Takefuji (1988). Neste trabalho, os autores propuseram a resolução do problema de programação de sistemas job shop, buscando minimizar o tempo total de processamento (makespan). Os autores se esforçaram na redução do número de interconexões da rede, por meio do uso de um modelo de programação inteira associada ao modelo de Hopfield. Contudo, Van Hulle (1991) contradisse os resultados obtidos pelos autores, afirmando que o modelo de Simon e Takefuji (1988) poderia violar restrições do problema ou até convergir para pontos de ótimos locais.

Já no trabalho de Willems e Brandts (1995), os autores também aplicaram o modelo de Hopfield em sistemas job shop. A partir do estabelecimento de regras básicas, o espaço de busca foi reduzido, permitindo obter soluções factíveis em curtos espaços de tempo. Inicialmente, o problema foi modelado a partir de técnicas de programação linear inteira. A partir do modelo obtido, o problema foi adequado para a representação por meio de uma estrutura de RNAs. Os principais resultados obtidos para aquela época permitiram melhorar a velocidade de obtenção de soluções factíveis de resultados ótimos locais, habilitando seu emprego em aplicações reais de programação da produção em tempo real. Além disso, contribuiu com uma arquitetura genérica da rede neural que facilitou o emprego da metodologia em diferentes problemas. 
O trabalho de Willems e Brandts (1995) foi estendido por Yahyaoui, N. Fnaiech e F. Fnaiech (2011). Neste novo trabalho, os autores propuseram uma nova heurística e investigaram sua efetividade para reduzir o tempo total de obtenção da solução. No trabalho original de Willems e Brandts (1995), os autores inicializaram a rede neural com valores aleatórios para as variáveis de tempo de início das operações. Contudo, a nova heurística proposta por Yahyaoui, N. Fnaiech e F. Fnaiech (2011) visou calcular previamente os tempos de início das operações, de tal forma que as restrições de precedência já fossem satisfeitas. Com isso, foi eliminada a necessidade de cálculo das restrições pela rede neural, reduzindo o número de iterações necessárias para a obtenção da solução do problema. Além disso, os autores compararam os métodos, original e proposto, e concluíram que a inicialização aleatória das variáveis diminui a probabilidade de a rede neural convergir para uma solução ótima.

No trabalho realizado por Araz e Salum (2010), os autores apresentam um estudo sobre o problema de programação da produção em sistemas do tipo Dual Resource Constrained (DRC), onde diferentes regras de despacho são selecionadas em tempo real em função de alterações na dinâmica do sistema. Neste tipo de problema, não apenas as operações das máquinas devem ser levadas em consideração, mas também a alocação de cada um dos operadores. Trata-se de um problema de alta complexidade pois, além da distribuição das atividades para as máquinas, o modelo deve levar em consideração o "onde" e "quando" cada operador deve estar posicionado (XU, J.; XU, X.; XIE, 2011). Como apontado pelos autores, diferentes regras de despacho apresentam diferentes desempenhos para cada tipo de problema. Assim, não é possível generalizar uma regra "ótima" que atenda a todas as situações. Neste sentido, os autores propuseram a aplicação de RNAs para a estimativa de métricas de desempenho do sistema para cada opção de regra de despacho disponível. O objetivo desta estimativa foi permitir aos tomadores de decisão uma rápida escolha sobre qual regra seria empregada no sistema, sem ter que realizar diversas simulações para avaliar a melhor opção. Assim, a simulação foi aplicada somente durante a etapa de treinamento da rede, onde os autores coletaram dados amostrais extraídos a partir dos experimentos. A escolha da rede neural como ferramenta de modelagem foi feita devido a sua capacidade de rápido processamento, necessária para a tomada de decisão em tempo real, e por permitir simplificar a modelagem matemática entre as variáveis de entrada e saída.

Em Choi e K. Wang (2012), os autores sugerem uma nova abordagem para melhorar o desempenho de sistemas de manufatura do tipo flow shop flexível, a partir da identificação 
da natureza estocástica de cada grupo de máquinas. A decomposição sugerida para o sistema é feita com o auxílio de uma rede neural, que permite estimar o makespan para diferentes heurísticas de programação da produção. Para isso, inicialmente foi empregado o algoritmo K-Means para o agrupamento das máquinas com comportamentos estocásticos similares. Em cada grupo identificado, a rede neural foi empregada na simulação do desempenho de duas diferentes heurísticas para a programação da produção: Shortest Process Time (SPT) e AG. A heurística que apresentou melhores resultados (i.e., menor makespan) foi atribuída ao respectivo grupo de máquinas. Como resultados, os autores observaram que a SPT é mais adequada para situações de maior comportamento estocástico, enquanto o AG apresenta melhores resultados para situações mais determinísticas. Por fim, a contribuição do trabalho esteve na criação de um novo modelo que permite utilizar ambas as abordagens, SPT e AG, permitindo obter melhores resultados, se comparado com as heurísticas aplicadas individualmente.

\subsection{REDES NEURAIS APLICADAS À ANÁLISE ENERGÉTICA}

As RNAs têm sido amplamente utilizadas para a análise energética, em especial, para análises relacionadas ao setor industrial. As aplicações são diversas, indo desde a classificação de padrões de energia dos estados de operação das máquinas (LE et al., 2013), no controle da quantidade de energia empregada para o processamento químico de materiais (CHEN et al., 2017), até chegar ao gerenciamento de demanda das instalações (KARATASOU; SANTAMOURIS; GEROS, 2006). Neste sentido, 483 publicações voltadas à previsão do consumo de energia foram revisadas por Debnath e Mourshed (2018), onde os autores observaram que a rede neural artificial é o principal modelo empregado neste tipo de abordagem, representando cerca de $40 \%$ das publicações analisadas. Já em Benedetti et al. (2016), os autores ampliaram o horizonte de pesquisa, identificando outras aplicações presentes na literatura. As principais aplicações identificadas foram reunidas em quatro grupos, apresentadas e exemplificadas nas subseções seguintes. 


\subsubsection{Análise comparativa do desempenho energético entre diferentes plantas, indústrias ou nações}

O estudo de demanda possui um importante papel no planejamento das redes de distribuição e sistemas de geração de energia, pois permitem melhorar a eficiência e evitar problemas como apagões ou quedas repentinas de energia (MURALITHARAN; SAKTHIVEL; VISHNUVARTHAN, 2018). Até 2021, o Operador Nacional do Sistema Elétrico, a ONS, prevê a expansão do sistema de geração de energia brasileiro para uma capacidade instalada de $166.540 \mathrm{MW}$, o que representa um aumento de aproximadamente 17\% com relação ao ano de 2016 (ONS, 2018). O aumento da capacidade instalada também implica na extensão da rede de distribuição de energia, o que requer altos investimentos em infraestrutura. Contudo, a expansão do sistema de forma eficiente requer estudos prévios, que permitam predizer o crescimento de demanda e dimensionamento da real infraestrutura necessária (MURALITHARAN; SAKTHIVEL; VISHNUVARTHAN, 2018). Para o contexto apresentado, os trabalhos identificados neste grupo focam na análise energética a partir de fatores externos, como indicadores socioeconômicos e informações demográficas, e buscam disponibilizar métricas para a comparação de diferentes entidades como setores industriais ou nações (BENEDETTI et al., 2016).

O estudo apresentado por Kialashaki e Reisel (2014) aplicou RNA para a previsão de demanda energética do setor industrial dos EUA. Neste estudo, o modelo também foi aplicado para a realização de projeções futuras, considerando o período entre os anos de 2013 a 2030. Os autores observaram durante o trabalho que a demanda energética no setor industrial é significativamente afetada pelo preço da energia praticado. A partir da análise de correlação das variáveis, os autores consideraram o valor do Produto Interno Bruto (PIB) e dos custos de energia, e comparam a RNA com um modelo de regressão linear múltipla, onde concluíram que a RNA possui desempenho superior ao modelo de regressão. A partir do modelo proposto, foi possível estimar antecipadamente um aumento de $16 \%$ na demanda de energia do setor industrial norte americano até o ano de 2030.

Em Uzlu et al. (2014), os autores apresentam um estudo sobre a previsão de demanda de energia na Turquia, a partir da utilização de indicadores demográficos e socioeconômicos. Como variáveis de entrada, os autores consideram o valor do PIB, o tamanho da população e os valores totais com importações e exportações do país. Com isso, um estudo comparativo entre 
os algoritmos de treinamento Back-Propagation (BP) e Teacher-Learning-Based Optimization (TLBO) foi realizado. O conjunto de dados de treinamento abrangeu o período entre os anos de 1980 e 2005, sendo que a etapa de teste do modelo foi realizada utilizando dados dos anos de 2006 a 2012. A topologia de rede adotada considerou quatro camadas de entrada, quinze camadas ocultas e uma camada de saída. Para todos os cenários avaliados no estudo, o algoritmo TLBO apresentou melhores resultados do que quando comparado com o BP.

\subsubsection{Previsão da produção de energia em usinas geradoras}

Para este grupo de trabalhos, particularmente, as RNAs são empregadas para estimar a produção em usinas de energia renovável, devido a alta volatilidade do volume produzido. Esta volatilidade está associada a fatores como a fonte de energia utilizada, onde as RNAs também podem ser empregadas para estimar, por exemplo, a quantidade de radiação solar ou o fluxo eólico de uma determinada região (BENEDETTI et al., 2016).

Como exemplo, em Ogliari et al. (2016) os autores estudaram como alcançar os melhores parâmetros de uma rede neural com base nos dados climáticos da planta. Neste estudo, a rede neural foi emprega na previsão da energia total produzida por uma planta de geração fotovoltaica, considerando um horizonte de 24 horas de antecipação. A melhor configuração foi estudada em termos do número de neurônios, número de camadas e dimensão do conjunto de treinamento, para melhorar a qualidade da estimação. Como parâmetros de entrada, foram considerados dados meteorológicos (e.g. direção do vento, pressão, umidade relativa, etc.), hora do dia e dia do ano, além de parâmetros relacionados à planta geradora como a temperatura dos painéis e a potência de saída.

No estudo apresentado por Vaz et al. (2016), além das variáveis meteorológicas, os autores também consideraram medições realizadas em diferentes plantas geradoras situadas nas proximidades da planta estudada. No total, foram consideradas cinco diferentes plantas dentro de um raio de $7,5 \mathrm{~km}$. O estudo avaliou o efeito da utilização dos dados para diferentes combinações de plantas, além de uma estação meteorológica, onde o melhor resultado obtido ocorreu quando os dados de todas as plantas e estação foram contempladas. Uma rede neural recorrente foi empregada no estudo utilizando a arquitetura Nonlinear AutoRegressive with eXo- 
genous (NARX), onde elementos de memórias foram empregados no deslocamento temporal das variáveis.

Também podemos encontrar aplicações das RNAs na previsão de energia em sistemas eólicos. Em Shuang-Xin Wang et al. (2018), os autores propuseram a aplicação da rede neural Small-World BP (SWBP) no estudo de predição antecedendo os próximos 15 minutos, em uma usina eólica situada na província de Jiangsu, China. No modelo apresentado, os autores aplicaram o algoritmo modificado de análise de informações mútuas (do inglês, Mutual Information) para selecionar quais candidatas a variáveis de entrada seriam aplicadas ao modelo, eliminando assim a existência de possíveis redundâncias. Por fim, o modelo foi avaliado e comparado com uma rede do tipo Perceptron de Múltiplas Camadas (PMC), onde sua aplicação se mostrou factível quando avaliados os aspectos de convergência, tempo de treinamento e acurácia da previsão realizada.

\subsubsection{Previsão de carga para o gerenciamento de demanda e balanceamento de rede de energia}

Realizar a previsão de carga de forma precisa é de extrema importância para o gerenciamento de demanda, principalmente para evitar a ocorrência de sobrecargas nos sistemas elétricos empregados ao longo de toda a infraestrutura de geração e transmissão de energia (MURALITHARAN; SAKTHIVEL; VISHNUVARTHAN, 2018). O aumento da acurácia na previsão de demanda impacta diretamente na disponibilidade da rede distribuição, principalmente em se tratando das redes de distribuição inteligentes (Smart Grids) (KUO; HUANG, C.-J., 2018). Os trabalhos relacionados à previsão de carga no gerenciamento de demanda podem ser classificados em função do intervalo de tempo antecipado pela estimativa. Mesmo não havendo uma separação formal, os trabalhos são comumente classificados como sendo de curtíssimo prazo (Very Short Term Forecasting (VSTF)), curto prazo (Short Term Forecasting (STF)), médio prazo (Medium Term Forecasting (MTF)) e longo prazo (Long Term Forecasting (LTF)). No curtíssimo prazo, intervalos variando entre poucos minutos até um dia a frente são contemplados, permitindo tomadas de decisões mais eficientes nas plantas geradoras. Intervalos de curto prazo consideram a predição para os próximos dias ou semanas. Para predições de médio prazo considera-se intervalos variando de algumas semanas até meses. Por fim, predições de 
longo prazo consideram a estimativa de consumo para vários anos a frente, sendo comumente empregadas para o avaliar as necessidades de expansão de infraestrutura de sistemas de geração e transmissão de energia(MURALITHARAN; SAKTHIVEL; VISHNUVARTHAN, 2018; KUO; HUANG, C.-J., 2018).

Em Muralitharan, Sakthivel e Vishnuvarthan (2018), os autores investigam os efeitos da aplicação de diferentes algoritmos de treinamento na previsão de consumo do tipo STF, MTF e LTF. Foram avaliadas três diferentes abordagens de RNAs na predição de consumo, onde os autores compararam o método convencional de predição CNN, com treinamento realizado por meio do algoritmo BP, e dois outros métodos baseados em algoritmos heurísticos. As heurísticas empregadas foram o Neural Network based Genetic Algorithm (NNGA) e Neural Network based Particle Swarm Optimization (NNPSO), empregados no cálculos dos coeficientes de peso da rede. Para todos os horizontes de tempo avaliados, os métodos baseados em algoritmos heurísticos tiveram melhores desempenhos do que a rede convencional. Em particular, o NNGA teve um melhor desempenho durante a predição STF, enquanto o NNPSO apresentou melhores resultados para os problemas de MTF e LTF.

No trabalho apresentado por Kuo e Chiou-Jye Huang (2018), os autores discutem sobre a importância dos modelos de predição de carga no contexto das redes de distribuição inteligentes. Segundo os autores, o correto balanceamento entre carga e geração permite evitar a ocorrência de custos desnecessários com o descarte e/ou armazenamento da energia extra, ou até evitar prejuízos maiores com a falta de energia. Com isso, o trabalho apresentado introduz um modelo chamado DeepEnergy, onde os autores propuseram a utilização de técnicas de deep learning integradas a redes neurais convolucionais. Experimentos foram realizados com os dados de consumo de energia pública do estado do Texas, EUA, durante o ano de 2016. O modelo proposto foi comparado a outras técnicas como o Support Vector Machine (SVM), Radial Basis Function (RBF), PMC, entre outras. Apesar de todos os modelos apresentarem resultados satisfatórios, o modelo proposto foi o que apresentou os menores erros de predição. 


\subsubsection{Previsão do consumo de energia para plantas industriais, transportes e instalações prediais}

Benedetti et al. (2016) também identificaram aplicações de RNAs empregadas à predição do consumo de plantas industriais, transportes e prédios comerciais. Segundo os autores, estes trabalhos buscam realizar a predição de energia para serem comparados com os valores reais de consumo da instalação, a fim de identificar desvios de maior significância.

Neto e Fiorelli (2008) estudam o desempenho de RNAs na predição do consumo de energia em um prédio administrativo. O estudo foi realizado a partir dos dados coletados para o prédio de Administração da Universidade de São Paulo. Foi empregada uma rede neural feed forward de quatro camadas, avaliando o desempenho para dois conjuntos distintos de variáveis de entrada. No primeiro conjunto foram consideradas as temperaturas externas máximas e mínimas, além do dia da semana e horário. Já o segundo conjunto de dados considerou os valores médios diários da temperatura externa, da umidade relativa, da radiação solar global e da radiação solar difusa. Observou-se que as novas variáveis climáticas adotadas no segundo conjunto de dados implicaram em pouca melhora na qualidade da predição, indicando para o caso estudado uma menor influência das variáveis no total de energia consumida. Neste estudo, os valores estimados pela rede neural foram comparados os valores simulados pelo software EnergyPlus, onde os valores da rede neural foram levemente superiores. Contudo, os autores apontam que os resultados da rede poderiam ser melhorados a partir da escolha de uma topologia mais adequada ao problema.

Em Chae et al. (2016), os autores utilizaram RNAs para a análise sub-horária, considerando intervalos de 15 minutos, na previsão de carga de um complexo comercial de três prédios de escritórios. Inicialmente, os autores avaliaram o desempenho de diferentes técnicas de aprendizado de máquina e selecionaram a rede neural artificial por apresentar os melhores resultados. Então, uma análise das variáveis disponíveis mais relevantes foi realizada, segregadas em três grupos: ambientais, indicadores temporais e condições operacionais. Em seguida, os autores realizaram um estudo para a determinação do número de neurônios na camada oculta da rede e observaram que pouca melhora nos erros médio, máximo e mínimo a partir da utilização de 50 neurônios. Também foi avaliado o desempenho do modelo quando aplicados os métodos de treinamento estático, acumulativo e por janela de deslocamento. 
Para o treinamento da rede, Chae et al. (2016) consideraram os dados coletados para o mês de julho de 2012, sendo avaliado o desempenho do modelo durante os meses subsequentes de setembro e outubro. Para o mês de agosto, mês seguinte ao mês de treinamento, os três métodos apresentaram resultados satisfatórios, com coeficiente de determinação $\left(R^{2}\right)$ iguais a $0.904,0.912$, e 0.902 , respectivamente. Contudo, para o mês de setembro, os métodos de treinamento acumulativo e por deslocamento, mantiveram valores satisfatórios $(0.914$ e 0.919 , respectivamente), porém o modelo estático apresentou resultados não tão bons como em agosto $\left(R^{2}=0.798\right)$. Por fim, foi avaliada a capacidade dos métodos de treinamento em prever os picos diários de energia. Novamente, os resultados foram próximos para o mês de agosto entre os métodos de treinamento, com erro variando entre $2.84 \%$ e $3.37 \%$ para os dias da semana, mas para o mês de setembro os modelos adaptativos desempenharam melhor do que o modelo estático. 



\section{FUNDAMENTAÇÃO TEÓRICA}

Para Mello, Martins e Turrioni (2013), a fundamentação teórica busca apresentar uma visão crítica sobre o conhecimento científico relevante ao trabalho de pesquisa. Esta visão permite relacionar o conhecimento existente na literatura com o conhecimento necessário para o desenvolvimento do projeto. Desta forma, as seções seguintes introduzem as principais ferramentas e conceitos empregados, fornecendo subsídios ao desenvolvimento deste trabalho.

\subsection{REDES NEURAIS ARTIFICIAIS}

As RNAs são modelos computacionais inspirados nas redes neurais biológicas. Segundo Kialashaki e Reisel (2014), sua estrutura busca representar de forma matemática o modelo de cognição humana, como a capacidade de aprender e armazenar informações a partir de experiências anteriores. Apesar da técnica ter sido originada na década de 1940 (ZHANG; HUANG, 1994), trata-se de um modelo muito popular ainda hoje no campo do aprendizado de máquina (KUO; HUANG, C.-J., 2018). Isso ocorre devido ao seu grande poder computacional, que na prática apresenta (VAZ et al., 2016):

a) Processamento massivamente paralelo, o qual permite respostas rápidas por não depender da busca sequencial das informações;

b) Aprendizado a partir de experiências, onde o treinamento da rede é feito expondo o modelo a exemplos de como ele deverá se comportar;

c) Generalização dos resultados, permitindo identificar valores factíveis mesmo quando as entradas não fizeram parte do conjunto de treinamento.

\subsubsection{Representação básica de uma rede neural}

Os elementos básicos que compõem uma rede neural são as unidades de processamento, chamadas de neurônios, e os pesos de interligação entre os neurônios, as sinapses. Desta forma, cada variável de entrada de um neurônio é multiplicada por seu respectivo valor de peso sináptico e acumulado, compondo o valor da variável net, para então ser transferido à função de ativação do neurônio. A figura 7 traz uma representação esquemática do neurônio artificial. Note que a expressão que calcula o valor de net possui um termo $B$, denominado bias, cujo 
valor é o produto entre uma constante igual a 1 e o peso sináptico $w_{n}$. O valor do bias permite que o neurônio produza um valor de saída, mesmo na ausência de sinais em sua entrada (VAZ et al., 2016).

Figura 7 - Representação do modelo matemático de um neurônio artificial

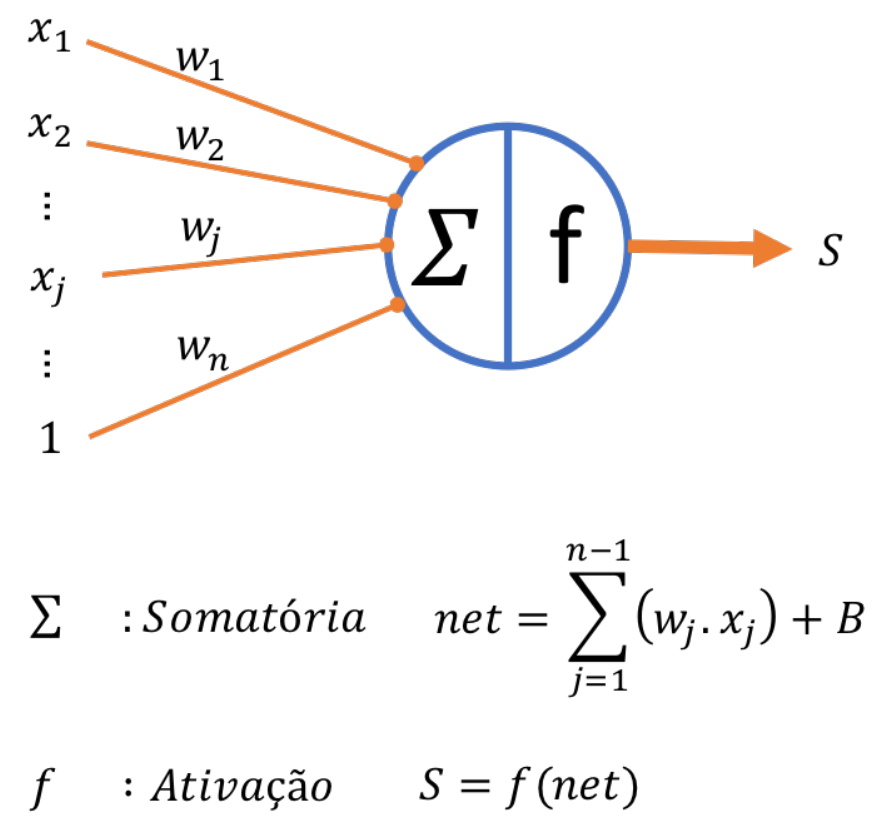

Fonte: Autor

Os valores de pesos podem ser positivos, representando conexões excitatórias, ou negativos, representando conexões inibitórias (ZHANG; HUANG, 1994). Com isso, o aprendizado experimental da rede será armazenado a partir dos valores dos pesos sinápticos, que interconectam os neurônios da rede (VAZ et al., 2016).

Já a função de ativação é responsável por descrever o comportamento e amplitude do sinal de saída do neurônio, para uma dada combinação de entrada. Há vários tipos de funções que podem ser empregadas na ativação do neurônio, onde as principais identificadas na literatura foram: degrau de Heaviside (1); pseudo-linear (2); sigmoide unipolar (3); sigmoide bipolar (4); e tangente hiperbólica (5).

$$
f(\text { net })= \begin{cases}1 & \text { se } n e t>0 \\ 0 & \text { se } n e t \leq 0\end{cases}
$$




$$
\begin{gathered}
f(\text { net })= \begin{cases}1 \quad & \text { se } n e t>x \\
n e t & \text { se } 0<n e t \leq x \\
0 \quad & \text { se } n e t \leq 0\end{cases} \\
f(\text { net })=\frac{1}{1+e^{-n e t}} \\
f(\text { net })=\frac{1-e^{-n e t}}{1+e^{-n e t}} \\
f(\text { net })=\frac{\operatorname{senh}(\text { net })}{\cosh (\text { net })}=\frac{e^{n e t}-e^{-n e t}}{e^{n e t}+e^{-n e t}}
\end{gathered}
$$

\subsubsection{Classificação das redes neurais artificiais}

Partindo dos elementos básicos apresentados, as RNAs podem ser compreendidas como sendo conjuntos de neurônios interconectados, conforme ilustrado nas figuras 8 e 9. Ainda, a partir dos sentidos das conexões entre os neurônios, podemos chegar a uma segunda forma de classificação das RNA, baseado percurso no qual o sinal flui pela rede. Basicamente, as redes podem ser classificadas em dois grupos em função do tipo de propagação, i.e., redes feed-forward e redes recorrentes. Para as redes do tipo feed-forward, o sinal se propaga em apenas um sentido, partindo da camada de entrada, passando pelas camadas ocultas, até chegar à camada de saída. Já para as redes recorrentes, os sinais podem ser retropropagados da saída de qualquer neurônio para a entrada de qualquer outro neurônio (ZHANG; HUANG, 1994).

As RNAs também podem ser classificadas em função do tipo de treinamento empregado. Segundo Braga, Carvalho e Ludermir (2014), há dois principais paradigmas que podem ser empregados, diferenciando um do outro pela quantidade de informações empregadas no treinamento da rede. Estes paradigmas são:

a) Aprendizado supervisionado (supervised learning): o treinamento é realizado por meio de pares de informações (valores de entrada e saída). Com isso, um conjunto de valores reais são aplicados à entrada da rede e sua saída é comparada com o valor esperado. Desta forma, este paradigma busca minimizar a diferença entre o valor e estimado e o valor esperado, reduzindo o erro da rede; 
Figura 8 - Exemplo de rede neural do tipo feed-forward

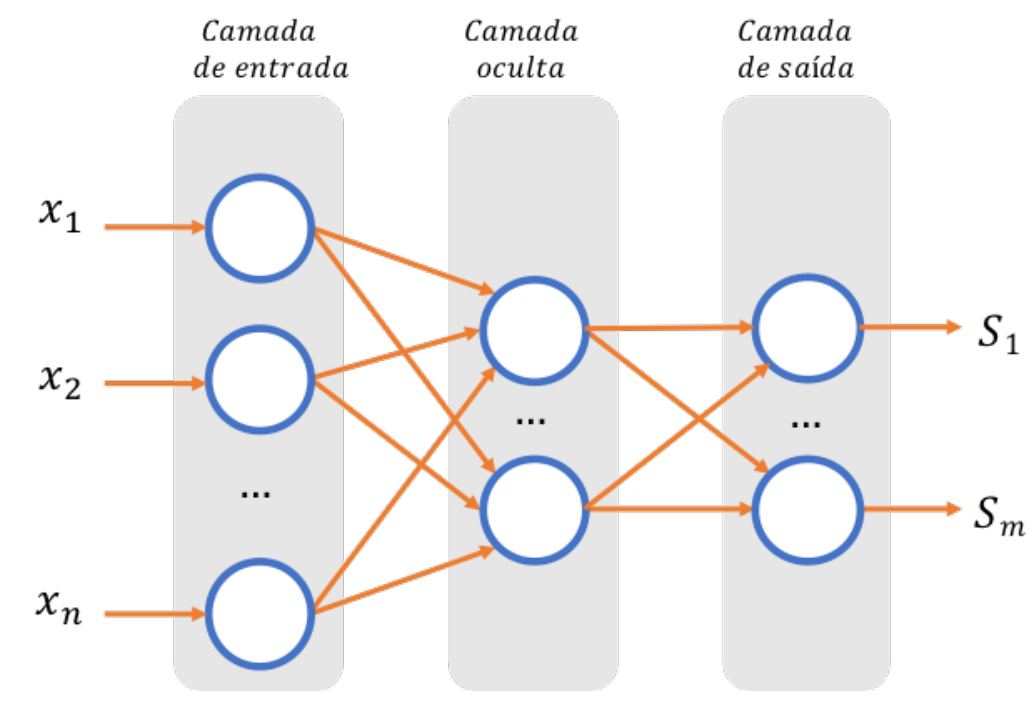

Fonte: Autor

Figura 9 - Exemplo de rede neural do tipo recorrente

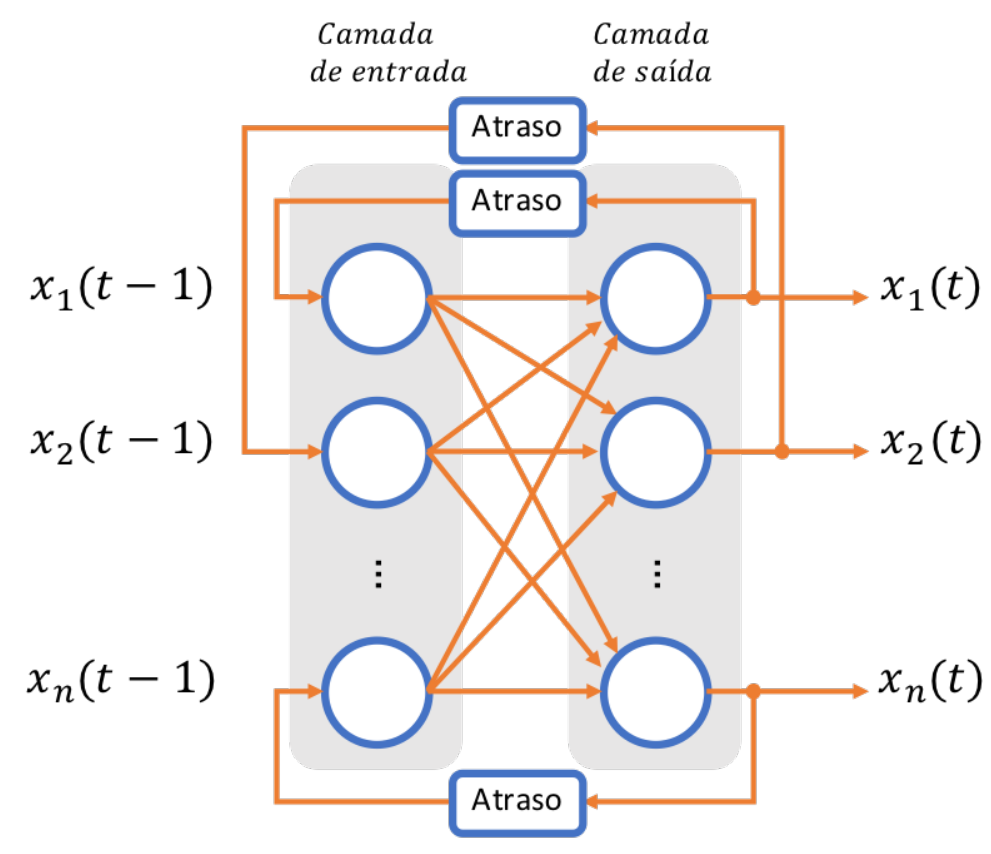

Fonte: Autor

b) Aprendizado não-supervisionado (unsupervised learning): durante o treinamento da rede apenas os valores das variáveis de entrada estão disponíveis. Com isso, a rede é responsável por identificar padrões e características a partir dos dados de treinamento, permitindo assim o agrupamento de informações (clusterização). 


\subsubsection{Rede Perceptron de Múltiplas Camadas}

Há diversas técnicas de RNAs estudadas em aprendizado de máquina, onde as redes do tipo PMC costumam ser as mais comumente empregadas (KUO; HUANG, C.-J., 2018), principalemente no contexto da manufatura (ZHANG; HUANG, 1994). Trata-se de uma rede do tipo feed-forward, de aprendizado supervisionado e com algoritmo de treinamento baseado no método do gradiente descendente (MURALITHARAN; SAKTHIVEL; VISHNUVARTHAN, 2018), denominado como algoritmo Back-Propagation.

Conforme apontado por Kialashaki e Reisel (2014), o processo de treinamento da rede PMC pode ser sintetizado em três estágios. No primeiro, um padrão de treinamento é aplicado à entrada da rede e seu valor é propagado até a camada de saída. O segundo estágio calcula o erro entre o valor propagado e o valor esperado para o padrão aplicado. Por fim, o terceiro estágio retro-propaga o erro e reajusta os valores dos pesos sinápticos da rede. Estes três estágios são repetidos até que o critério de erro mínimo definido seja alcançado.

O algoritmo BP foi proposto por Rumelhart, Hinton e Williams (1986), sendo um dos modelos de aprendizado mais empregados no treinamento de RNAs. O método busca realizar o ajuste dos pesos sinápticos por meio do cálculo do gradiente descendente, a partir do erro encontrado na camada de saída da rede. Para um padrão de variáveis apresentado à entrada da rede, o erro entre o valor estimado e o valor esperado é calculado na camada de saída e retropropagado para as camadas anteriores. Desta forma, o algoritmo busca minimizar o erro total da rede, $E$, dado pela equação:

$$
E=\frac{1}{2} \cdot \sum_{c} \sum_{j}\left(y_{j, c}-o_{j, c}\right)^{2}
$$

onde $y_{j, c}$ e $o_{j, c}$ representam os valores esperado e calculado pela rede, respectivamente, para o padrão de entrada $c$.

O ajuste dos pesos sinápticos é realizado na direção contrária ao gradiente, em quantidade proporcional à derivada parcial do respectivo erro de cada elemento processador (ZHANG; 
HUANG, 1994). Assim, o peso pode ser ajustado conforme equação 7, onde $\eta$ corresponde à taxa de aprendizado da rede, sendo uma constante positiva determinada pelo usuário.

$$
w_{i j}(t+1)=w_{i j}(t)-\eta \cdot \frac{\partial E}{\partial w_{i j}}
$$

\subsubsection{Treinamento e validação da rede}

O treinamento de uma RNA requer a obtenção de dados amostrais para o ajuste do modelo. Em especial, para as redes de aprendizado supervisionado, como a rede PMC, estes dados são formados por pares de informações contendo as variáveis de entrada e os valores esperados de saída, que descrevem o comportamento desejado do sistema. A capacidade da RNA representar o sistema dependerá do nível de flexibilidade empregado na construção da rede, de tal forma que ela não seja superdimensionada a ponto de resultar em overfitting, nem subdimensionada, resultando em underfitting (BRAGA; CARVALHO; LUDERMIR, 2014).

Algumas técnicas são apresentadas na literatura para evitar o overfitting. Uma delas é a técnica conhecida como dropout, onde algumas unidades de processamento são descartadas junto com as suas conexões, durante a fase de treinamento (SRIVASTAVA et al., 2014). Nesta técnica, os neurônios de menor relevância e suas respectivas conexões são descartados a partir da seleção aleatória, de tal forma que não haja prejuízo na representação da função da rede.

Outra técnica identificada na literatura é a segregação do banco de treinamento em dois conjuntos: treinamento e validação (KIALASHAKI; REISEL, 2014; BENEDETTI et al., 2016; MURALITHARAN; SAKTHIVEL; VISHNUVARTHAN, 2018). Nesta técnica, o conjunto de treinamento é utilizado durante a etapa de ajuste dos pesos sinápticos, sendo que a partição de validação é utilizada para verificar a capacidade de generalização da RNA, além de também ser utilizada para determinar a acurácia do modelo. Apesar de não ter sido observada uma definição formal sobre o tamanho de cada partição, encontra-se na literatura proporções em torno de $70 \%$ e 30\% para o treinamento e validação, respectivamente (KIALASHAKI; REISEL, 2014; BENEDETTI et al., 2016).

Braga, Carvalho e Ludermir (2014) recomendam interromper o processo de treinamento da RNA com base na análise do erro obtido para a partição de validação. Segundo os autores, deverá ser monitorado o erro do conjunto de validação, de tal forma que a interrupção ocorra 
ao se observar que o erro começa a aumentar. Os autores apontam que é neste instante em que a rede passa a incorporar os ruídos do conjunto de treinamento, diminuindo então a sua capacidade de generalização.

Para avaliar a qualidade do treinamento realizado é necessária a definição de indicadores de desempenho da rede. Em especial, a acurácia é uma das principais preocupações na criação de modelos voltados à predição do consumo de energia (BENEDETTI et al., 2016). Para isso, a literatura apresenta uma série de indicadores aplicados na análise de desempenho de RNA, onde são destacados no quadro 2 os principais modelos identificados.

Quadro 2 - Principais métricas de desempenho de RNA identificadas na literatura

\begin{tabular}{|c|c|}
\hline Métrica de Avaliação & Referências \\
\hline $\begin{array}{l}\text { Mean Square Error (MSE) } \\
\mathrm{MSE}=\frac{1}{n} \cdot \sum_{i=1}^{n}\left(y_{i}-o_{i}\right)^{2}\end{array}$ & $\begin{array}{l}\text { Kialashaki e Reisel (2014) } \\
\text { Benedetti et al. (2016) } \\
\text { Arriandiaga et al. (2017) } \\
\text { Muralitharan, Sakthivel e Vishnuvarthan (2018) }\end{array}$ \\
\hline $\begin{array}{l}\text { Root Mean Square Error (RMSE) } \\
\text { RMSE }=\left[\frac{1}{n} \sum_{i=1}^{n}\left(y_{i}-o_{i}\right)^{2}\right]^{1 / 2}\end{array}$ & $\begin{array}{l}\text { Uzlu et al. (2014) } \\
\text { Olanrewaju e Mbohwa (2016) } \\
\text { Vaz et al. (2016) } \\
\text { Azimi e Soofi (2017) } \\
\text { Geng et al. (2017) } \\
\text { Shuang-Xin Wang et al. (2018) }\end{array}$ \\
\hline $\begin{array}{l}\text { Coeficient of Determination }\left(\mathrm{R}^{2}\right) \\
\mathrm{R}^{2}=1-\left\{\frac{\sum_{i=1}^{n}\left(y_{i}-o_{i}\right)^{2}}{\sum_{i=1}^{n}\left(y_{i}-\bar{y}\right)^{2}}\right\}\end{array}$ & $\begin{array}{l}\text { Benedetti et al. (2016) } \\
\text { Chae et al. (2016) } \\
\text { Azimi e Soofi (2017) } \\
\text { Chen et al. (2017) }\end{array}$ \\
\hline $\begin{array}{l}\text { Mean Absolute Error (MAE) } \\
\mathrm{MAE}=\frac{1}{n} \cdot \sum_{i=1}^{n}\left|\left(y_{i}-o_{i}\right)\right|\end{array}$ & $\begin{array}{l}\text { Uzlu et al. (2014) } \\
\text { Olanrewaju e Mbohwa (2016) } \\
\text { Shuang-Xin Wang et al. (2018) }\end{array}$ \\
\hline $\begin{array}{l}\text { Relative Error (RE) } \\
\mathrm{RE}=\frac{1}{n} \cdot \sum_{i=1}^{n} \frac{\left(y_{i}-o_{i}\right)}{y_{i}} \cdot 100 \%\end{array}$ & $\begin{array}{l}\text { Uzlu et al. (2014) } \\
\text { Geng et al. (2017) }\end{array}$ \\
\hline
\end{tabular}




\subsection{SISTEMAS JOB SHOP}

Os sistemas job shop, também conhecidos como sistemas de produção por encomenda, possuem como principais características o baixo volume de produção e alta diversidade, definidos conforme os pedidos dos clientes. Cada pedido pode envolver diferentes projetos, demandando diferentes operações para a produção (PALOMINO, 2004). Desta forma, o sistema deve ser capaz de processar múltiplas operações simultaneamente em diferentes máquinas, onde as rotas de passagem em cada máquina são diferentes entre si. Para o caso particular onde as rotas são as mesmas, o sistema é chamado de flow shop. Ainda, caso um job necessite visitar a mesma máquina uma ou mais vezes, o sistema é classificado como job shop com recirculação (PINEDO, 2016).

A definição formal do sistema job shop sem recirculação é dada como segue. Trata-se de um sistema que processa $N$ diferentes jobs $(1,2,3 \ldots, n)$, a serem processados por $M$ diferentes máquinas $(1,2,3 \ldots, m)$. Cada job é processado por uma máquina de cada vez, a partir de um sequenciamento pré-estabelecido. Cada operação dura um dado período de tempo, sendo que o tempo de setup das máquinas está incluso no tempo de processamento e independe do sequenciamento adotado. A tabela 1 exemplifica, de forma condensada, as características dos jobs possíveis no sistema.

Tabela 1 - Exemplo de tabela de sequenciamento e tempos das operações

\begin{tabular}{ccccc}
\hline Jobs & \multicolumn{5}{c}{ Máquina (tempo) } \\
& $O_{i, 1}$ & $O_{i, 2}$ & $O_{i, 3}$ & $O_{i, 4}$ \\
\hline$J_{1}$ & $4(95)$ & $1(69)$ & $5(13)$ & $3(92)$ \\
\hline$J_{2}$ & $5(82)$ & $1(9)$ & $4(93)$ & $2(27)$ \\
\hline$J_{3}$ & $4(4)$ & $2(88)$ & $5(67)$ & $1(1)$ \\
\hline$J_{4}$ & $5(77)$ & $4(90)$ & $1(13)$ & $2(10)$ \\
\hline
\end{tabular}

Fonte: Autor

Na tabela 1, as linhas referem-se aos jobs $\left(J_{i}\right)$, bem como as colunas às operações $\left(O_{i, j}\right)$. Cada operação é realizada por uma máquina $\left(M_{m}\right)$ durante um certo tempo de processamento $\left(t_{i, j}\right)$. Ainda, cada elemento $O_{i, j}$ da tabela é composto pelo índice da máquina que executará a operação, seguido do tempo de processamento entre parênteses (i.e., $m\left(t_{i, j}\right)$ ). Com isso, o 
problema consiste na identificação do melhor sequenciamento das operações, de tal forma que seja melhorado o desempenho de alguma métrica do sistema (i.e., tempo total de atravessamento (MKS), energia total consumida (TEC), etc.) (BENYOUCEF; GRABOT, 2010).

A representação esquemática apresentada na figura 10 refere-se a um sistema do tipo job shop típico, onde cada job visita uma única vez cada máquina, bem como não ocorrem paralelismo de máquinas e recirculação para a realização da mesma operação. Também é possível observar que cada job possui um roteamento particular, o que difere o sistema de outros ambientes de manufatura, como o flow shop, onde as operações são processadas em estágios sucessivos, de forma contínua (MORALES; RONCONI, 2016).

Figura 10 - Exemplo de um sistema do tipo job shop

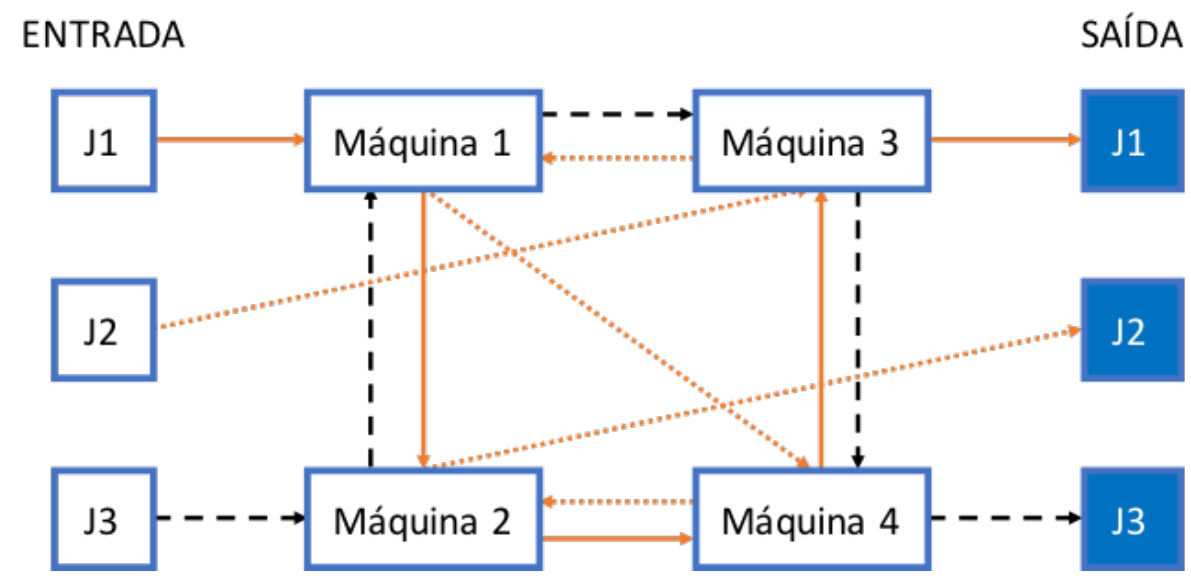

Fonte: Autor

Os sistemas do tipo job shop têm sido estudados amplamente ao longo das últimas décadas, principalmente a partir da perspectiva de produtividade do sistema. Isso resultou em diversos problemas de testes registrados na literatura, como os apresentados em Muth e Thompson (1963) e Adams, Balas e Zawack (1988), que serviram de base para a comparação de diferentes técnicas de otimização e heurísticas, desenvolvidos ao longo das últimas décadas (MAY et al., 2015).

Para a formatação de um problema de teste, sua configuração pode ser dada de forma aleatória. Como exemplo, no problema FT10 (10 jobs e 10 máquinas) proposto por Muth e Thompson (1963), as 10 operações de cada job passam em cada uma das máquinas do sistema, com sequenciamento definido de forma randômica. Para os tempos de processamento, os valores são aleatoriamente gerados a partir de uma distribuição uniforme, com intervalo variando 
entre $[1,99]$. Por fim, para simular sistemas mais próximos da realidade, May et al. (2015) apontam que as máquinas de menores índices devem ser alocadas na execução das operações iniciais de cada job e as de maiores índices, para as operações derradeiras.

\subsection{ALGORITMO GENÉTICO}

O AG é uma técnica computacional muito popular para a resolução de problemas combinatórios, em especial, na resolução dos problemas de programação em sistemas de manufatura (BIERWIRTH, 1995; LIU, Y. et al., 2015; MAY et al., 2015; ZHANG, R.; CHIONG, 2016). Trata-se de um modelo matemático introduzido por John H. Holland, ainda na década de 1960 (HOLLAND, 1992). Este modelo foi inspirado no processo de evolução natural descrito por Chales Darwin em que, conforme destacado pelo próprio Holland (1992), a maior parte dos organismos vivos evoluem a partir de dois processos básicos: a seleção natural e a reprodução sexuada. Na seleção natural, indivíduos mais aptos sobrevivem e se reproduzem. Já a reprodução sexuada permite a diversidade genética, de tal forma que as características dos indivíduos sejam transmitidas para as gerações posteriores.

Partindo de um conjunto de soluções candidatas a resposta do problema, um casal de indivíduos (pais) é selecionado e soluções descendentes são produzidas (filhos) a partir do uso de operadores genéticos (i.e., crossover e mutação). Os filhos podem ser mais aptos ou não de que seus pais, podendo ser descartados ou mantidos, durante a formação da próxima geração. A avaliação do grau de aptidão de um indivíduo é feita a partir do cálculo de seu fitness, que poderá assumir diferentes formas, dependendo do tipo de problema avaliado (e.g., rentabilidade, tempo de fabricação, consumo de energia, etc.)(HOLLAND, 1992).

A compreensão sobre o processo evolucionário permitu a Holland (1992) criar um algoritmo capaz de ser traduzido para um programa de computador. O algoritmo estruturado conta com alguns elementos básicos que permitem melhor compreender seu comportamento, e também realizar um paralelo com o processo biológico. São eles:

a) Cromossomos: um cromossomo equivale a uma solução candidata a resposta. Além disso, esta resposta poderá depender de uma série variáveis. Cada variável representa um gene, sendo que, assim como na biologia, um cromossomo será um conjunto de genes; 
b) População inicial ou geração inicial: trata-se do conjunto inicial de cromossomos (indivíduos) gerados aleatoriamente, que são candidatos à resposta do problema;

c) Seleção: o processo de seleção é feito por meio do sorteio de dois indivíduos (pais). Contudo, os indivíduos que compõem a geração atual possuem probabilidades diferentes de serem sorteados, que é proporcional aos seus graus de aptidão. Logo, indivíduos mais aptos possuem maiores chances de seleção e perpetuação de seus genes;

d) Operador crossover: a partir do par de indivíduos sorteado, aplica-se o operador de crossover para a geração de dois novos filhos. Para este operador, uma posição de seccionamento é aleatoriamente definida e realizado o cruzamento entre as partes resultantes. A troca de material genético entre os indivíduos resulta em dois novos filhos, conforme ilustrado na figura 11. A incidência do operador é determinada por uma probabilidade de ocorrência, denominada probabilidade de crossover;

e) Operador mutação: este operador trabalha com a alteração de um único gene do cromossomo. Segundo Holland (1992), a mutação por si só não causa grandes impactos na busca da solução, contudo ela permite que as gerações posteriores não fiquem presas em pontos de ótimos locais;

f) Função fitness: como já mencionado, a função fitness permite mensurar a qualidade de um indivíduo. Sua forma varia com o tipo e objetivo do problema dado. Por exemplo, um problema cujo objetivo seja a redução do consumo de energia, e que tenha a função fitness definida como sendo o valor da energia total consumida, terá indivíduos mais aptos aqueles com menores valores de fitness. Por outro lado, caso o objetivo do problema seja maximizar o lucro, quanto maior o valor do fitness, melhor.

g) Reprodução: O tamanho do conjunto de soluções candidatas à resolução do problema deverá ser mantido fixo. Isso para que não haja estouro de memória e redução da eficiência computacional devido ao aumento contínuo do número de indivíduos (BENYOUCEF; GRABOT, 2010). Além disso, poderá ser feita a troca parcial ou total dos indivíduos, por novos cromossomos gerados aleatoriamente a cada nova geração. 
Figura 11 - Aplicação do operador de crossover

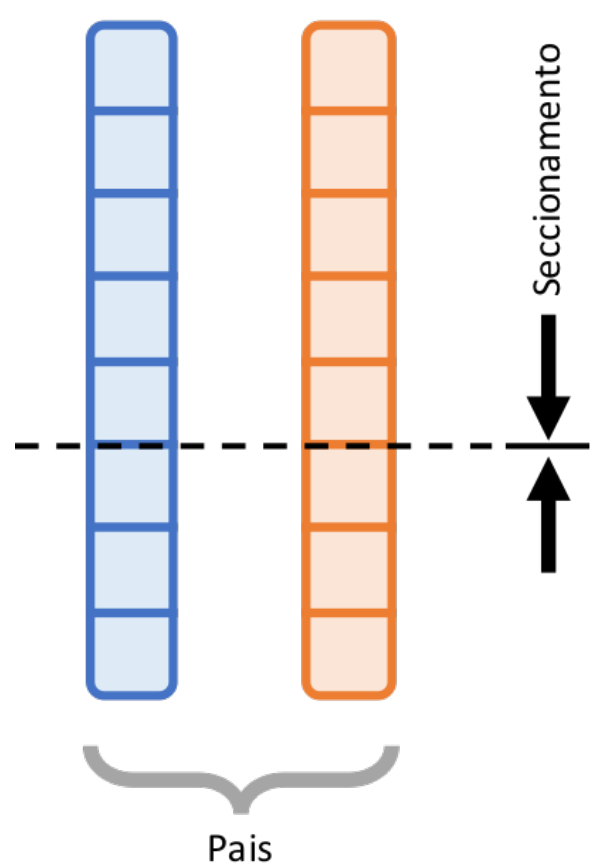

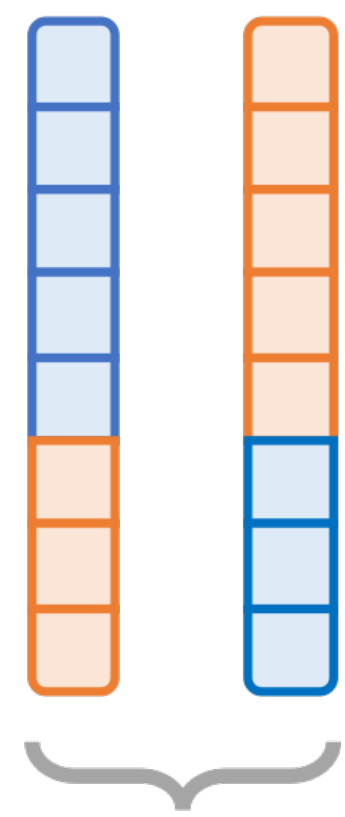

Filhos

Fonte: Autor

Após a etapa de reprodução, o algoritmo retorna para a etapa de seleção, onde um novo par é selecionado e todo o processo de realizado novamente. O algoritmo é executado por repetidas vezes, até que o critério de término definido seja alcançado, conforme ilustrado na figura 12. Michalewicz (1996) aponta que três principais critérios de término são tradicionalmente empregados para o término de algoritmos do tipo evolutivos, como o AG:

a) Quando alcançado um número limite especificado de gerações do algoritmo;

b) Quando o melhor valor de fitness se repete por um número limite de cromossomos;

c) Quando as chances de alcançar resultados significativamente melhores são muito baixas para uma próxima geração.

A aplicação dos AGs na resolução de problemas de programação da produção requer atenção durante a etapa de representação do problema. Isso porque a posterior aplicação dos operadores genéticos tradicionais, crossover e mutação, poderão resultar em novos indivíduos inadequados para a solução do problema. Neste sentido, Bierwirth (1995) traz uma abordagem de aplicação dos AGs na resolução do problema de job shop, onde a representação matemática conhecida como permutação com repetição, é empregada. Esta representação é melhor discutida na Seção 4.1, bem como sua decodificação é ilustrada na figura 19. 
Neste mesmo trabalho, Bierwirth (1995) introduz um novo operador genético chamado Generalization of Order-Crossover (GOX), para problemas representados como permutação com repetição. Para compreender o funcionamento do operador genético proposto, considere o cromossomo da figura 13.

A linha "índice"na figura, indica o número de ocorrências do gene no cromossomo "pai", quando lido da esquerda para a direita. Para um segundo cromossomo "mãe", este realiza um papel de doador de genes, onde uma fração do cromossomo, com comprimento variando entre metade e um-terço do comprimento do cromossomo, é sorteada. A figura 14 ilustra este segundo cromossomo e a fração sorteada.

A próxima etapa é mesclar a fração de genes sorteada no cromossomo "mãe"com o cromossomo "pai". Para isso, todos os genes do cromossomo "pai"com os mesmos índices dos genes sorteados, são identificados. Então, a fração sorteada é alocada dentro do cromossomo "pai", na posição subsequente onde coincide o primeiro gene da fração com o gene do cromossomo "pai", conforme ilustrado na figura 15.

Por fim, a figura 16 ilustra o cromossomo "filho", que é resultado logo após a exclusão dos genes destacados, possuindo dimensão igual ao do cromossomo "pai". 
Figura 12 - Estrutura básica do Algoritmo Genético

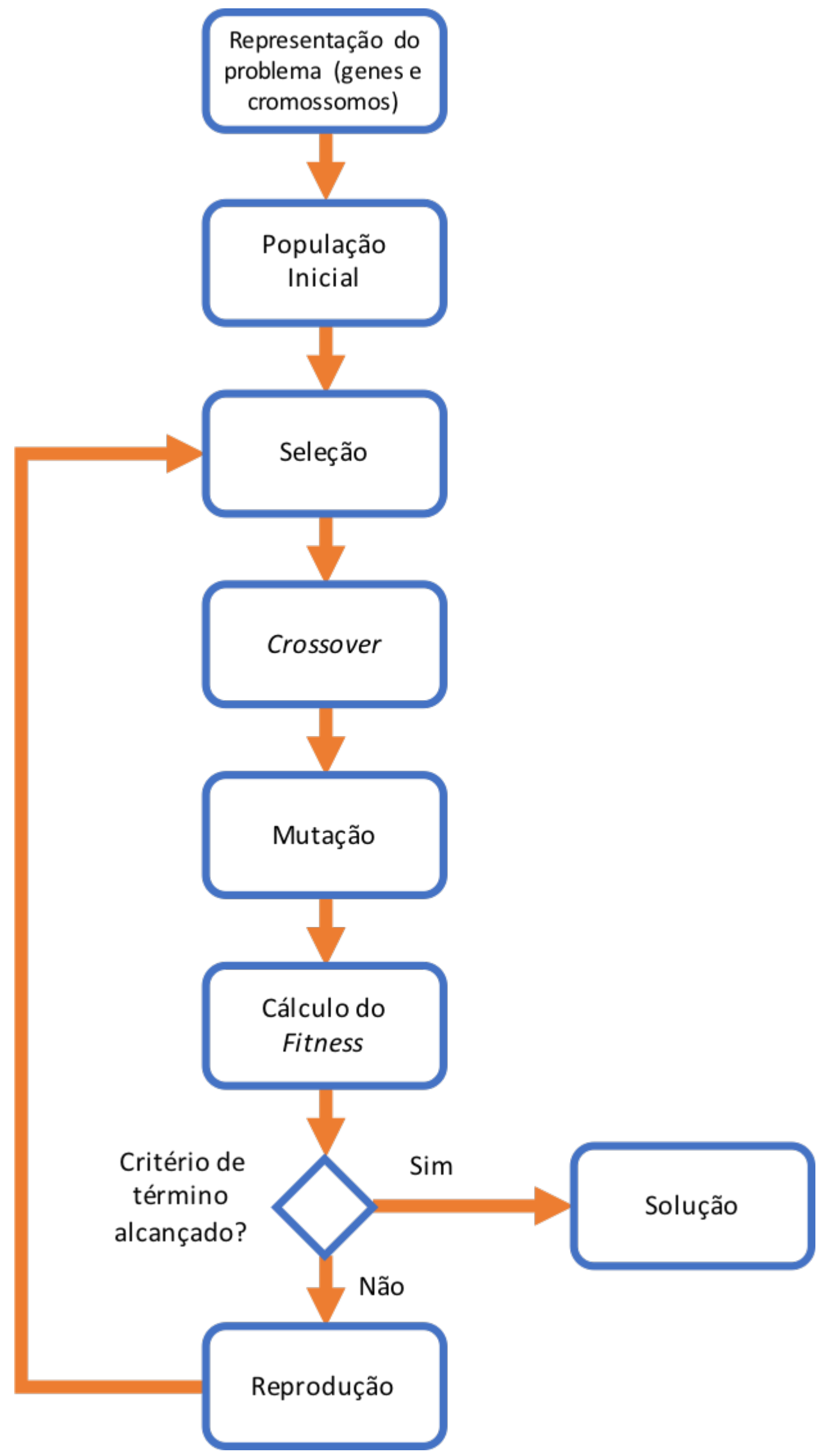

Fonte: Autor “adaptado de” Benyoucef e Grabot (2010), p. 19 
Figura 13 - Operador GOX - Cromossomo "Pai"

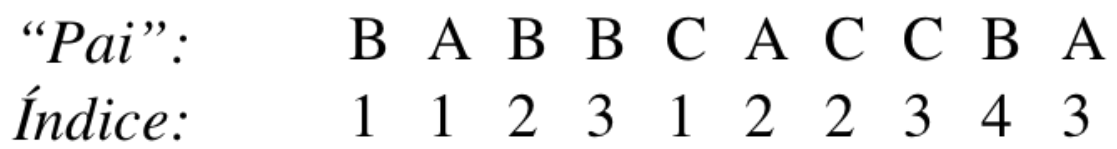

Fonte: Autor “adaptado de” Bierwirth (1995), p. 89

Figura 14 - Operador GOX - Cromossomo "Mãe"

"Mãe":
Indice:

Fonte: Autor “adaptado de” Bierwirth (1995), p. 90

Figura 15 - Operador GOX - Cromossomo "Pai"adequado
"Pai":
B A B B C A A C A B C C B A
Índice:
$\begin{array}{llllll}1 & 1 & 2 & 3 & 1 & 2\end{array}$
$\begin{array}{lllll}2 & 3 & 4 & 3\end{array}$

Fonte: Autor "adaptado de" Bierwirth (1995), p. 90

Figura 16 - Operador GOX - Cromossomo "Filho"

$$
\begin{array}{lllllllllll}
\text { "Filho": } & \text { B } & \text { A } & \text { B } & \text { A } & \text { C } & \text { A } & \text { B } & \text { C } & \text { C } & \text { B } \\
\text { Indice: } & 1 & 1 & 2 & 2 & 1 & 3 & 3 & 2 & 3 & 4
\end{array}
$$

Fonte: Autor "adaptado de" Bierwirth (1995), p. 90 



\section{MODELAGEM CONCEITUAL DO PROBLEMA}

Do ponto de vista da análise energética, o modelo proposto neste trabalho enquadrase no nível da linha de produção, discutido no quadro 1 e destacado na figura 17, uma vez que busca auxiliar durante a etapa de programação das máquinas, mas não levando em consideração questões relacionadas à forma de execução dos processos, tipos de máquinas e/ou layouts de instalação.

Figura 17 - Análise energética no nível da linha de produção

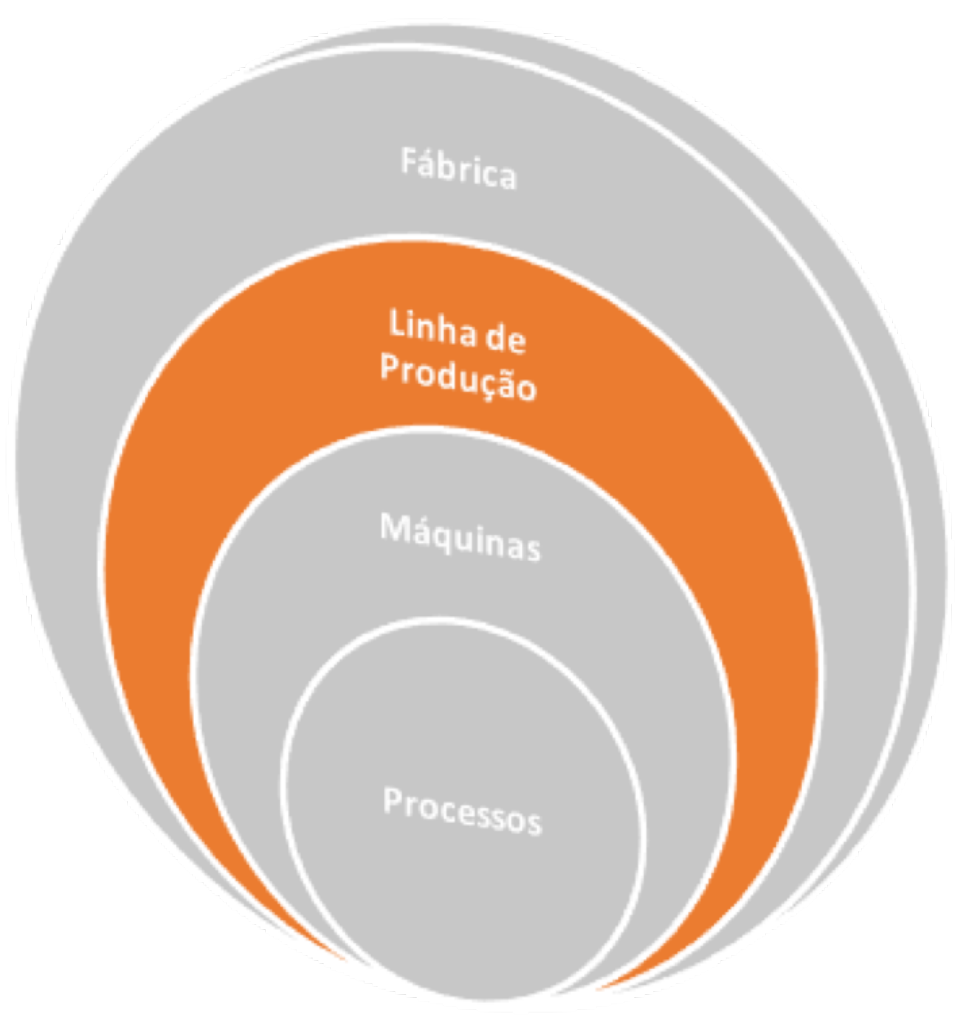

Fonte: Autor "adaptado de” Fysikopoulos et al. (2014), p.1439

Para a modelagem e simulação do problema de pesquisa, foi utilizado o software Plant Simulation $^{\circledR}$, desenvolvido pela Siemens PLM Software Inc. Trata-se de um software de simulação de eventos discretos voltado à criação de modelos digitais de sistemas logísticos (e.g. linhas de produção), permitindo explorar as características dos sistemas e melhorar seus desempenhos (SIEMENS, 2018). Além disso, o software conta com ferramentas para melhoria combinatória (e.g., algoritmo genético), RNAs e ferramentas para a análise energética. 
Conforme introduzido na Seção 3.2, sistemas do tipo job shop processam $N$ diferentes jobs, que visitam $M$ diferentes máquinas. Diferentemente dos sistemas do tipo flow shop, onde todos os jobs seguem a mesma rota de passagem pelas máquinas, os sistemas do tipo job shop permitem rotas diferentes para cada job processado (PINEDO, 2016). Além disso, R. Sule (2007) sugere a classificação dos sistemas job shop com sendo estáticos ou dinâmicos, com base no tipo de regra de decisão adotado para a execução de cada operação. Nos sistemas estáticos, a prioridade dos jobs são definidas previamente e são iguais para todas as máquinas (e.g., o primeiro que chega é o primeiro a ser processado). Já os sistemas dinâmicos, há flexibilidade para definição de diferentes prioridades em cada máquina.

O trabalho realizado pode ser divido em duas principais etapas. Na primeira, o modelo de simulação foi criado com base no gap de pesquisa identificado, permitindo coletar dados experimentais para o treinamento da RNA (Learn). Vale ressaltar que os dados utilizados nesta primeira etapa foram gerados de forma randômica, ou seja, os sequenciamentos simulados não tiveram compromisso algum em minimizar ou maximizar qualquer variável do sistema, porém permitiram acelerar o processo de coleta das informações. Já na segunda etapa, a RNA treinada foi utilizada para estimar o consumo de diferentes programações de máquinas geradas com o auxílio do AG (Recall). O algoritmo foi empregado a fim de minimizar o MKS, de tal forma que o sequenciamento das operações estivesse o mais próximo de um cenário real. Ao final, o consumo de energia estimado pela RNA foi comparado com o valor simulado pelo software.

\subsection{DESCRIÇÃO GERAL DO MODELO}

A introdução realizada aponta para a necessidade de buffers antecedendo a entrada de cada uma das máquinas, para a modelagem de um sistema job shop. Isso porque a prioridade de execução de cada job deve ser analisada antes de seu processamento, além de ser possível o acúmulo de atividades aguardando a disponibilidade da máquina para a execução. Desta forma, levando em consideração esta necessidade, é apresentado na figura 18 o modelo de simulação utilizado neste estudo.

No início da simulação, todos os jobs estão disponíveis para a execução. Com isso, no instante de tempo $t=0$, os jobs são alocados para os respectivos buffers de entrada de cada máquina, para execução das primeiras operações. Quando a operação é concluída, o job é enca- 
Figura 18 - Modelo de simulação do sistema job shop
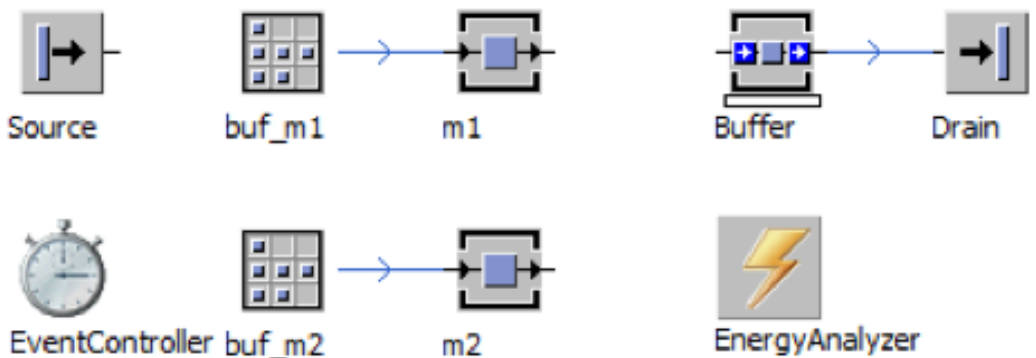

EventController buf_m2

$\mathrm{m} 2$

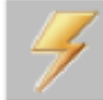

EnergyAnalyzer

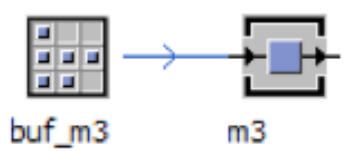

Energy $[\mathrm{kWh}]$ :

Operational [kWh]:

Power input $[\mathrm{kW}]$ :

Maximum [kW]:

0.0
0.0
0.0
0.0
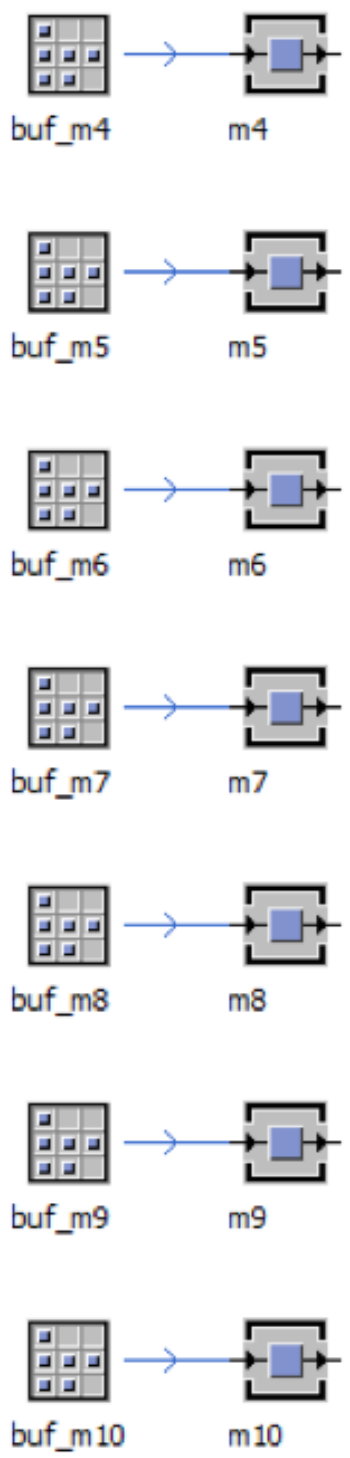

Fonte: Autor 
minhado para outra máquina, responsável por executar a próxima operação. Ao ser executada a última operação, o job está concluído e, então, é encaminhado para a saída do sistema.

Segundo a classificação de sistemas job shop apontada por R. Sule (2007), o modelo empregado é classificado como do tipo dinâmico. Isso porque os jobs possuem diferentes prioridades de execução em cada uma das máquinas do sistema. Desta forma, mesmo havendo diferentes jobs aguardando processamento nos buffers de entrada, será processado apenas aquele que tiver a maior prioridade definida para o dado instante de tempo. Esta prioridade é definida a partir do vetor de entrada, cuja a representação adotada neste trabalho é a mesma proposta em Bierwirth (1995), denominada como Permutação com Repetição.

Na representação adotada, cada job ocorre a mesma quantidade de vezes que o número de operações necessárias para a sua execução. Desta forma, avaliando o vetor de entrada da primeira para a última posição, a k-ézima ocorrência de um job refere-se à sua k-ézima operação. Na prática, esta representação permite sua decodificação em um gráfico de Gantt, realizando a alocação de cada operação em sua respectiva máquina. A figura 19 ilustra um exemplo de decodificação do vetor de entrada e sua respectiva programação resultante.

\subsection{CONFIGURAÇÃO GERAL DO SISTEMA SIMULADO}

Este trabalho adota o problema clássico FT10, proposto por Muth e Thompson (1963), como base para o desenvolvimento do modelo de simulação e estimação do consumo de energia. A arquitetura do problema FT10 foi escolhida por ser comumente utilizada no estudo de sistemas job shop, além de considerar uma quantidade elevada de máquinas no sistema (10 máquinas), quando comparado com sistemas reais.

O sequenciamento de máquina das operações demandadas por cada job, bem como os seus respectivos tempos de processamento, foram gerados de forma randômica, conforme procedimento descrito na seção Seção 3.2. Como resultado, o sequenciamento e seus respectivos tempos de processamento para cada operação foram sintetizados na tabela 2. Nela, os valores apresentados entre parênteses representam o tempo de processamento de cada operação $O_{i, j}$, assim como os valores do lado de fora dos parênteses indicam a máquina na qual a operação será realizada. 
Figura 19 - Exemplo de decodificação do vetor de entrada

a) Vetor de entrada

Maior
Menor
prioridade
prioridade

b) Sequenciamento das operações

c) Tempos de processamento

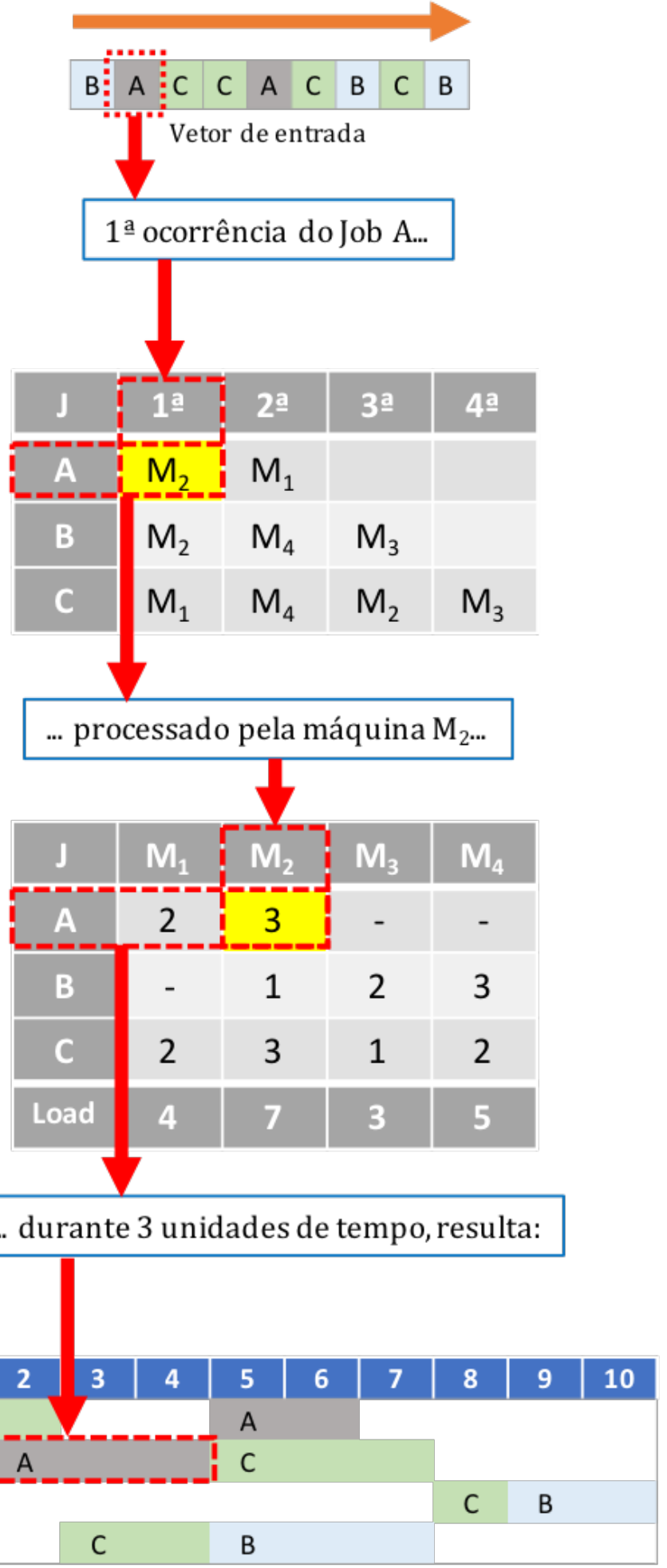

Fonte: Autor

Após a definição dos aspectos de sequenciamento e tempos de processamento das operações, a próxima etapa está na definição das potências elétricas consumidas por cada máquina. 
Tabela 2 - Tabela de sequenciamento e tempos das operações de cada job

\section{Máquina (tempo de processamento)}

\begin{tabular}{ccccccccccc} 
Jobs & $O_{i, 1}$ & $O_{i, 2}$ & $O_{i, 3}$ & $O_{i, 4}$ & $O_{i, 5}$ & $O_{i, 6}$ & $O_{i, 7}$ & $O_{i, 8}$ & $O_{i, 9}$ & $O_{i, 10}$ \\
\hline$J_{1}$ & $4(95)$ & $1(69)$ & $5(13)$ & $3(92)$ & $2(85)$ & $6(50)$ & $7(31)$ & $9(90)$ & $8(65)$ & $10(4)$ \\
\hline$J_{2}$ & $5(82)$ & $1(9)$ & $4(93)$ & $2(27)$ & $3(25)$ & $7(69)$ & $10(45)$ & $9(91)$ & $8(95)$ & $6(7)$ \\
\hline$J_{3}$ & $4(4)$ & $2(88)$ & $5(67)$ & $1(1)$ & $3(93)$ & $8(2)$ & $6(13)$ & $7(99)$ & $10(92)$ & $9(42)$ \\
\hline$J_{4}$ & $5(77)$ & $4(90)$ & $1(13)$ & $2(10)$ & $3(42)$ & $7(9)$ & $6(75)$ & $8(16)$ & $10(15)$ & $9(47)$ \\
\hline$J_{5}$ & $3(77)$ & $1(46)$ & $2(24)$ & $4(34)$ & $5(36)$ & $9(30)$ & $8(41)$ & $10(91)$ & $7(73)$ & $6(28)$ \\
\hline$J_{6}$ & $2(51)$ & $3(97)$ & $5(56)$ & $4(31)$ & $1(63)$ & $6(97)$ & $9(23)$ & $7(25)$ & $10(70)$ & $8(56)$ \\
\hline$J_{7}$ & $2(89)$ & $3(84)$ & $4(82)$ & $5(36)$ & $1(79)$ & $8(4)$ & $9(89)$ & $7(20)$ & $10(71)$ & $6(25)$ \\
\hline$J_{8}$ & $1(99)$ & $5(92)$ & $4(95)$ & $2(85)$ & $3(90)$ & $9(39)$ & $10(92)$ & $8(69)$ & $6(24)$ & $7(48)$ \\
\hline$J_{9}$ & $1(20)$ & $3(79)$ & $2(14)$ & $5(10)$ & $4(46)$ & $8(10)$ & $6(72)$ & $7(62)$ & $9(6)$ & $10(96)$ \\
\hline$J_{10}$ & $3(81)$ & $5(54)$ & $4(3)$ & $1(96)$ & $2(63)$ & $6(53)$ & $8(39)$ & $9(90)$ & $7(36)$ & $10(9)$ \\
\hline
\end{tabular}

Fonte: Autor

Para isso, faz-se necessário definir a política energética aplicada ao sistema de produção, a qual indicará os estados de energia possíveis para as máquinas. Levando-se em consideração que este trabalho adota a política energética de número dois, apresentada por May et al. (2015), o comportamento das máquinas é dado por:

a) No instante inicial $(t=0)$, todas as máquinas encontram-se desligadas;

b) Então, as máquinas são ligadas individualmente no instante em que a primeira operação demandar o uso da máquina;

c) Ao término de uma operação, a máquina é colocada em estado de espera, consumindo menos energia. Caso a operação executada seja última planejada para a máquina, ela é então desligada.

Baseado na política energética descrita, três estados de energia são possíveis para as máquinas: desligado, operando e em espera. Para o estado desligado, considera-se não haver consumo de energia elétrica. Já o estado operando é o de maior consumo de energia, onde a máquina encontra-se executando uma operação. Por fim, o estado em espera refere-se ao estado de baixo consumo de energia, onde a máquina não está processando nenhum job, mas encontra-se energizada e pronta para iniciar uma nova operação. 
Para a determinação das potências consumidas em cada máquina durante o estado operando, um método similar ao utilizado na definição dos tempos de processamento foi empregado. Foram gerados valores aleatórios distribuídos uniformemente entre [15, 50] kVA. Este intervalo foi definido a partir da análise dos catálogos dos tornos CNC da linha ROMI Centur, fabricados pelas Indústrias ROMI S.A. (INDÚSTRIAS ROMI S.A., 2018), onde foram considerados os valores declarados de potência total instalada para cada máquina. Outros modelos de equipamentos deste fabricante, de diferentes tipos e linhas, também foram avaliados, porém todos apresentaram valores próximos ou dentro do intervalo considerado. Com isso, o intervalo adotado foi considerado como razoável para a simulação do sistema de manufatura.

Observa-se que os valores de potência tipicamente apresentados para estes tipos de equipamentos, são dados em unidades de kVA (quilovolt-ampere). Em eletricidade, esta unidade refere-se ao valor da potência aparente, cujo valor é a soma vetorial entre a potência ativa $(\mathrm{kW})$ e potência reativa (kVAr). Neste estudo não será feita distinção entre estes tipos de potências elétricas, sendo adotado o valor da potência ativa $(\mathrm{kW})$ como sendo igual ao valor da potência aparente (kVA) especificada para cada máquina.

O consumo de energia para o estado em espera não foi identificado no catálogo do fabricante. Entretanto, subentendesse que a energia consumida neste estado é inferior ao valor da potência total instalada para a máquina. Conforme discutido por Salonitis e Ball (2013), a energia total de uma máquina pode ser desmembrada conforme a Eq. 8. Naquela equação, o valor de $E_{\text {proc }}$ representa a fração de energia requerida para a execução do processamento físico do job, ou seja, durante o estado operando. Já a fração de energia $E_{\text {perif }}$ representa todos os demais dispositivos periféricos da máquina, que permanecem ligados mesmo quando a máquina encontra-se no estado em espera (e.g., bombas de refrigeração, sistemas de ventilação, iluminação, etc.). Os autores apontam que, mesmo durante os períodos de ociosidade do equipamento, as máquinas podem consumir quantias superiores a $50 \%$ de suas potências máximas. Contudo, como esse valor não se trata de uma regra e poderá variar para mais ou para menos em função do tipo de equipamento e/ou fabricante, os valores adotados neste trabalho foram aleatoriamente definidos entre $40 \%$ e $60 \%$ do valor da potência total de cada máquina. Isso resultou nos valores apresentados na tabela 3 .

$$
E_{\text {total }}=E_{\text {proc }}+E_{\text {perif }}
$$


Definidos os estados energéticos e as potências consumidas pelas máquinas, estes dados são inseridos no modelo de simulação. Contudo, além dos estados de energia descritos para o modelo, o software Plant Simulation ${ }^{\circledR}$ permite a configuração de uma série de outros parâmetros de energia, como o consumo nos estados transitórios, consumo durante o setup do equipamento, durante a ocorrência de falhas, entre outros. A figura 20 apresenta a guia de configuração dos parâmetros de energia do objeto SingleProc utilizado para a representação das máquinas, bem como o quadro 3 traz a equivalência entre os estados energéticos considerados neste trabalho e os estados disponíveis no software de simulação.

Tabela 3 - Potência consumida pelas máquinas

\begin{tabular}{cccc}
\hline \multirow{4}{*}{ Máquina } & \multicolumn{3}{c}{ Potência consumida por estado } \\
& Desligado [kW] & Em espera [kW] & Operando [kW] \\
\hline$M_{1}$ & 0,00 & 15,49 & 28,06 \\
\hline$M_{2}$ & 0,00 & 20,39 & 40,68 \\
\hline$M_{3}$ & 0,00 & 21,03 & 43,08 \\
\hline$M_{4}$ & 0,00 & 14,86 & 30,23 \\
\hline$M_{5}$ & 0,00 & 12,69 & 25,04 \\
\hline$M_{6}$ & 0,00 & 7,16 & 16,34 \\
\hline$M_{7}$ & 0,00 & 17,32 & 34,41 \\
\hline$M_{8}$ & 0,00 & 10,60 & 18,17 \\
\hline$M_{9}$ & 0,00 & 17,82 & 42,89 \\
\hline$M_{10}$ & 0,00 & 18,26 & 41,94 \\
\hline
\end{tabular}

Quadro 3 - Equivalência entre os parâmetros utilizados no modelo e os disponíveis no software

\begin{tabular}{|c|c|}
\hline $\begin{array}{c}\text { Estados de energia } \\
\text { do } \text { Plant Simulation }^{\circledR}\end{array}$ & $\begin{array}{c}\text { Estados de energia } \\
\text { do modelo }\end{array}$ \\
\hline Working $^{\text {Operando }}$ \\
\hline Setting-up & - \\
\hline Operational & Em espera \\
\hline Failed & - \\
\hline Standby & - \\
\hline Off & Desligado \\
\hline
\end{tabular}


Figura 20 - Janela de configuração dos parâmetros de energia da máquina

\begin{tabular}{|c|c|c|c|c|c|c|}
\hline Importer & \multicolumn{2}{|c|}{ Failure Importer } & Energy & \multicolumn{3}{|c|}{ User-defined Attributes } \\
\hline \multicolumn{7}{|l|}{$\checkmark$ Active } \\
\hline \multicolumn{3}{|c|}{ Power input [kw] } & \multicolumn{4}{|l|}{ Transition times } \\
\hline Working: & 20 & $\boxminus$ & \multicolumn{2}{|c|}{ Operational $\rightarrow$ Off: } & 0 & $\square$ \\
\hline Setting-up: & 10 & $\square$ & \multicolumn{2}{|c|}{ off $\rightarrow$ Operational: } & 0 & 曰 \\
\hline Operational: & 10 & $\square$ & \multicolumn{2}{|c|}{ Operational $\rightarrow$ Standby: } & 0 & $\boxminus$ \\
\hline Failed: & 10 & 曰 & \multicolumn{2}{|c|}{ Standby $\rightarrow$ Operational: } & 0 & $\square$ \\
\hline Standby: & 7 & $\boxminus$ & \multirow{2}{*}{\multicolumn{2}{|c|}{$\begin{array}{l}\text { Standby } \rightarrow \text { Off: } \\
\text { Off } \rightarrow \text { Standby: }\end{array}$}} & 0 & $\square$ \\
\hline Off: & 0 & $\square$ & & & 0 & $\square$ \\
\hline \multicolumn{3}{|c|}{ State Transition } & State: & \multicolumn{3}{|c|}{ Operational } \\
\hline
\end{tabular}

Fonte: Autor

Após a atribuição das potências consumidas por cada máquina, é inserido ao modelo o módulo de análise energética. O software Plant Simulation ${ }^{\circledR}$ registra a cada mudança no estado de operação, o consumo de energia dos objetos simulados. Além disso, o software armazena a soma total da energia consumida por cada objeto monitorado e dispõe da ferramenta EnergyAnalyser para a análise estatística das informações (BANGSOW, 2015). Dentre os dados disponíveis, o software permite visualizar, graficamente, a energia consumida por estado de cada máquina monitorada e a energia total consumida pelos equipamentos. As figuras $21 \mathrm{e}$ 22 ilustram, respectivamente, estes modos de visualização. Além da informação gráfica, o software também permite o acesso à variável que registra a soma total da energia consumida pelos equipamentos monitorados pelo módulo de análise energética.

\subsection{CONJUNTO DE TREINAMENTO PARA ESTIMAÇÃO DA ENERGIA TOTAL CON- SUMIDA}

A principal função da RNA neste trabalho está na estimação do consumo total de energia de um sistema job shop, a partir de um vetor de entrada de sequenciamento das atividades. Conforme ilustrado anteriormente na figura 19, o comprimento do vetor de entrada depende diretamente do número de jobs selecionados e do número de operações de cada demandada por cada job. Com isso, faz-se necessário definir um critério que permita fixar o número de 
Figura 21 - Gráfico do consumo de energia por estado de cada máquina

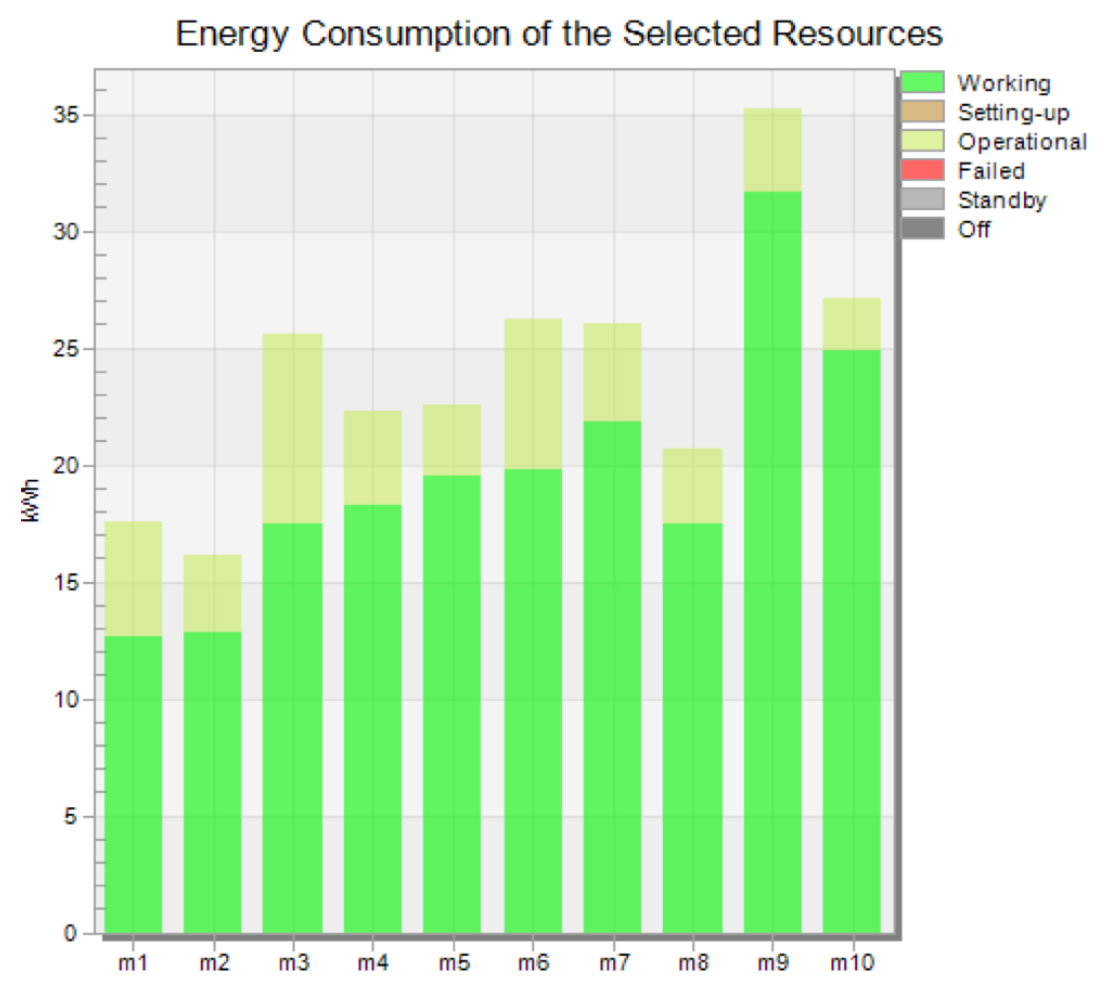

Fonte: Autor

variáveis de entrada da RNA, para diferentes combinações de jobs. Isso é necessário para se buscar a generalização do modelo, sem que seja preciso modelar uma nova rede para cada novo vetor de entrada.

Para contornar esta questão, o critério adotado foi vincular o número de entradas da RNA ao número de máquinas do sistema. Isso permite aproximar o modelo proposto às configurações típicas das empresas de manufatura, onde o número de máquinas normalmente é fixo no sistema, variando a configuração da ordem de produção. Com isso, cinco grupos de variáveis foram selecionados, conforme discutido nas subseções seguintes.

\subsubsection{Nuance 1 - Fator de Prioridade}

O primeiro conjunto de variáveis está relacionado à prioridade de entrada de uma máquina em operação. Conforme discutido anteriormente e ilustrado na figura 19a, o vetor de entrada pode ser interpretado como uma lista de prioridades de execução, onde as operações à esquerda do vetor, possuem prioridade mais elevada do que às operações localizadas à direita. 
Figura 22 - Gráfico de consumo total de energia

\section{Power Input}

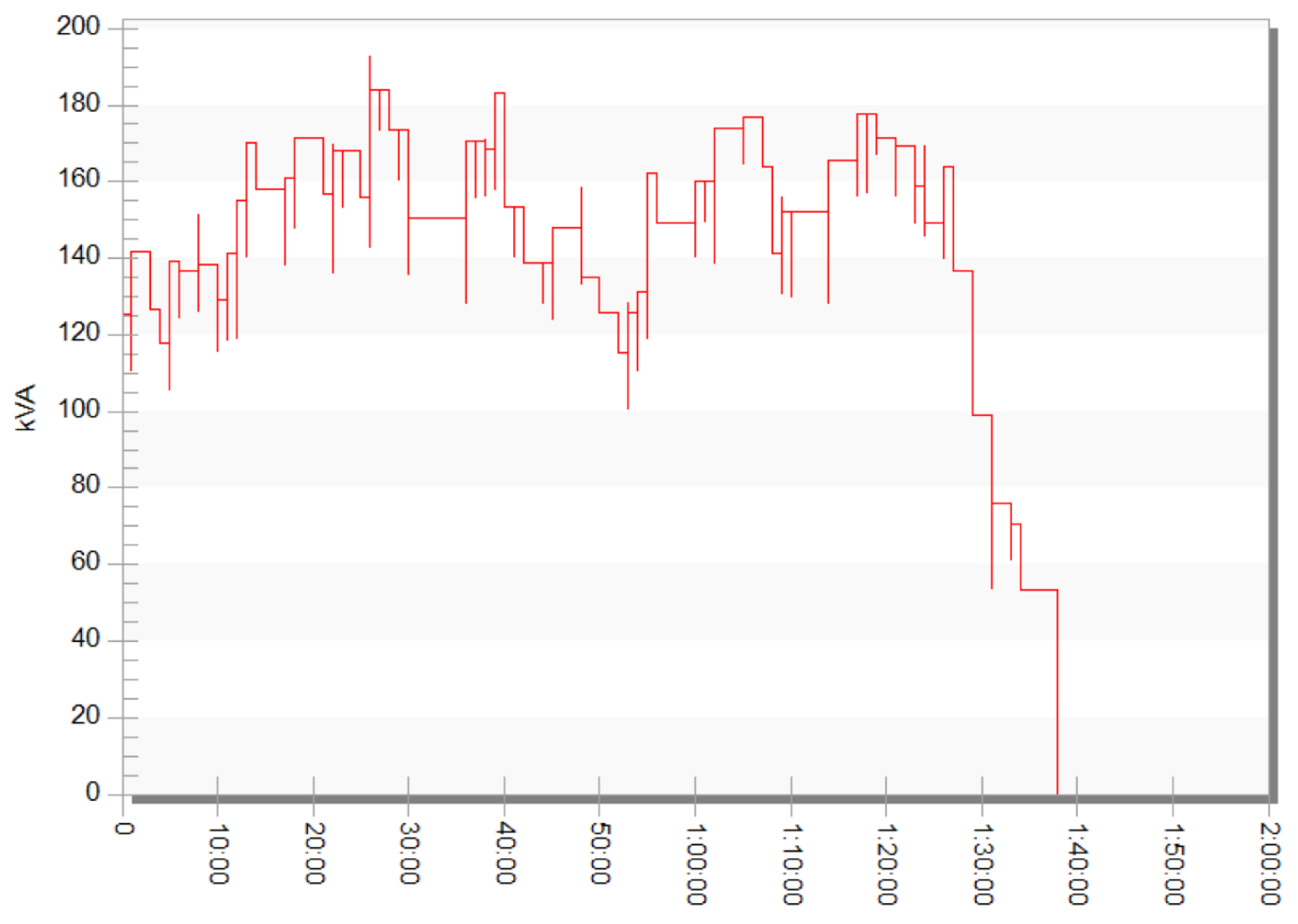

Time

Fonte: Autor

Desta forma, se uma máquina é alocada para executar a primeira operação de todos os jobs (e.g., inspeção de matéria-prima), ela terá um fator de prioridade mais elevado do que uma máquina empregada somente na etapa final do processo (e.g., embaladora). Com isso, o fator de prioridade para cada máquina $\left(F P_{m}\right)$ pode ser definido como a soma do valor inverso do índice de prioridade $i$ das operações executadas pela máquina $m$.

$$
F P_{m}=\sum \lambda \times \frac{1}{i}
$$

onde $i$ é o índice de prioridade, que corresponde à posição da operação dentro do vetor de entrada, $\lambda$ é o fator de escolha e recebe valor igual a 1 quando a operação da posição $i$ é executada pela máquina $m$ e 0 , quando não. 
A figura 23 exemplifica o cálculo do fator de prioridade para a máquina 2. Com isso, um fator de prioridade $F P_{m}$ deverá ser calculado para cada máquina presente no sistema. Figura 23 - Exemplo do cálculo da nuance fator de prioridade

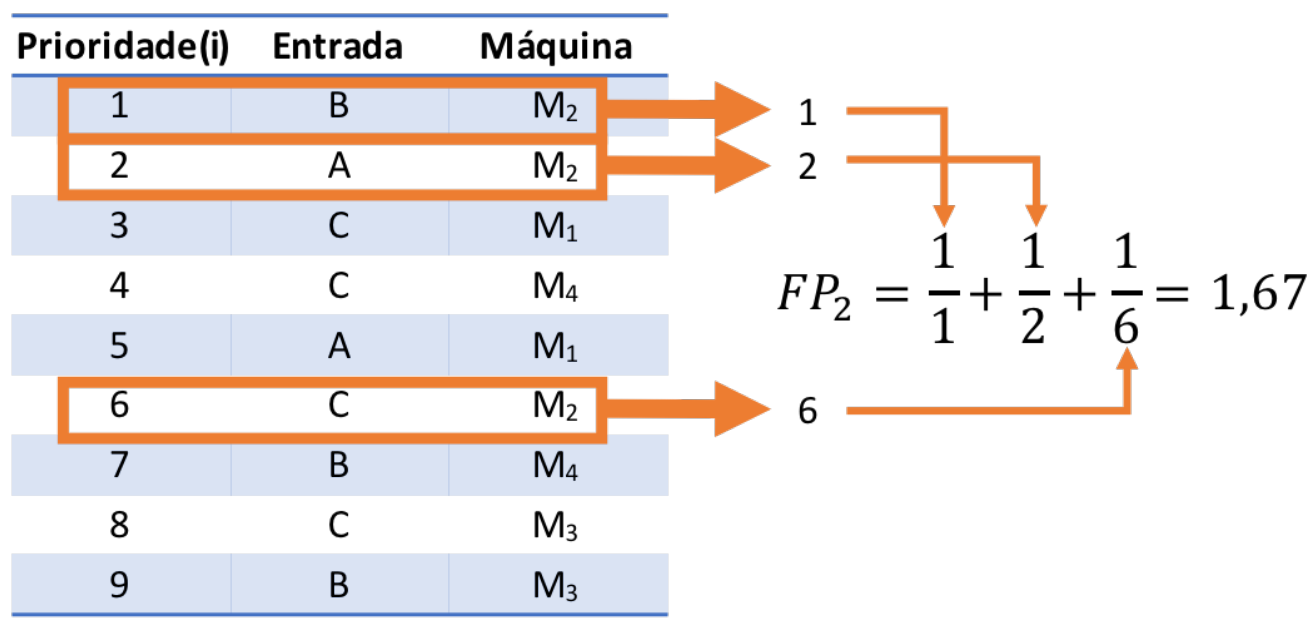

Fonte: Autor

\subsubsection{Nuance 2 - Instante de Início}

O segundo conjunto de variáveis refere-se ao instante de início da primeira operação de cada máquina $\left(S T_{m}\right)$. A determinação do instante de início pode ser feita a partir do algoritmo de programação semi-ativo ilustrado em (BIERWIRTH, 1995). Programações semi-ativas são aquelas onde não há operações que possam ser antecipadas, sem que haja, ao menos, a alteração do sequenciamento de uma máquina (PINEDO, 2016).

No algoritmo apresentado no Apêndice A, o vetor contendo os instantes de tempo da entrada em operação de cada máquina, $S T_{m}$, é inicializado com valor infinito. A cada iteração, é verificado se a máquina iniciou a operação corrente em instante inferior ao registrado. Caso seja verdadeiro, a posição do vetor referente à máquina utilizada na operação atual é atualizado.

\subsubsection{Nuance 3 - Instante de Término}

De forma análoga ao conjunto de variáveis da nuance 2, o instante de término das operações, $E T_{m}$, também é calculado pelo algoritmo do Apêndice A. Entretanto, a inicialização do vetor é feita com valor nulo, para todas as posições. A partir daí, a cada iteração, o instante de 
término da operação é verificado. Caso o valor observado seja superior ao registrado em $E T_{m}$, o valor é então atualizado.

\subsubsection{Nuance 4 - Carga de máquina}

O quarto conjunto de variáveis refere-se ao tempo total de processamento $M L_{m}$, previsto para cada máquina. Este valor pode ser extraído a partir da tabela de tempos de processamento, ilustrada na figura 19c, seguindo os passos descritos abaixo:

a) Identificar os jobs presentes na ordem de produção;

b) Da tabela de tempos de processamento, remover as linhas relativas aos jobs não identificados no passo anterior;

c) Por fim, somar os valores por colunas e atribuir o total à respectiva variável $M L_{m}$. Caso haja máquinas não utilizadas, o valor nulo é atribuído.

\subsubsection{Nuance 5 - Quantidade de jobs}

Por fim, a quinta nuance empregada no modelo refere-se à contagem restrita de jobs $J$ presentes no vetor de entrada (NumJobs). Ou seja, a quantidade de diferentes jobs que serão processados na ordem de produção corrente.

\subsection{CAPTURA DE DADOS PARA O TREINAMENTO DO MODELO}

Uma das dificuldades na implantação das RNAs em sistemas de manufatura está na obtenção de dados reais para a modelagem e treinamento da rede. Neste sentido, Tang, Wenxin Liu e Jiyin Liu (2005) propuseram o uso de softwares de simulação para a geração do conjunto de dados necessários para o treinamento de uma rede, empregada na resolução do problema de programação em sistemas do tipo flow shop.

Para a geração do conjunto de treinamento deste trabalho, foram implementados três novos métodos em linguagem de programação SimTalk 2, nativa do software Plant Simulation ${ }^{\circledR}$ e voltada para expansão dos recursos da ferramenta (BANGSOW, 2015). Os novos métodos 
foram executados a cada rodada de aquisição, registrando os exemplos de treinamento em uma tabela auxiliar.

O primeiro método implementado foi responsável pela geração aleatória das ordens de produção. Neste método, primeiramente foi sorteada a quantidade de jobs, ou produtos, da ordem de produção a serem processados. Em seguida, foram sorteados os jobs de cada uma das posições definidas pelo primeiro sorteio. O sorteio dos tipos de jobs foi realizado de forma recursiva, onde um job não poderia ser selecionado mais do que uma vez dentro da mesma ordem de produção. A composição do banco de treinamento com jobs de diferentes tamanhos e configurações, buscou a generalização do modelo para a configuração do sistema adotado, dando flexibilidade para a produção de diferentes combinações. No segundo método foram implementados os algoritmos descritos na seção anterior para a extração das nuances a partir da configuração da ordem de produção sorteada. Por fim, o terceiro método foi o responsável por realizar a leitura do módulo de análise energética. Nele, o consumo total da energia elétrica consumida pelo sistema simulado é obtido e registrado, compondo o conjunto de treinamento.

Com a construção do modelo de simulação e criação dos métodos mencionado, cada rodada de simulação resultou em apenas um exemplo para o treinamento da rede. Desta forma, a geração do conjunto de treinamento é feita mediante a execução do modelo de simulação por repetidas vezes.

\subsection{IMPLEMENTAÇÃO DA RNA NO MODELO DE SIMULAÇÃO}

Para a implementação da RNA, o software Plant Simulation ${ }^{\circledR}$ possui uma biblioteca de classe chamada NeuralNet. Esta biblioteca permite o emprego de RNAs integradas ao modelo de simulação.

A configuração da RNA é iniciada a partir da definição sobre quais são as variáveis dependentes e independentes no conjunto de treinamento. Para o software de simulação empregado neste estudo, as variáveis independentes são mapeadas como sendo variáveis de entrada, e as variáveis dependentes como variáveis de saída, conforme ilustrado na figura 24.

A biblioteca de classe NeuralNet permite empregar RNAs do tipo PMC, treinadas por meio do algoritmo BP, de forma integrada ao modelo de simulação. Para isso, algumas obser- 
Figura 24 - Mapeamento das variáveis de entrada e saída

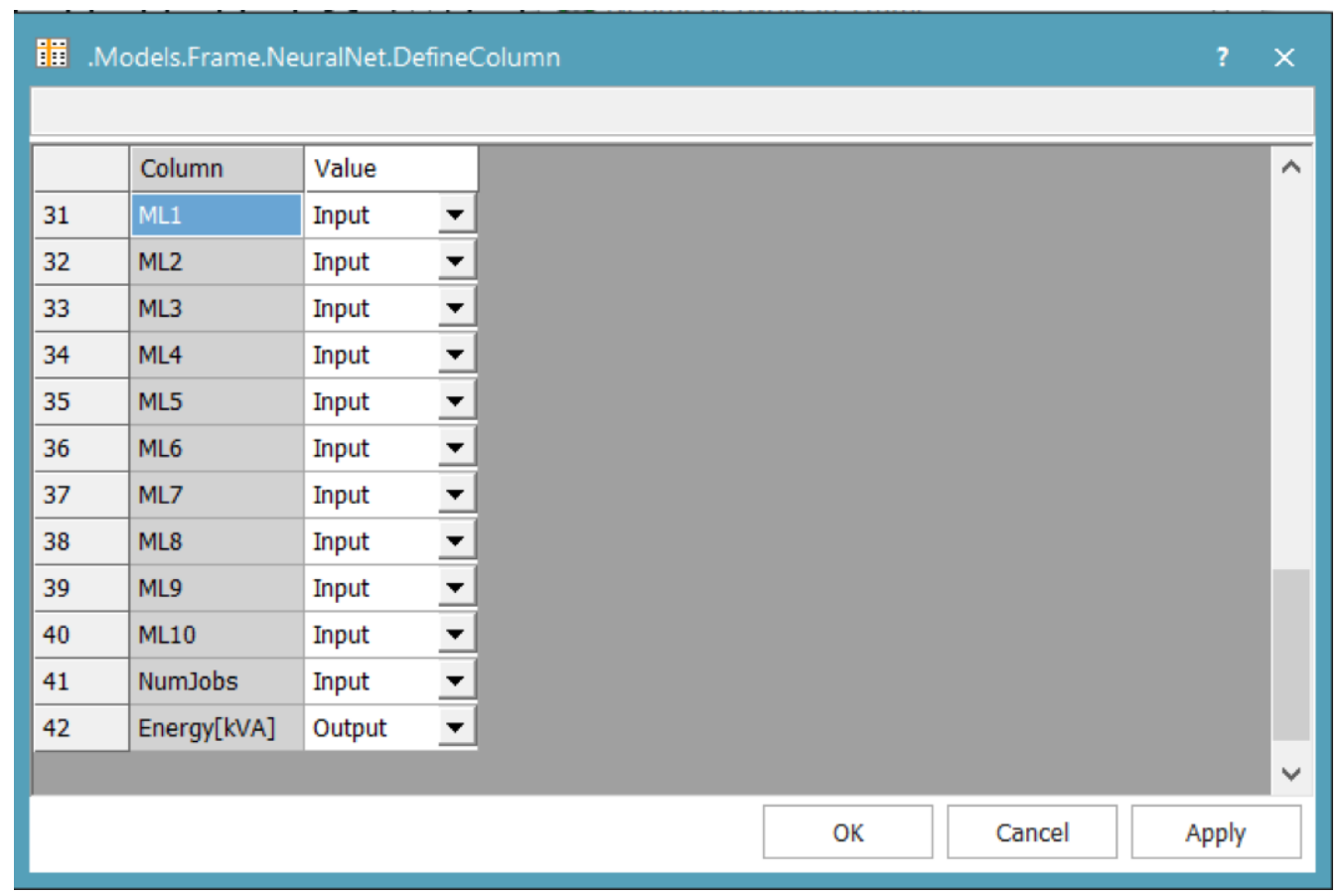

Fonte: Autor

vações devem ser feitas com relação aos parâmetros de configuração disponíveis no software. Os parâmetros disponíveis são:

a) Número de camadas: seleciona-se a quantidade de camadas ocultas (uma ou duas), bem como o número de neurônios que compõe cada uma delas;

b) Função de ativação: seleciona-se uma dentre os quatro tipos de funções de ativação disponíveis (tangente hiperbólica, sigmoide, senoidal e linear);

c) Amplitude de ativação: define-se um valor de amplitude máxima para a função de ativação;

d) Fração de treinamento: define-se o percentual do conjunto de dados que será utilizado para o treinamento. O restante dos dados são utilizados para a validação da rede;

e) Reinicialização: define-se o valor percentual de reinicialização da rede, onde os valores dos pesos sinápticos são aleatoriamente redefinidos. A redefinição dos pesos ocorre a cada vinte interações do algoritmo de treinamento, caso não houver uma variação percentual superior ao valor definido. Caso a variação seja inferior, o algoritmo entende estar preso em um mínimo local, forçando a reinicialização para a busca de novos pontos de mínimo que sejam melhores; 
f) Taxa de aprendizado: definem-se os limites mínimo e máximo da taxa de aprendizado, que será dinamicamente ajustado durante o algoritmo de treinamento;

g) Coeficiente de momento $(\alpha)$ : define-se um valor para $\alpha$ que permite diminuir as oscilações durante o treinamento.

O treinamento da RNA se estenderá até que o número de iterações definidas inicialmente pelo usuário seja alcançado. $\mathrm{O}$ algoritmo de treinamento também poderá ser interrompido pelo usuário, caso os resultados parciais observados estejam em níveis satisfatórios. Para isso, o módulo NeuralNet dispõe de um gráfico de acompanhamento do erro de saída da RNA, que apresenta os valores dos erros mínimo, médio e máximo, para os conjuntos de treinamento e validação da rede. A figura 25 ilustra o gráfico mencionado.

Figura 25 - Gráfico de acompanhamento do erro de treinamento e validação do módulo NeuralNet

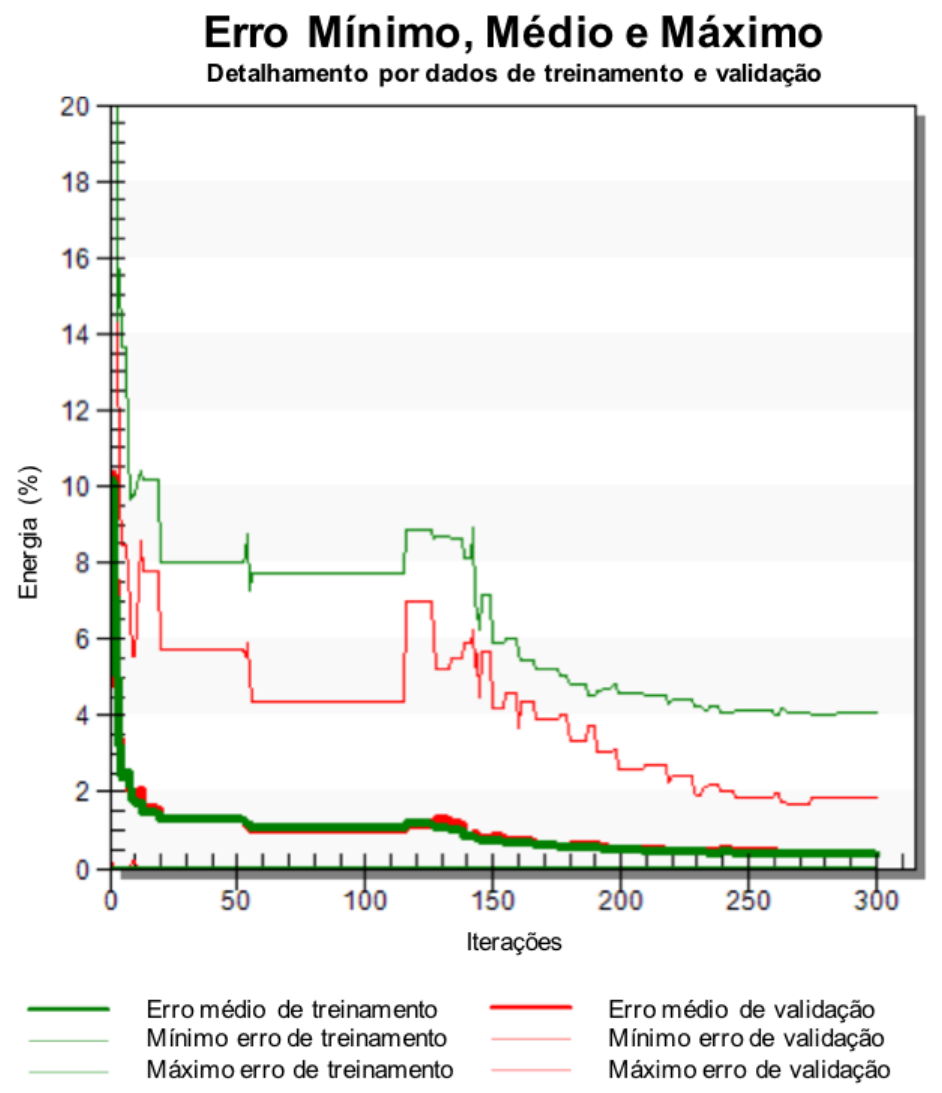

Fonte: Autor

O valor do erro médio apresentado pelo software de simulação pode ser calculado por meio do erro relativo apresentado na tabela 2 e destacado na equação 10. 


$$
\mathrm{RE}=\frac{1}{n} \cdot \sum_{i=1}^{n} \frac{\left(y_{i}-o_{i}\right)}{y_{i}} \cdot 100 \%
$$

onde $y_{i}$ representa o valor real de saída do conjunto de treinamento, $o_{i} \mathbf{O}$ valor de saída estimado pela RNA e $n$ o número total de lições no conjunto de treinamento. 



\section{RESULTADOS EXPERIMENTAIS}

A definição de arquitetura da RNA empregada neste trabalho foi realizada de forma empírica, onde foram avaliados os resultados de diferentes experimentos realizados. A configuração de melhor desempenho encontrada foi adotada e, em seguida, empregada na realização de experimentos considerando diferentes configurações de ordens de produção.

\subsection{ARQUITETURA DA REDE NEURAL}

A coleta de dados experimentais iniciou-se com a geração do conjunto de treinamento da RNA. Para isso, diversas simulações foram realizadas considerando diferentes ordens de produção. As ordens de produção foram definidas aleatoriamente, onde sorteou-se a quantidade de jobs para compor a ordem e, em seguida, os tipos de jobs, conforme a tabela 2. A figura 26 ilustra o processo de geração do conjunto de treinamento, onde cada ciclo representa uma rodada de simulação, que resulta em uma lição para o banco de treinamento.

Como o modelo proposto faz uso de dados simulados, a quantidade de amostras para o treinamento pode ser determinada pelo usuário. Neste estudo, a quantidade de amostras foi determinada de maneira empírica, onde iniciou-se a análise com um banco de treinamento contendo 1000 lições, com a hipótese de que ele estaria superdimensionado.

A partir da geração do banco de treinamento inicial, uma RNA do tipo PMC foi empregada neste trabalho. Os dados do conjunto de treinamento não foram normalizados, sendo utilizados conforme descrito na seção 4.3. O conjunto de treinamento foi dividido em duas partições, sendo a primeira composta por $70 \%$ das lições para o treinamento e a segunda com os 30\% restantes, empregados na validação da RNA. Já para os parâmetros função de ativação, magnitude de ativação, reinicialização e taxa de aprendizado, foram mantidos os valores padrões do software de simulação. Por fim, o coeficiente de momento foi ajustado para o valor nulo. Em resumo, os parâmetros de configuração da RNA foram:
a) Função de ativação: Tangente Hiperbólica
b) Magnitude de ativação: 0,9
c) Reinicialização: $1 \%$
d) Taxa de aprendizado: 0,2 2
e) Coeficiente de momento $(\alpha): 0$ 
Figura 26 - Ciclo de geração do banco de treinamento

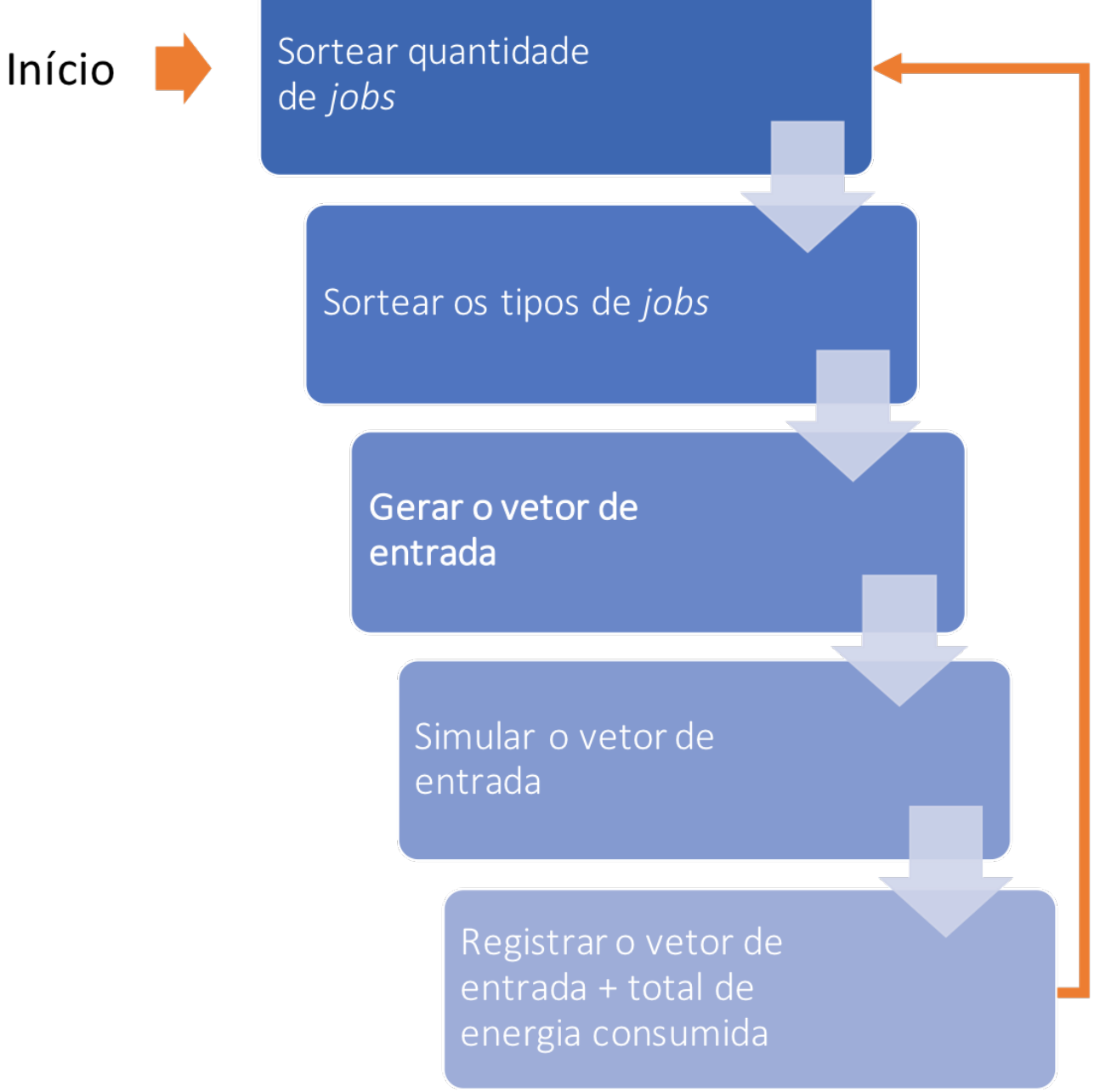

Fonte: Autor

Considerando o cenário apresentado no parágrafo anterior, os primeiros experimentos executados buscaram a identificação do número de neurônios para configuração da RNA. Para isso, a investigação ocorreu de maneira empírica, onde oito experimentos foram realizados alternando o número de neurônios e camadas da RNA. Para a avaliação da resposta de cada configuração, o gráfico de evolução de treinamento foi acompanhado, bem como o valor do erro médio de validação calculado pelo software de simulação. As figuras 27 a 34 apresentam os gráficos de evolução de treinamento para os experimentos realizados.

Em todos os cenários avaliados, observa-se que o erro médio de validação tende a ser constante. Como não ocorre a inversão de tendência do erro de validação, que faça com que o erro médio volte a aumentar, conclui-se que a rede não apresenta overfitting em seu treinamento, 
Figura 27 - Erro de treinamento para o experimento 1
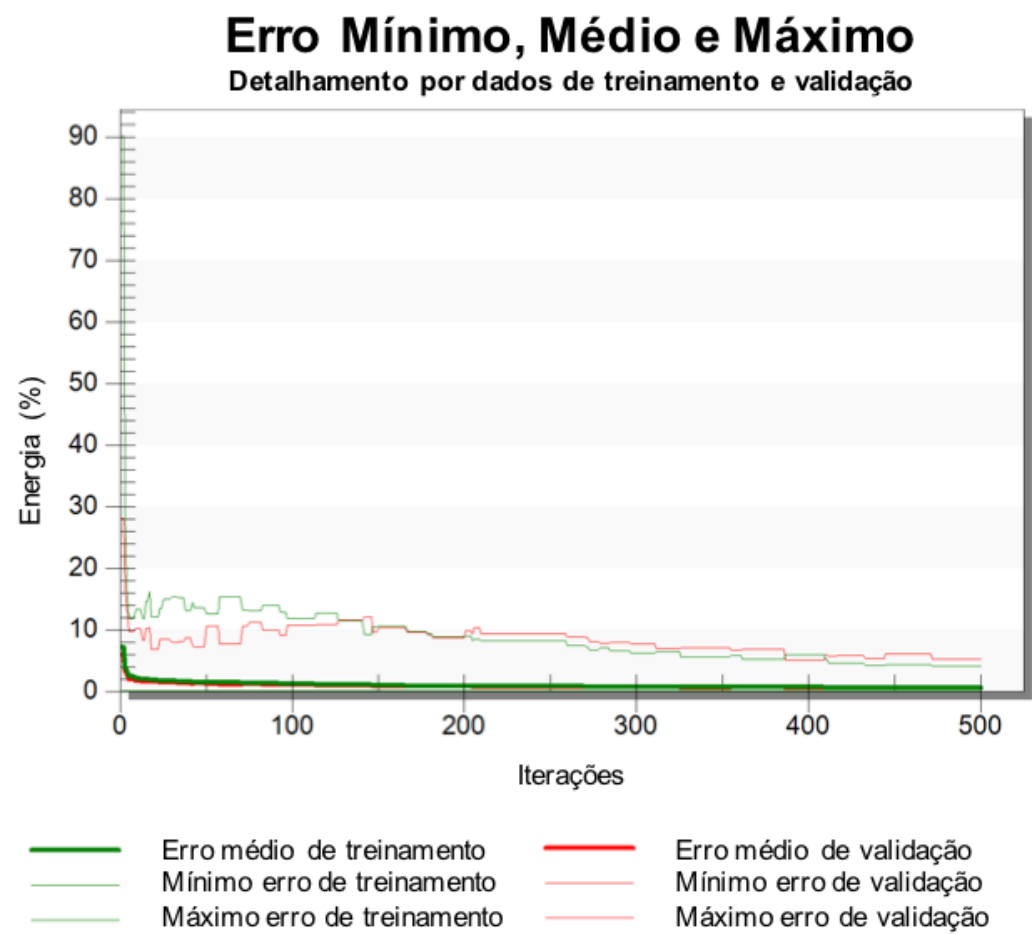

Fonte: Autor

Figura 28 - Erro de treinamento para o experimento 2

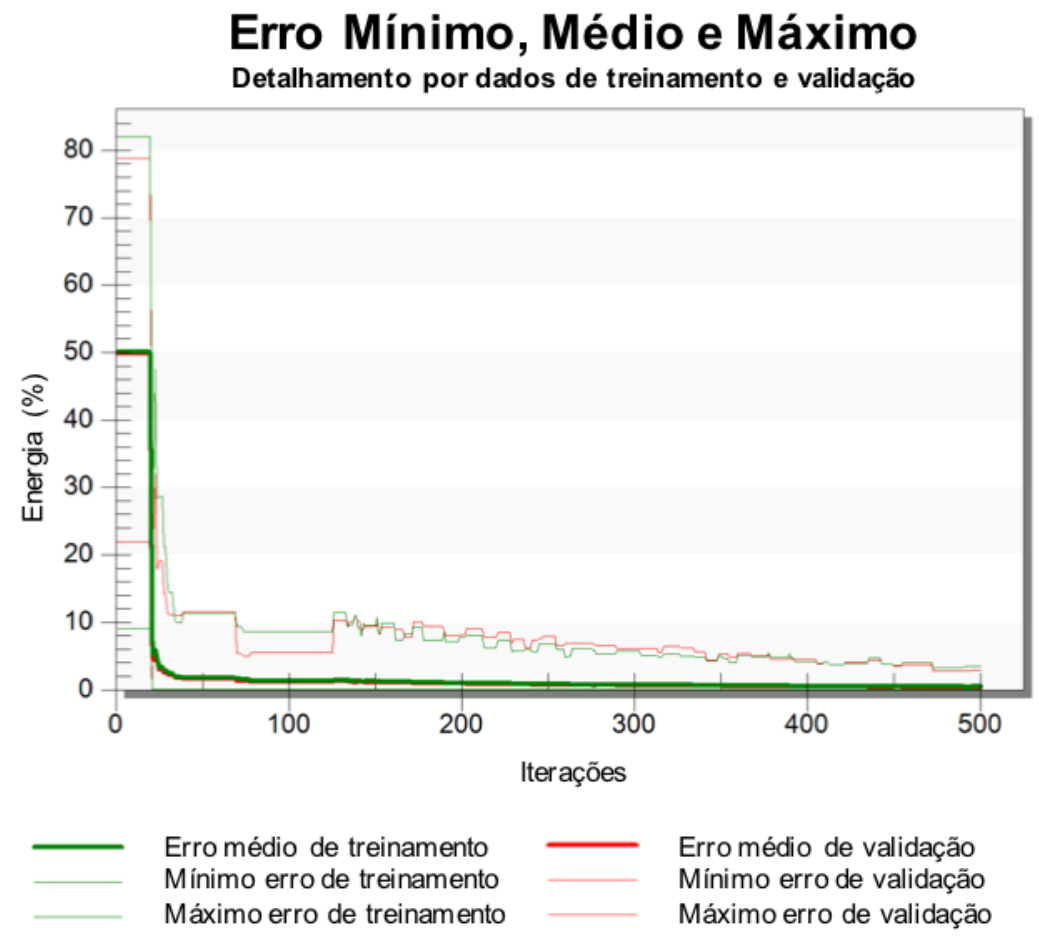

Fonte: Autor 
Figura 29 - Erro de treinamento para o experimento 3

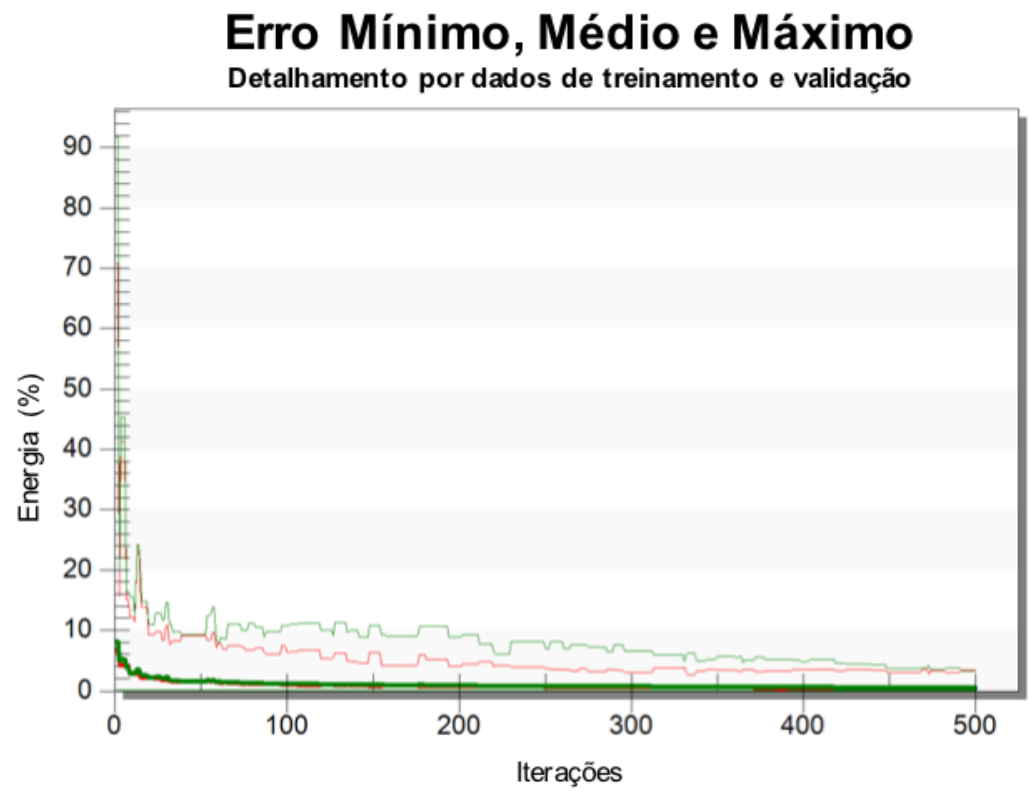

$$
\begin{array}{lll}
\text { Erro médio de treinamento } & & \text { Erro médio de validação } \\
\text { Mínimo erro de treinamento } & \quad & \text { Mínimo erro de validação } \\
\text { Máximo erro de treinamento } & \quad \text { Máximo erro de validação }
\end{array}
$$

Fonte: Autor

Figura 30 - Erro de treinamento para o experimento 4

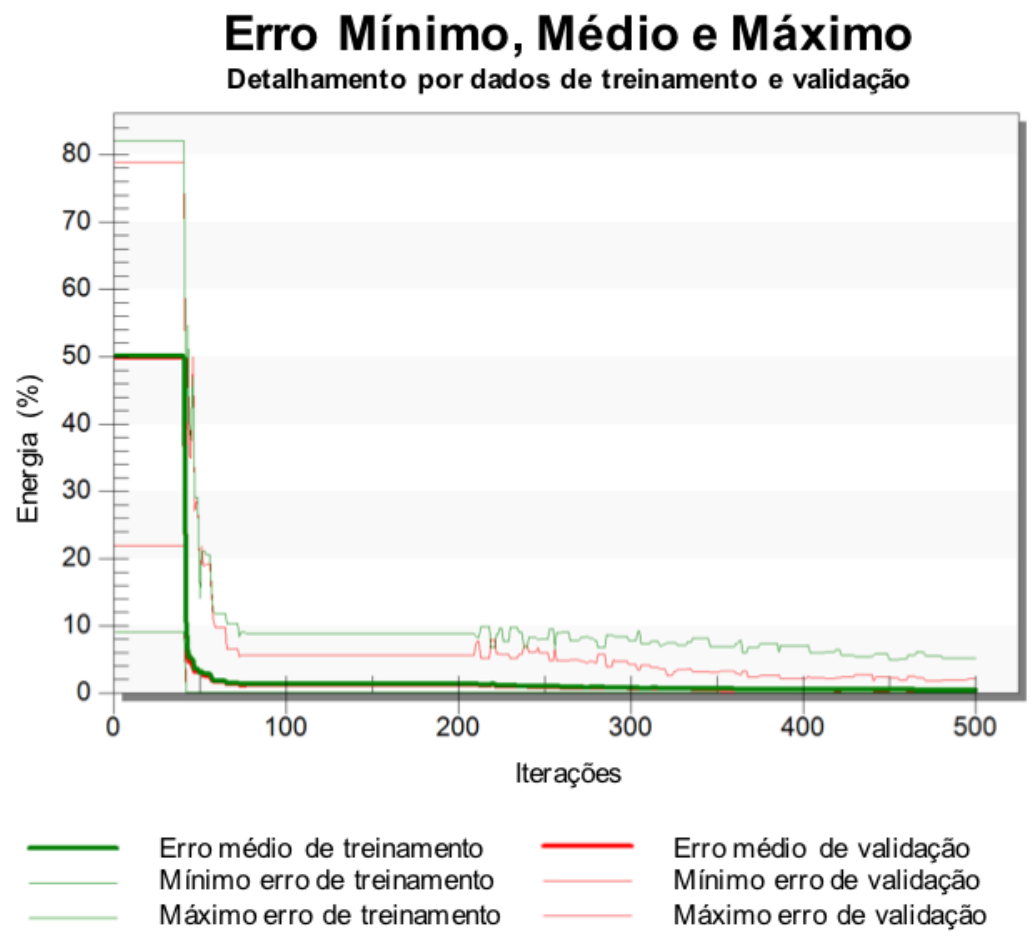

Fonte: Autor 
Figura 31 - Erro de treinamento para o experimento 5

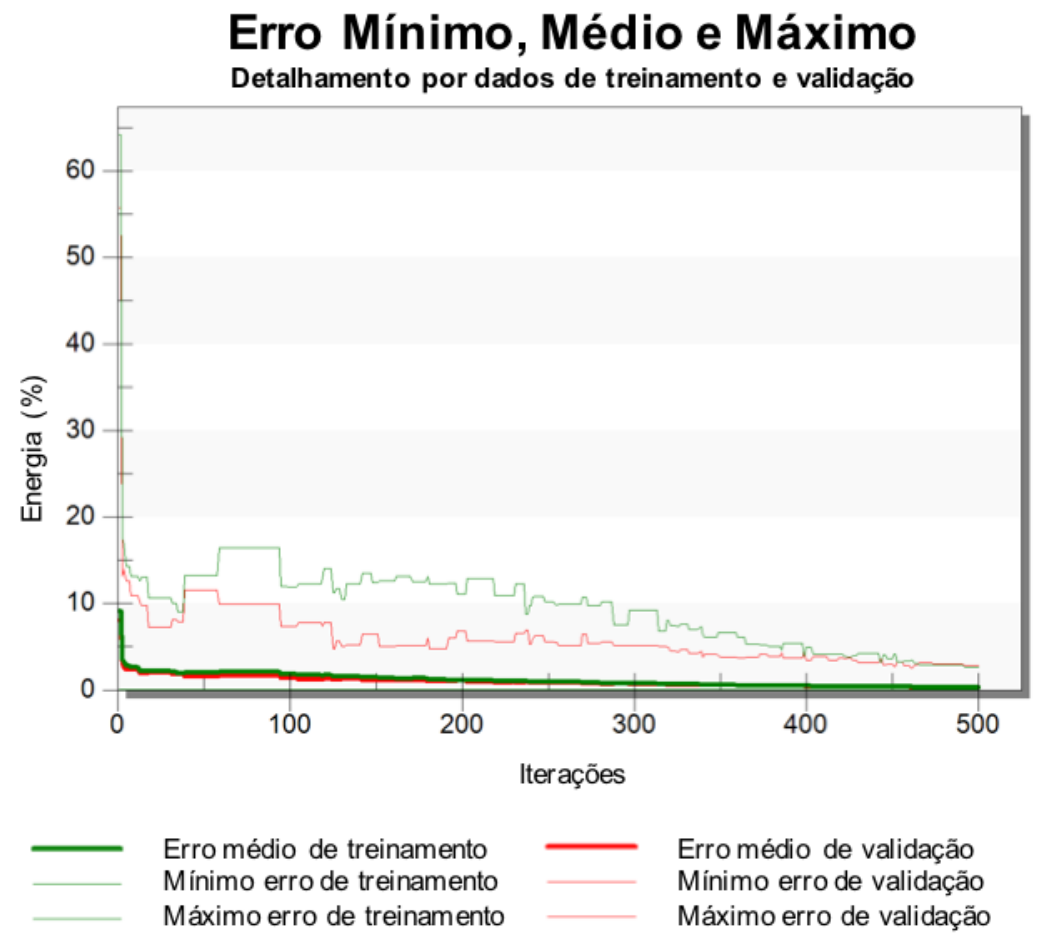

Fonte: Autor

Figura 32 - Erro de treinamento para o experimento 6
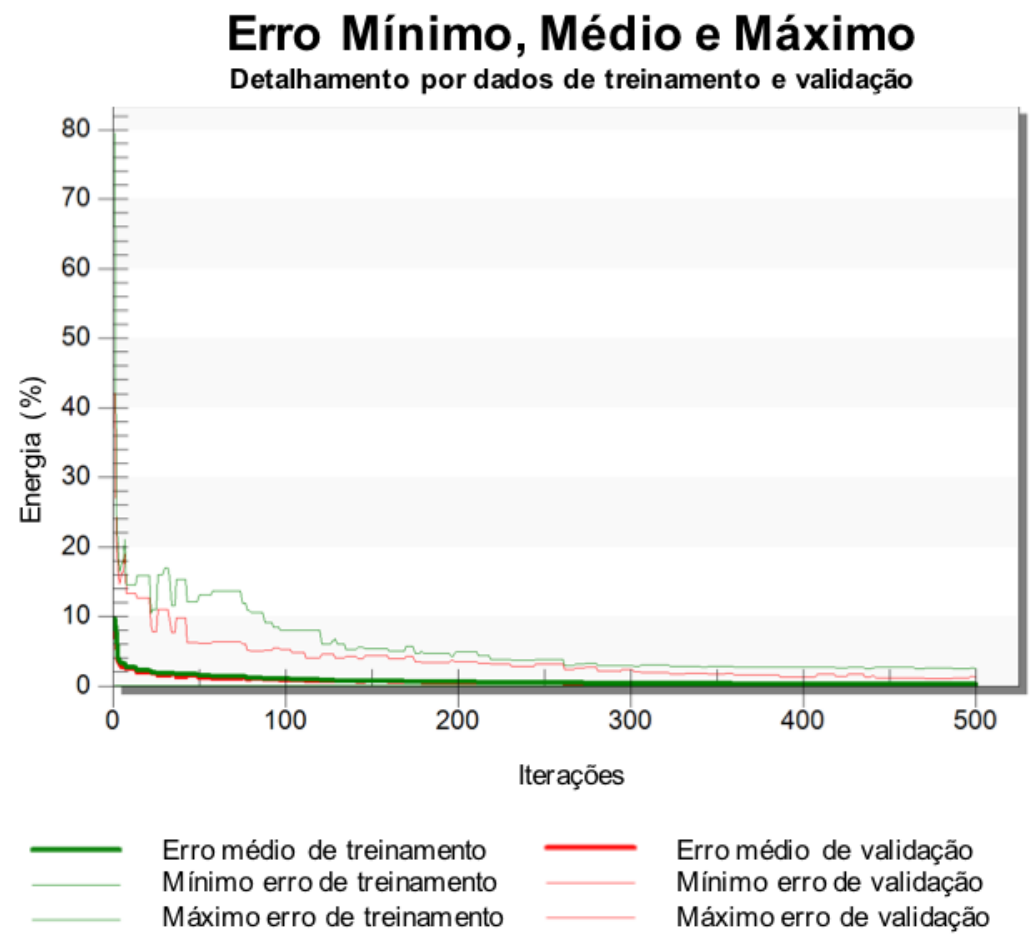

Fonte: Autor 
Figura 33 - Erro de treinamento para o experimento 7

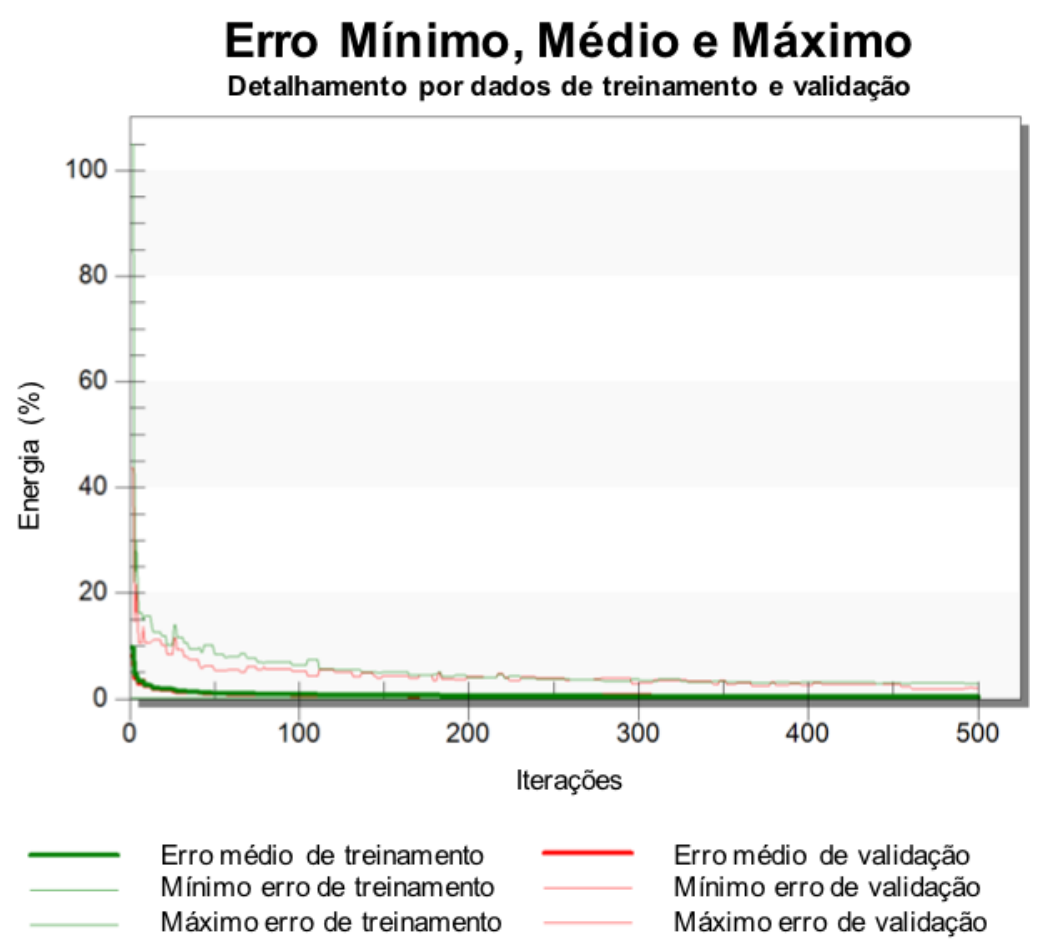

Fonte: Autor

Figura 34 - Erro de treinamento para o experimento 8

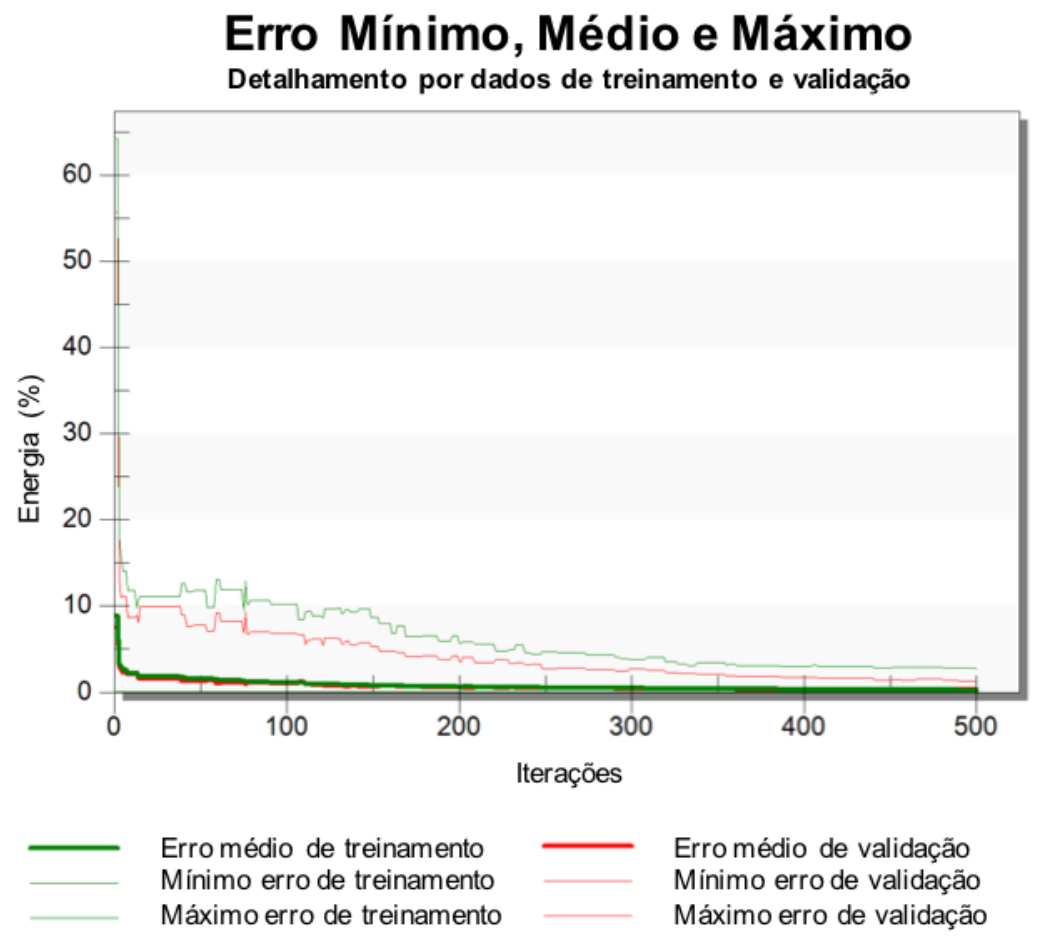

Fonte: Autor 
alcançando o estado de generalização do modelo, conforme apontado por Braga, Carvalho e Ludermir (2014).

A tabela 4 sintetiza os resultados dos experimentos realizados. A última coluna apresenta o tempo total de processamento gasto no treinamento da rede para a execução de 500 iterações. Esta quantidade de iterações foi adotada para permitir a comparação entre as diferentes configurações onde, após a realização de experimentos preliminares, observou-se que esta quantidade seria suficiente para a convergência dos resultados das diferentes configurações experimentadas. Observa-se que o tempo total de processamento é fortemente influenciado pelo número de neurônios empregados na primeira camada oculta da RNA. O aumento de 2 para 8 neurônios nos experimentos 1 e 4, resultou em um aumento do tempo total de processamento superior a 2 minutos, enquanto o mesmo aumento realizado na segunda camada para os experimentos 5 e 8 , resultaram em um aumento de cerca de 30 segundos.

Tabela 4 - Resumo dos resultados para cada configuração da RNA

\begin{tabular}{ccccc}
\hline \multirow{2}{*}{ Experimento } & \multicolumn{2}{c}{ Quantidade de Neurônios } & \multirow{2}{*}{ RE } & \multirow{2}{*}{ Tempo } \\
& Camada Oculta 1 & Camada Oculta & & \\
\hline 1 & 2 & 0 & $0,548 \%$ & $01: 48,61$ \\
\hline 2 & 4 & 0 & $0,439 \%$ & $03: 04,00$ \\
\hline 3 & 6 & 0 & $0,433 \%$ & $04: 31,20$ \\
\hline 4 & 8 & 0 & $0,413 \%$ & $04: 22,13$ \\
\hline 5 & 2 & 2 & $0,312 \%$ & $02: 02,14$ \\
\hline 6 & 2 & 4 & $0,250 \%$ & $02: 08,35$ \\
\hline 7 & 2 & 6 & $0,303 \%$ & $02: 20,89$ \\
\hline Fonte: Autor & 2 & 8 & $0,261 \%$ & $02: 30,59$ \\
\hline
\end{tabular}

Avaliando o gráfico da figura 28, observam-se ao menos duas grandes descontinuidades ocorridas nas iterações 20 e 80. Estas descontinuidades estão relacionadas ao parâmetro de reinicialização da rede, que aleatoriamente redefine os valores dos pesos sinápticos quando não observados ganhos significativos dentro de um intervalo de 20 iterações do algoritmo de treinamento. Com isso, o algoritmo de treinamento entende estar preso em um ponto de mínimo local, redefinindo os valores dos pesos para buscar novos pontos de mínimo melhores. As diversas ocorrências de reinicialização dos pesos durante o treinamento podem ser observadas no gráfico da figura 35, que apresenta o erro médio e máximo à cada iteração. As linhas verticais 
tracejadas na cor magenta, indicam o exato instante de reinicialização dos pesos sinápticos da RNA, durante o experimento 2 apresentado.

Figura 35 - Atuação do algoritmo de reinicialização da RNA para o experimento 2

\section{Progresso do erro médio e máximo}

Com reinicialização durante o treinamento

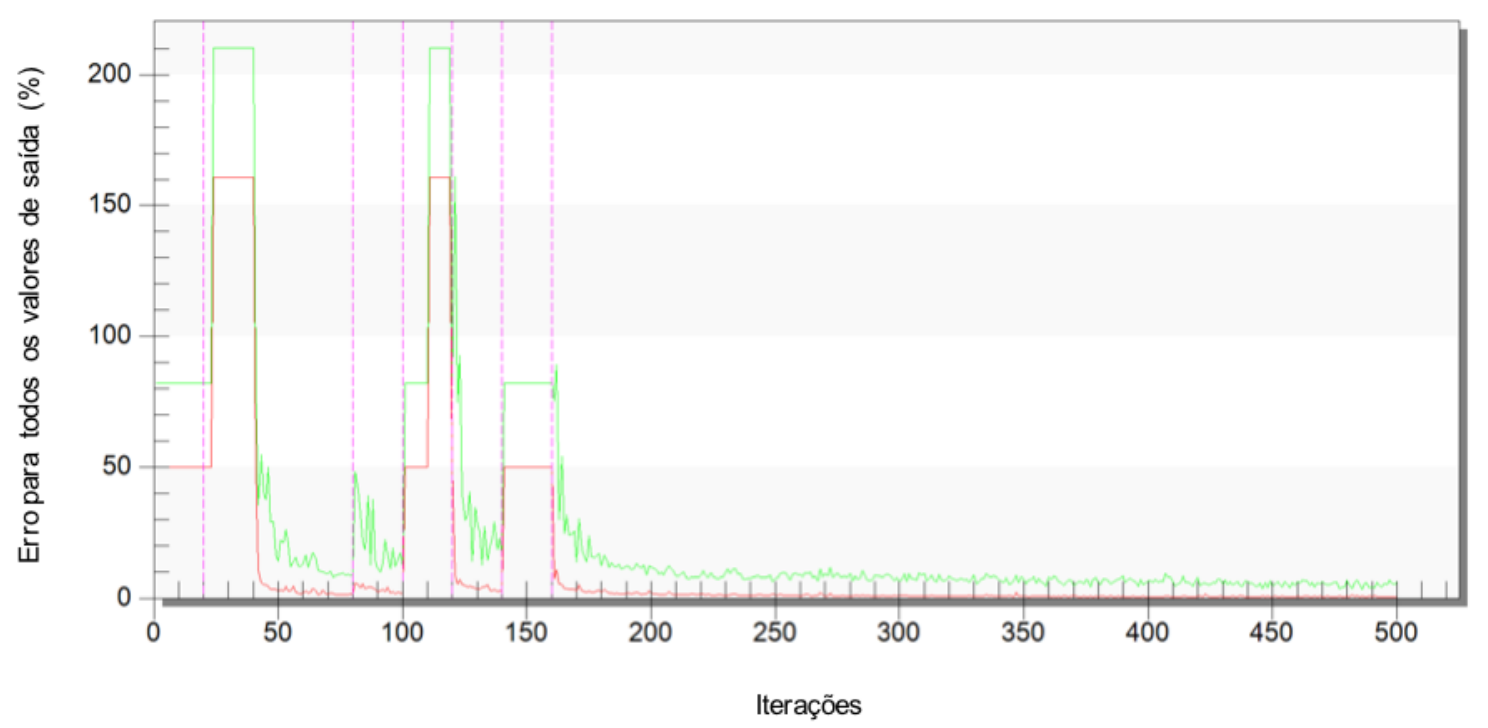

Fonte: Autor

Com base nos resultados apresentados na tabela 4, a configuração da RNA empregada no experimento 6 foi escolhida, por apresentar o menor erro médio e tempo de treinamento muito próximo ao menor tempo encontrado dentre as demais configurações. Isso resultou em uma RNA com a seguinte configuração:
a) Camada de entrada: 41 neurônios
b) Camada oculta 1:2 neurônios
c) Camada oculta 2: 4 neurônios
d) Camada de saída: 1 neurônio

Definida a configuração da RNA a ser empregada, um estudo sobre a influência do coeficiente de momento $(\alpha)$ foi realizado. Partindo da configuração adotada, o valor do parâmetro $\alpha$ foi alterado entre 0 e 2, com passo igual a 0,2 . Para cada valor de $\alpha$, seis experimentos foram realizados e identificados os valores mínimo, médio e máximo do erro médio de treinamento. Os resultados obtidos são apresentados na tabela 5 . 


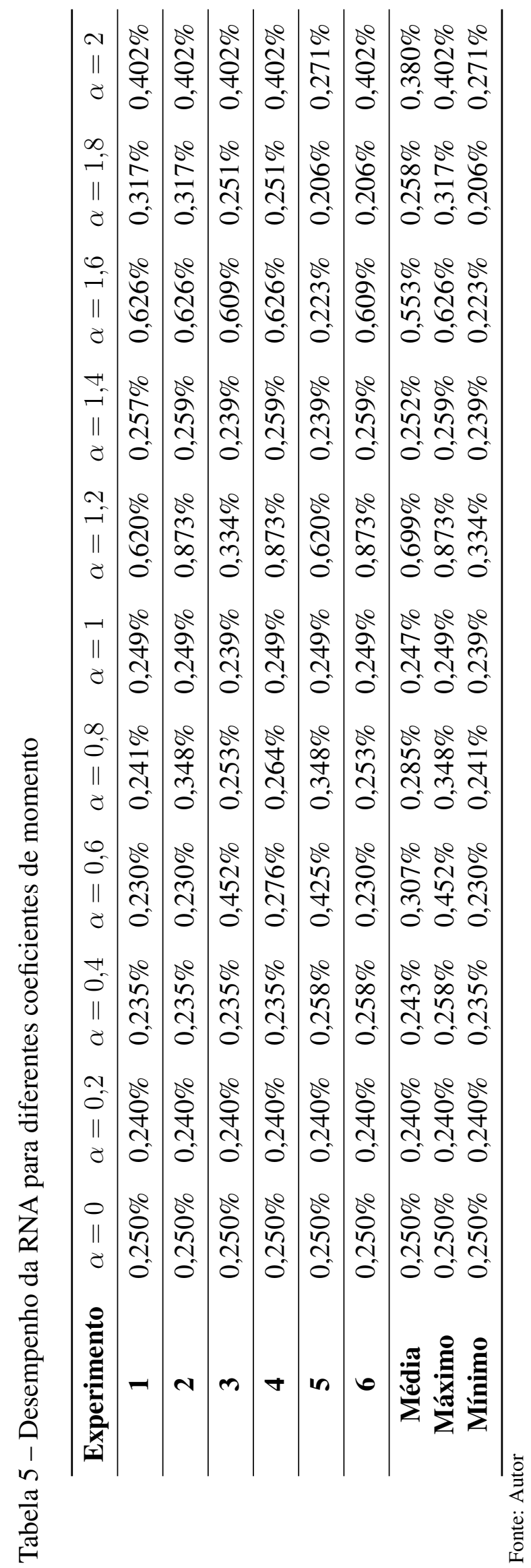


Para os experimentos realizados, observa-se que o mínimo erro de treinamento encontrado ocorre quando aplicado o valor de $\alpha=1,8$. Entretanto, se avaliada a média por coeficiente de momento, o menor valor obtido ocorre para $\alpha=0,2$. Ainda, assim como para $\alpha=0$, todos os experimentos realizados nesta configuração apresentaram discrepância nula para os valores coletados. Com isso, por se tratar do menor valor de erro médio identificado, o coeficiente de momento adotado para a rede foi $\alpha=0,2$.

\subsection{ESTIMAÇÃO DO CONSUMO DE ENERGIA PARA ORDENS DE PRODUÇÃO DE TAMANHOS VARIADOS}

Conforme apresentado na Seção 5.1, o conjunto criado para o treinamento da RNA foi gerado de forma aleatória. Isso significa que os vetores de entrada dificilmente atenderiam aos critérios de menor consumo de energia ou makespan. Com isso, certamente estas combinações não seriam aplicadas na programação de um sistema real de produção, sem antes passar por uma etapa de melhoria no sequenciamento das operações realizadas por cada máquina.

Neste sentido, o software Plant Simulation ${ }^{\circledR}$ possui componentes integrados que permitem a busca dos parâmetros ótimos, ou quase ótimos, por meio de algoritmos de otimização ou heurísticas. Para isso, o software utiliza o modelo simulado como uma função de avaliação do algoritmo de otimização escolhido, variando os parâmetros de entrada, e verificando se uma melhor resposta foi encontrada. A figura 36 ilustra a iteração realizada pelo software. Dentre as opções disponíveis, destacam-se os algoritmos (SCHMIDT, 2016):
a) Branch \& Bound
b) Dynamic Programming
c) Simulated Annealing
d) Tabu Search
e) Genetic Algorithm

A representação de sequenciamento das operações do sistema job shop adotada neste trabalho, seguiu o modelo proposto por Bierwirth (1995) de permutação com repetição. Nesta representação, qualquer ordenação do vetor de entrada poderá ser decodificada em uma saída de implementação factível. Com isso, o autor propôs a utilização da heurística AG para melhorar o sequenciamento em cada máquina, de tal forma a reduzir o tempo total de processamento. 
Figura 36 - Integração entre o modelo de simulação e o algoritmo de otimização.

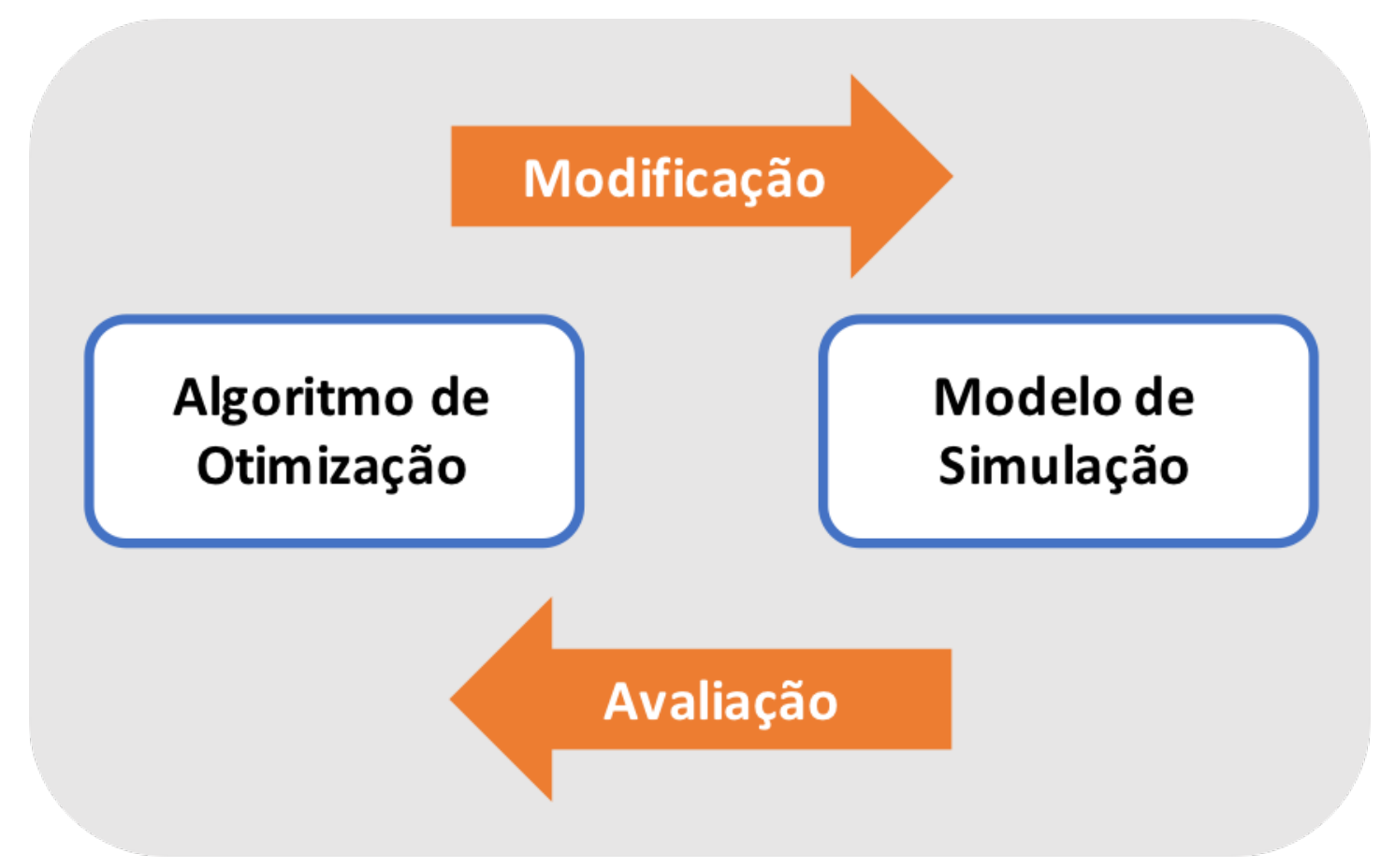

Fonte: Autor "adaptado de" Schmidt (2016)

Tirando proveito da representação adotada e da disponibilidade da heurística AG no software de simulação, ordens de produção contendo diferentes quantidades e tipos de jobs foram geradas e submetidas à heurística, buscando reduzir o makespan. Ao todo, 40 experimentos foram realizados, onde a quantidade por ordem de produção variou de 3 a 10 jobs. Os tipos de jobs de cada ordem foram sorteados aleatoriamente.

Após a execução da heurística, um vetor de entrada com o sequenciamento de makespan reduzido foi obtido. Então, o modelo de simulação foi ajustado para executar o sequenciamento encontrado. O makespan e a energia elétrica total consumida para a execução de cada vetor de sequenciamento encontrado foram registrados. Por fim, a energia total consumida também foi estimada pela RNA, a partir da extração das nuances dos vetores encontrados. Os valores obtidos em cada experimento são apresentados na tabela 6 . 


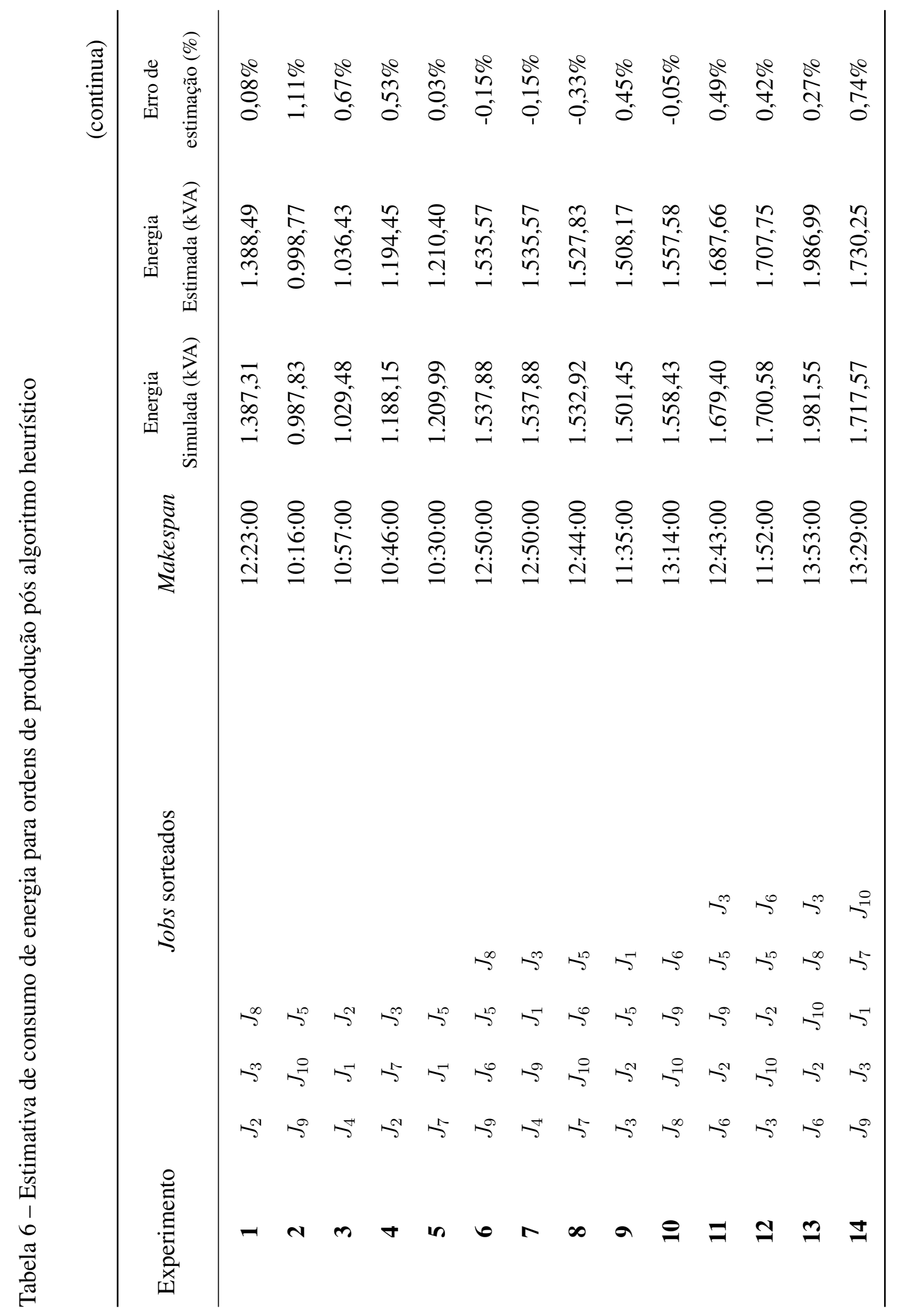




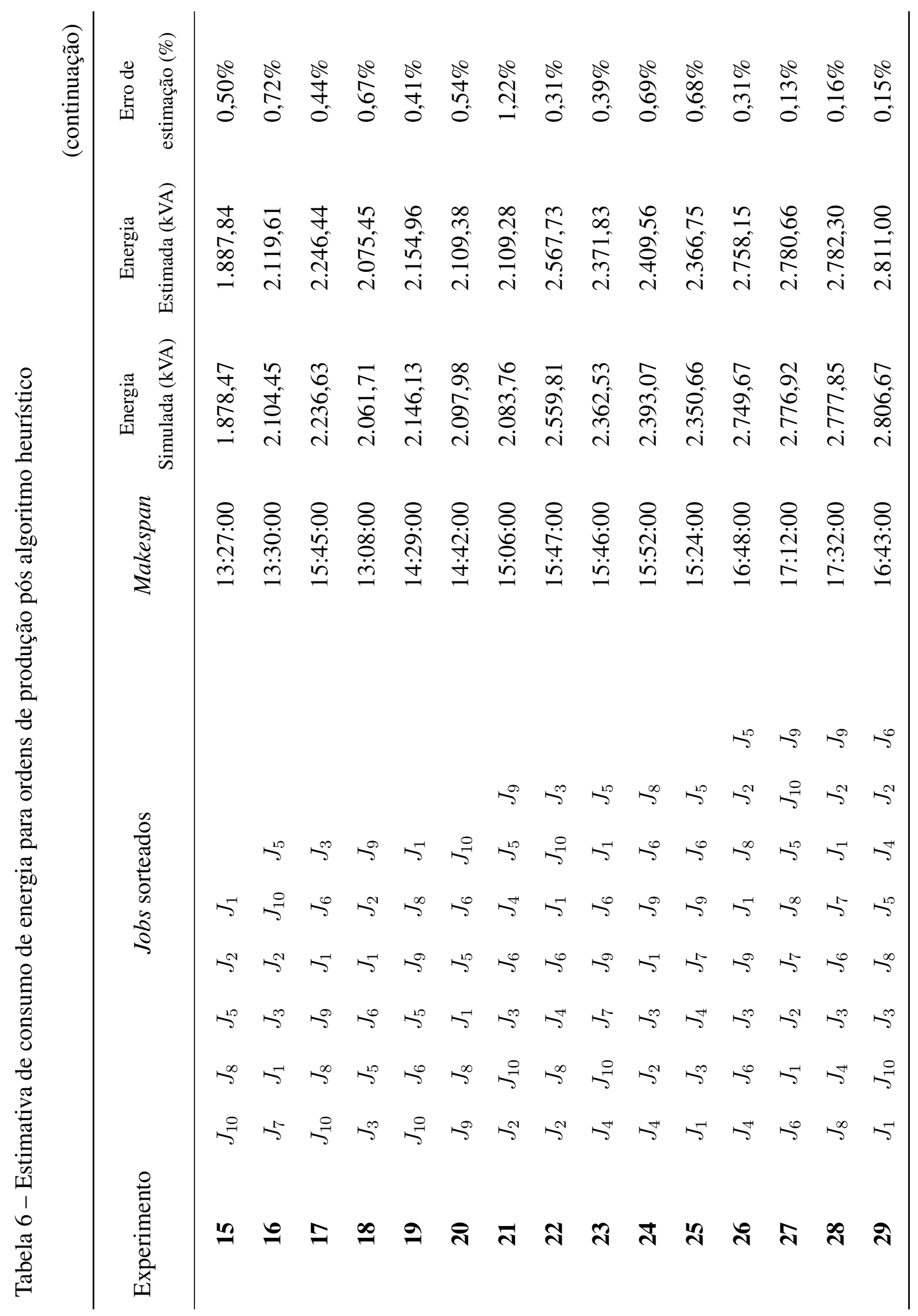




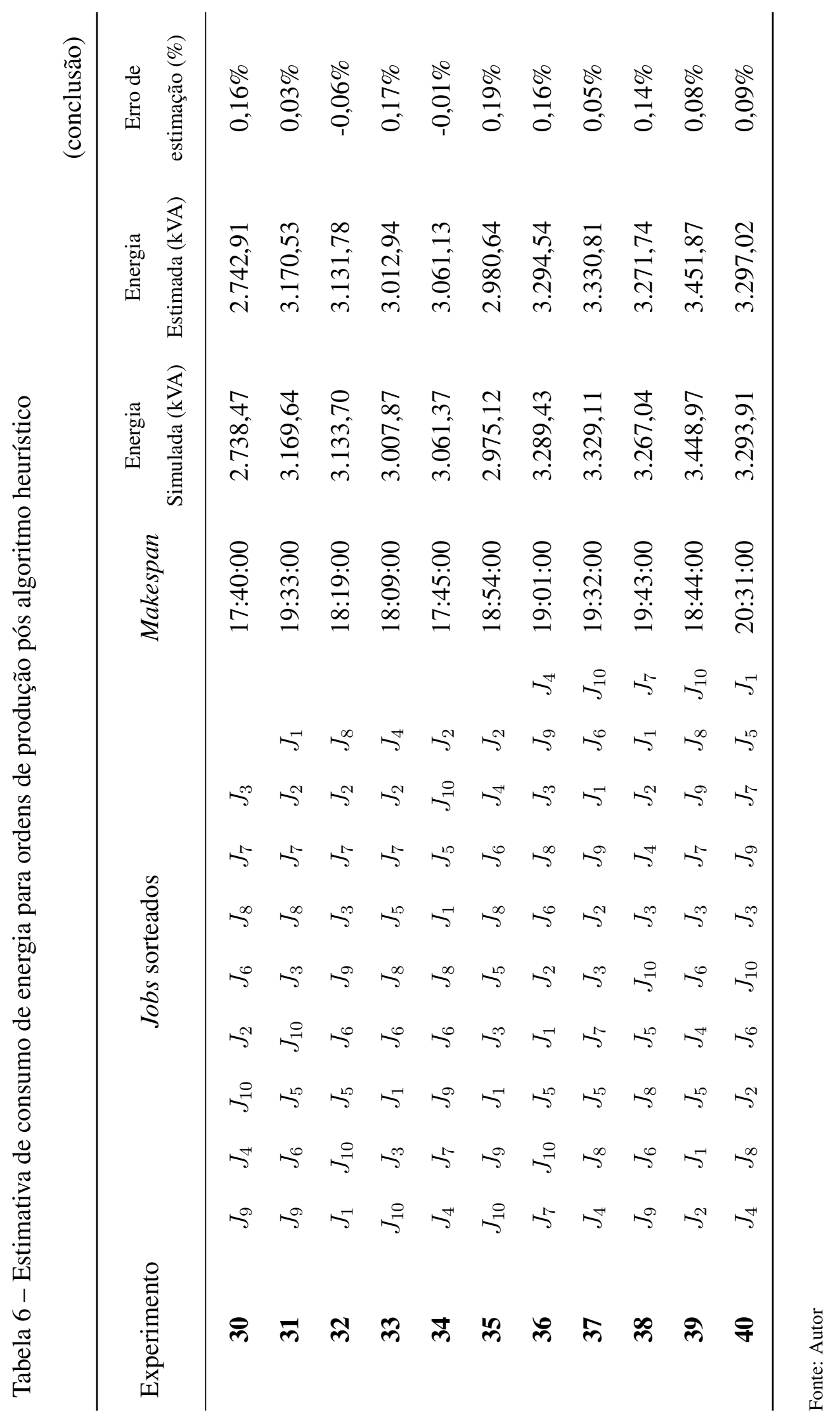


Para cada um dos experimentos realizados, a coluna Erro de estimação (\%) apresenta o erro relativo entre o total da energia obtida por meio da simulação e a energia total estimada pela RNA. Observa-se que os erros são relativamente baixos, onde o máximo valor obtido foi de $1,22 \%$, ocorrido no experimento . $^{\circ} 21$. O gráfico da figura 37 apresenta o comparativo entre o valor da energia simulada (valor alvo) e a energia estimada (saída da RNA). Já a figura 38 traz o histograma do erro de estimação para os experimentos realizados, onde é possível observar que a distribuição concentra-se muito próximo de zero. As métricas de desempenho apresentadas anteriormente na tabela 2 são apresentadas a seguir:

$$
\begin{aligned}
& \mathrm{MSE}=75,44 \\
& \mathrm{RMSE}=8,69 \\
& \mathrm{R}^{2}=99,985 \% \\
& \mathrm{MAE}=6,921 \\
& \mathrm{RE}=-0,311 \%
\end{aligned}
$$

Para todas as métricas empregadas, é possível observar a boa acurácia do modelo de estimação para os 40 experimentos realizados. Em especial, o erro relativo encontrado durante esta etapa de validação $(0,311 \%$, em módulo), é próximo aos erros observados durante a fase de treinamento da RNA (Tabela 5), o que também demonstra a boa generalização do modelo. 
Figura 37 - Comparativo entre o valor alvo e a saída da RNA

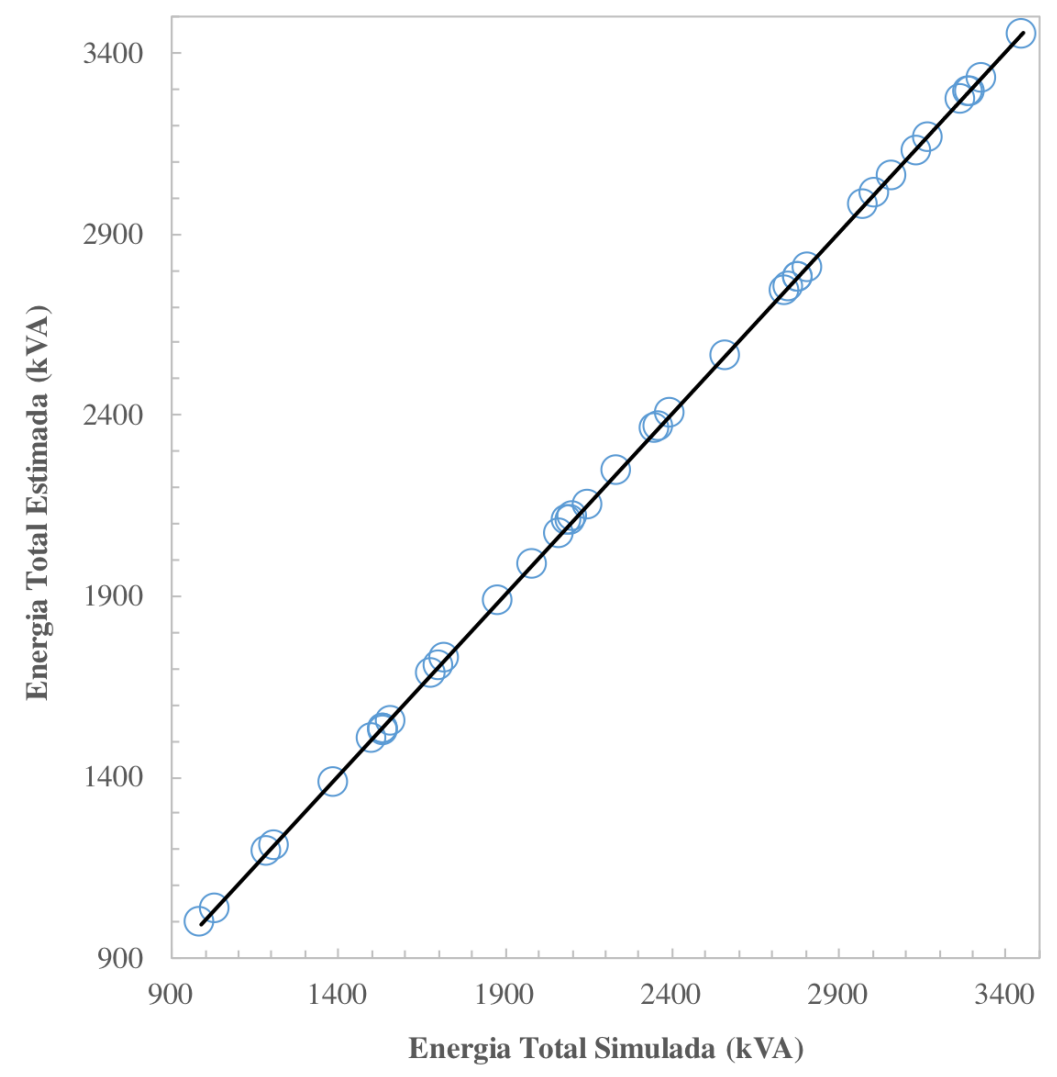

Fonte: Autor 


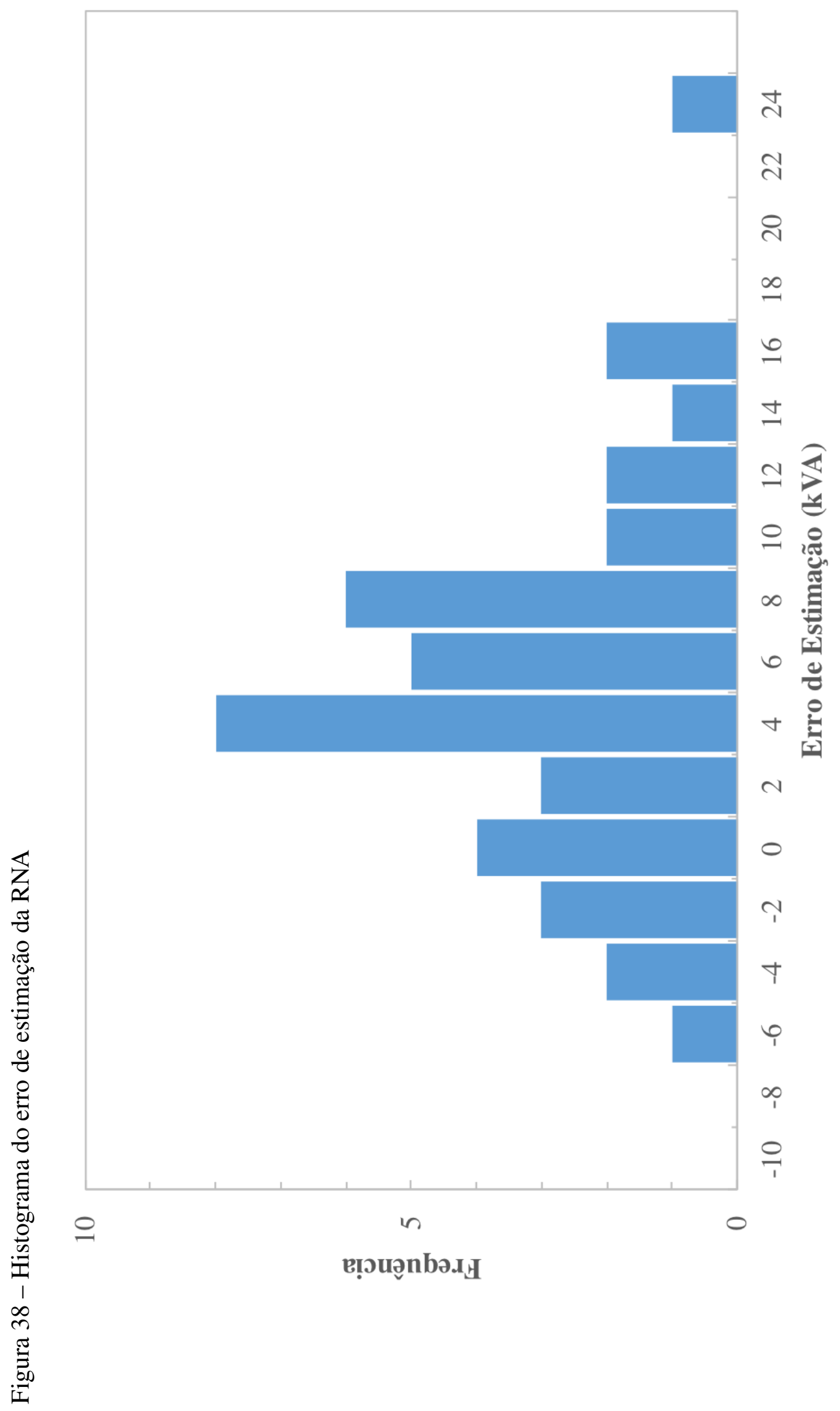




\subsection{ANÁLISE DA INFLUÊNCIA DAS VARIÁVEIS}

A Seção 4.3 descreve o conjunto de variáveis adotadas no modelo para a estimação do consumo de energia pela RNA. Podemos separar estas variáveis em três grupos, que variam em função das etapas em que elas são extraídas do modelo.

O primeiro grupo é composto pelas variáveis carga de máquina $(M L)$ e quantidade de jobs (NumJobs). Estas variáveis são imutáveis para qualquer sequenciamento de operações adotado e dependem apenas da seleção dos jobs que comporão a ordem de produção.

Para o segundo grupo, este é formado apenas pela variável fator de prioridade $(F P)$, cujo seu cálculo necessita da adoção de um sequenciamento para as operações. Entretanto, sua decodificação (Apêndice B) não requer uma análise detalhada das restrições de programação das máquinas e operações envolvidas, como a requerida pelo próximo grupo.

Por fim, o terceiro grupo de variáveis é formado pelos instantes de início $(S T)$ e término $(E T)$ de operação das máquinas. Estas variáveis dependem da decodificação do vetor de entrada por meio de um algoritmo de programação semi-ativo, descrito no Apêndice A. O algoritmo leva em consideração as restrições das operações de cada job, bem como as restrições de ocupação de cada máquina, demandando um maior esforço computacional quando comparado com o algoritmo empregado no cálculo do fator de prioridade (Apêndice B).

A análise da influência de cada variável sobre o total de energia consumida, foi realizada com o auxílio da linguagem Python, e suas bibliotecas comumente empregadas em Data Science e Machine Learning, como a Pandas, Numpy, Seaborn e scikit-learn.

\subsubsection{Análise de Correlação das Variáveis}

Partindo do conjunto de treinamento da RNA contendo as 1000 lições simuladas, um mapa de calor representando o grau de correlação entre pares de variáveis, foi construído (figura 39). Neste mapa, a intersecção entre duas variáveis apresenta em cores o grau de correlação entre elas, variando entre -1 e +1 , calculado conforme o coeficiente de correlação de Pearson (BENEDETTI et al., 2016). Esta representação facilita identificar as variáveis de maior correlação, onde as cores mais intensas (i.e., azul e o vermelho), apontam para correlações mais elevadas. 
Observando a última linha do mapa apresentado na figura 39, é possível observar a correlação de todas as variáveis de entrada com a variável Energy[kVA] de saída. Nesta linha, é possível observar que os conjuntos de variáveis NumJobs, $M L$ e ET, apresentam cores mais intensas que as demais. Para a variável NumJobs, era de se esperar que, quanto mais jobs são produzidos, maior seria o consumo de energia. Da mesma forma ocorre com a variável $M L$, onde um maior tempo de operação das máquinas, impactará diretamente no consumo total de energia. Já a variável ET está diretamente relacionada à programação gerada, onde términos mais distantes estão diretamente ligados a períodos onde as máquinas permanecem por mais tempo ociosas.

Figura 39 - Mapa de calor da correlação entre as variáveis

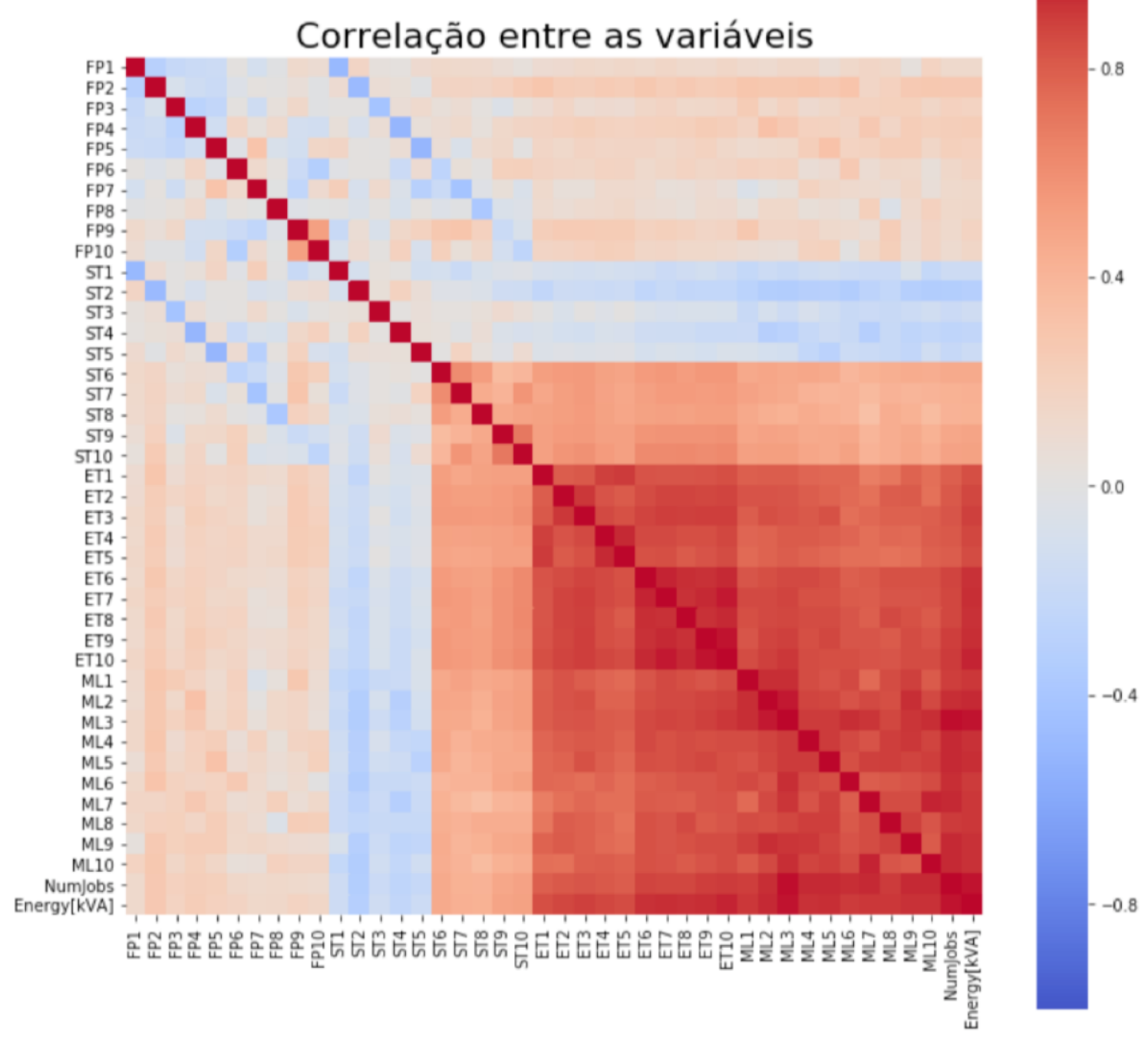


O conjunto de variáveis $S T$ apresenta dois diferentes comportamentos. As variáveis de 1 a 5 possuem correlação levemente voltadas à tonalidade azul, enquanto as variáveis de 6 a 10 estão mais voltadas à cor vermelha. Isso se dá devido à classificação feita para as máquinas em função de seus índices. Conforme discutido na Seção 3.2, May et al. (2015) sugerem que as máquinas de menores índices sejam vinculadas às operações iniciais dos jobs, enquanto as de maiores índices, às operações finais. Com isso, as variáveis de $S T_{6}$ a $S T_{10}$ estão mais positivamente correlacionadas (i.e., na cor vermelha) com o consumo de energia, uma vez que estas máquinas tendem a entrar em operação nas etapas finais do processo, permitindo um comportamento similar ao visto para o conjunto de variáveis $E T$. Já as variáveis $S T_{1}$ a $S T_{5}$ estão inversamente correlacionadas (i.e., na cor azul) à variável de saída. Isso ocorre porque, quanto antes as máquinas entrarem em operação e houver ociosidades no uso das máquinas, maior será o consumo de energia.

O conjunto de variáveis relacionadas ao fator de prioridade das máquinas traz uma coloração levemente avermelhada, porém mais próximo do tom acinzentado, o que aponta para um baixo grau de correlação. Contudo, conforme destacado no trabalho de Benedetti et al. (2016), o coeficiente de correlação de Pearson é empregado na identificação de correlações lineares entre pares de variáveis. Desta forma, afirmar que a variável fator de prioridade não possui relevância sobre o valor da energia consumida, ainda requer mais investigações, uma vez que seu comportamento frente a variável Energy $[k V A]$ poderia apresentar comportamento não linear.

\subsubsection{Análise empírica do conjunto de variáveis}

A análise de relevância das variáveis de entrada prosseguiu com a realização de testes empíricos alternando os tipos de variáveis consideradas no conjunto de treinamento. Para isso, inicialmente foi realizada a modelagem da RNA empregada anteriormente no software de simulação, porém empregando a biblioteca scikit-learn em linguagem Python(PEDREGOSA et al., 2011). Para validar a nova implementação e prosseguir com a análise, esperava-se que os resultados de treinamento fossem próximos aos obtidos no Plant Simulation ${ }^{\circledR}$. Contudo, os testes preliminares realizados apresentaram resultados completamente fora dos observados no software de simulação, com erro médio em torno dos $10 \%$. Os erros encontrados podem ser observados na figura 40. 
Figura 40 - Erros de estimação antes da normalização
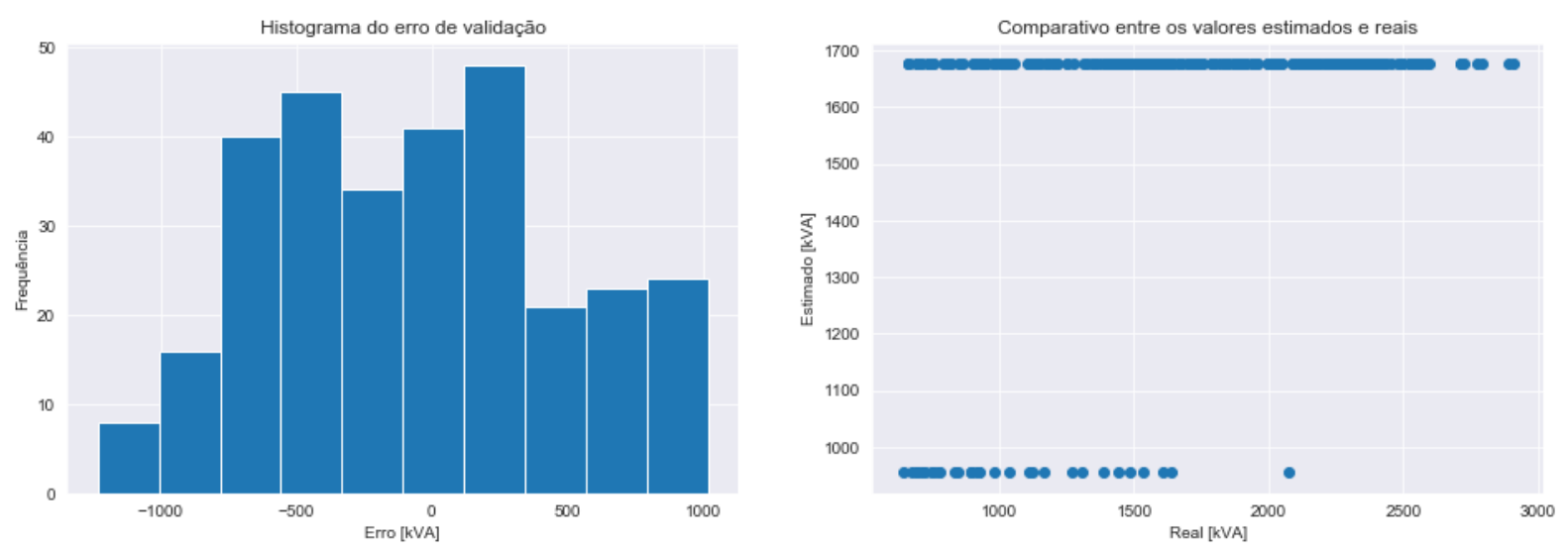

Fonte: Autor

Então, cada coluna de dados foi normalizada pelo método do desvio padrão, apresentado na equação 11:

$$
f\left(x_{i}\right)=\frac{\left(x_{i}-\bar{x}\right)}{\sigma}
$$

onde $x_{i}$ é o valor individual de cada instância da variável, $\bar{x}$ o valor médio da variável e $\sigma$ o desvio padrão da variável. Após a normalização, a RNA foi novamente treinada, reduzindo o erro médio para $2,5 \%$ (figura 41 ).

Figura 41 - Erros de estimação após a normalização
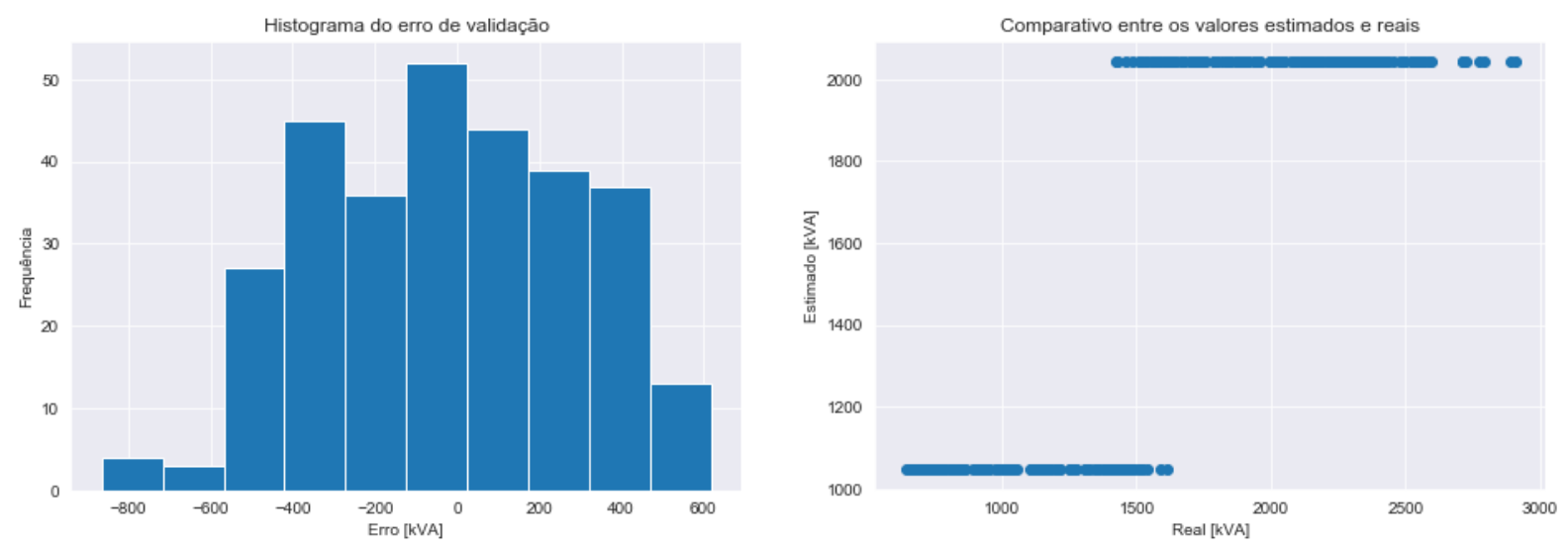

Fonte: Autor

Apesar da melhora obtida com a normalização, o erro encontrado ainda estava muito acima do obtido com o software de simulação. Então, foram avaliadas as diferentes opções de funções de ativação disponíveis na biblioteca de programação, onde a que apresentou melhores resultados, foi a função identidade $(f(x)=x)$. Os resultados encontrados são apresentados 
na figura 42, onde os erros de estimação foram praticamente nulos. Vale ressaltar que os três experimentos (figuras 40, 41 e 42) foram realizados com todas as variáveis de entrada do modelo (i.e., FP, ST, ET, ML e NumJobs).

Figura 42 - Erros de estimação para função de ativação identidade
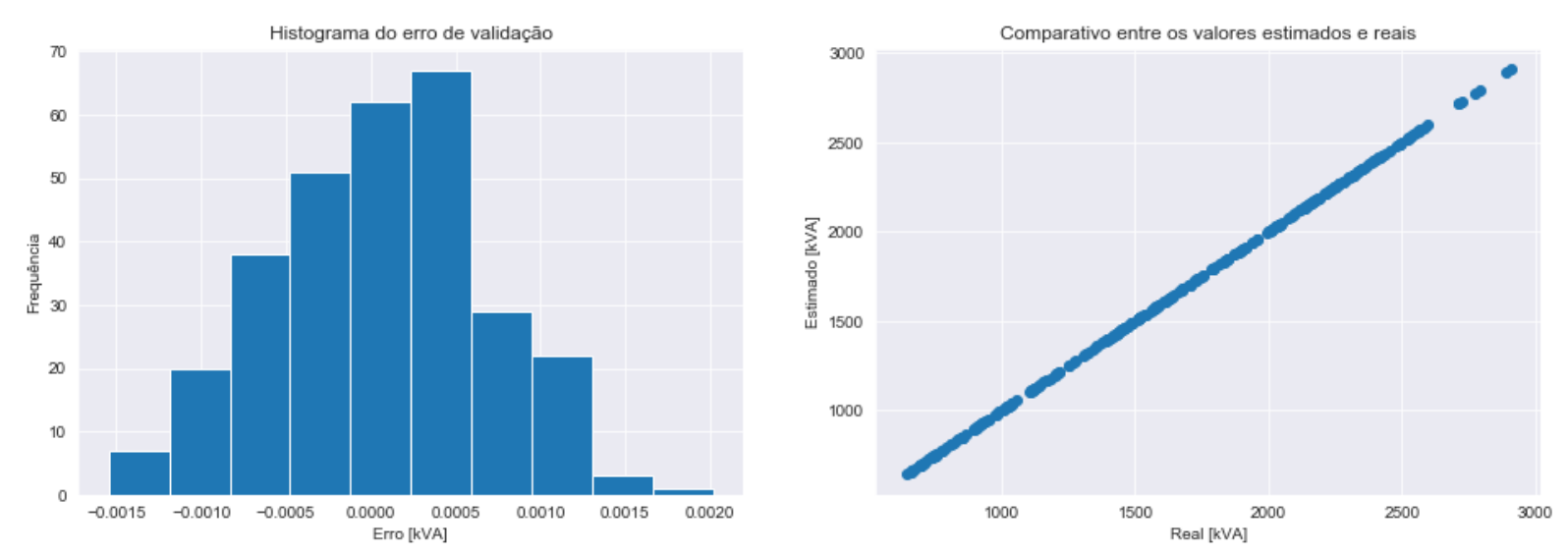

Fonte: Autor

Com o modelo de RNA ajustado e apresentando resultados similares aos encontrados anteriormente no software de simulação, foram realizados novos experimentos utilizando todas as combinações possíveis dos conjuntos de variáveis de entrada. Para cada experimento, foi avaliado o coeficiente de determinação $\left(\mathrm{R}^{2}\right)$, permitindo comparar o desempenho entre os diferentes conjuntos de dados. Este comparativo é apresentado na figura 43, onde os resultados foram ordenados de forma crescente.

Dos resultados sintetizados na figura 43 é possível verificar que, individualmente, a variável $M L$ é a que melhor apresenta capacidade de descrição da variável de saída Energy[kVA], apresentando o valor de $\mathrm{R}^{2}=96,3 \%$. De forma contrária, o conjunto de variáveis $S T$ foi o que apresentou piores resultados para a estimação do consumo de energia, com o valor de $\mathrm{R}^{2}=49,5 \%$. Isso pode ser explicado pelo fato que, mesmo sabendo o instante em que uma máquina é ligada, não é possível determinar somente a partir deste conjunto de variáveis quanta energia será desperdiçada por períodos de ociosidade dos equipamentos. O comportamento de ambos os cenários são apresentados nas figuras 44 e 45, onde é possível verificar a maior dispersão dos valores preditos quando se trata da variável que apresentou um menor coeficiente de determinação (i.e., a variável $S T$ ). 


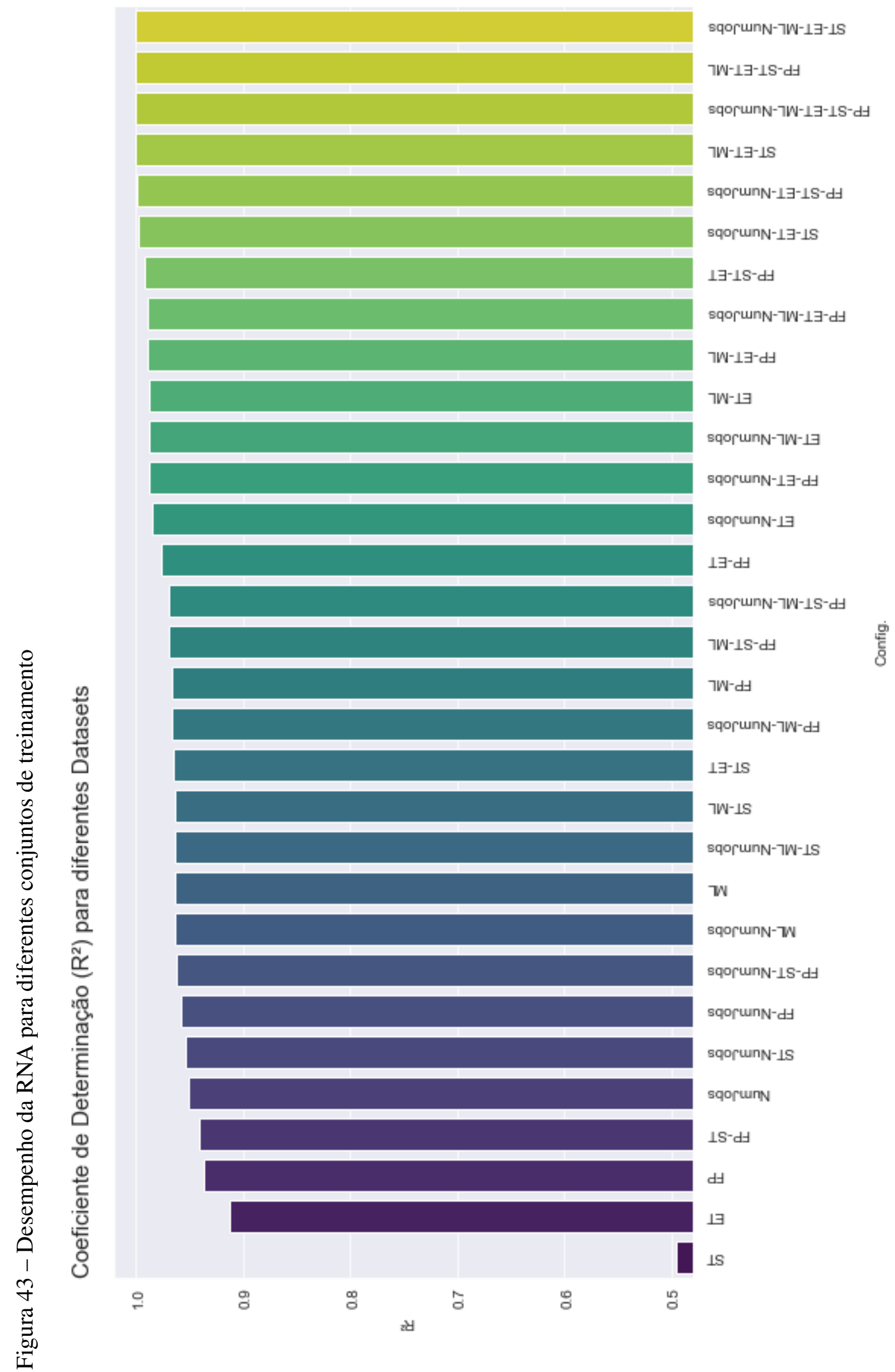


Figura 44 - Erros de estimação para o conjunto de treinamento $M L$
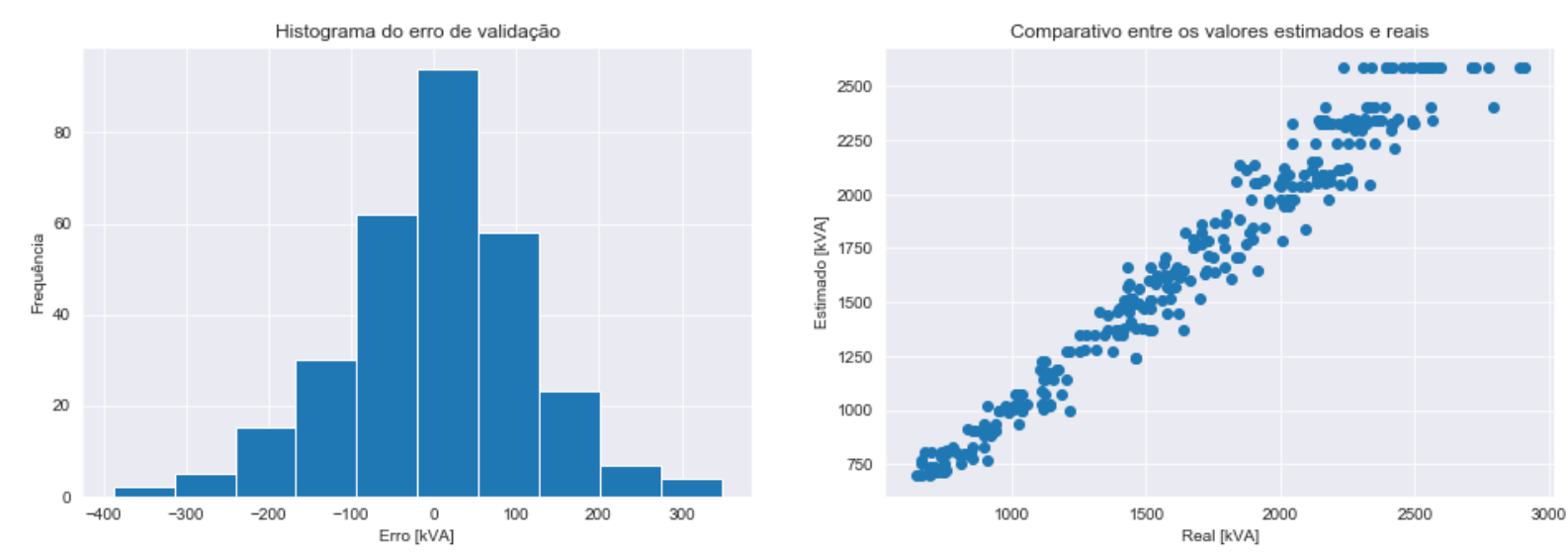

Fonte: Autor

Figura 45 - Erros de estimação para o conjunto de treinamento $S T$
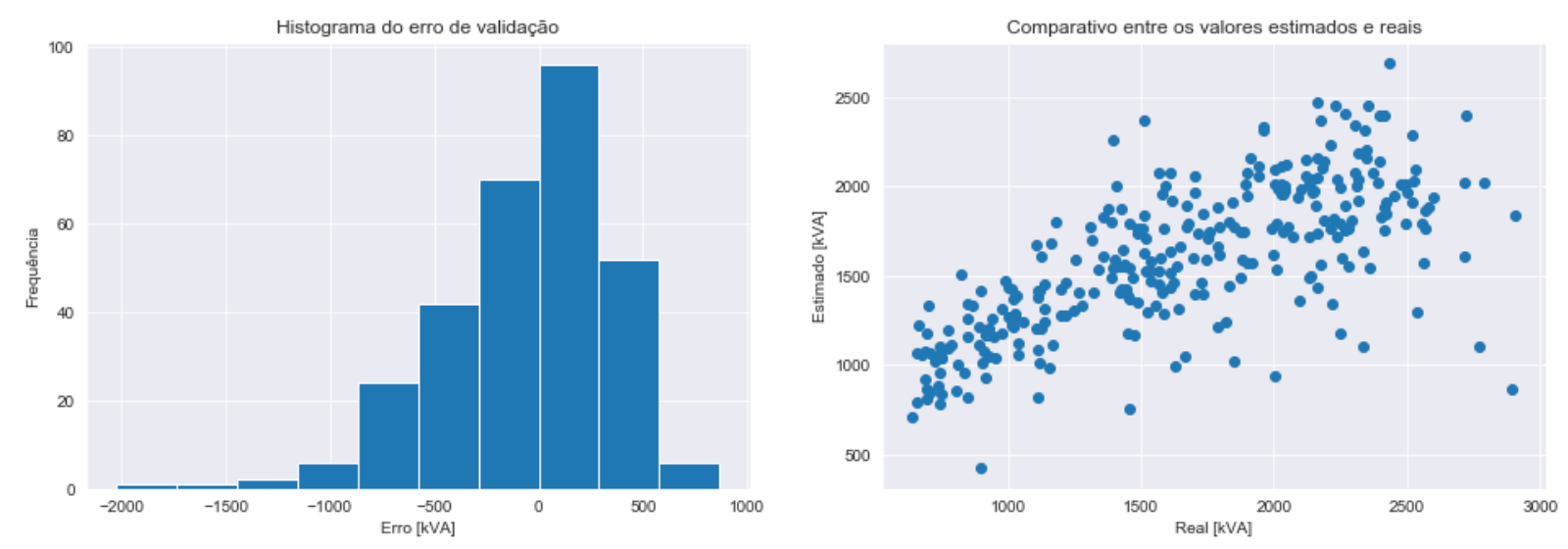

Fonte: Autor

Conforme sugerido na Seção 5.3, as variáveis de entrada podem ser agrupadas em três grupos, em função da complexidade envolvida para a aquisição de cada uma delas. Estes grupos são:
a) Grupo 1: $M L$ e NumJobs
b) Grupo 2: FP
c) Grupo 3: $S T$ e $E T$

A partir desta abordagem de grupos, duas perspectivas são possíveis para a análise. $\mathrm{Na}$ primeira, pode-se avaliar o melhor resultado obtido quando considerado apenas as variáveis que compõem cada grupo (resultado "individual"). Na segunda, as variáveis dos grupos anteriores, 
de menores complexidades, também são consideradas na análise (resultado "acumulado"). Estes resultados são apresentados na tabela 7 .

Tabela 7 - Melhor valor de $\mathrm{R}^{2}$ para cada um dos grupos de variáveis

Fonte: Autor

\begin{tabular}{ccc}
\hline Grupo & Individual & Acumulado \\
\hline 1 & $96,3 \%$ & $96,3 \%$ \\
\hline 2 & $93,7 \%$ & $96,7 \%$ \\
\hline 3 & $96,5 \%$ & $100 \%$ \\
\hline
\end{tabular}

A tabela 7 mostra que, de forma individual, nenhum dos grupos é capaz de descrever integralmente o valor do consumo de energia do sistema. Mesmo assim, todos apresentam resultados individuais elevados, superando os $90 \%$ de acerto. Entretanto, quando combinados permitem estimar praticamente sem erros o valor da energia consumida pelo sistema, como é o caso do grupo 3 acumulado. As figuras 46 à 48 apresentam os valores de erros individuais de cada grupo e as figuras 49 à 51 os respectivos valores acumulados.

Figura 46 - Erros de estimação para o Grupo 1 Individual (ML+NumJobs)
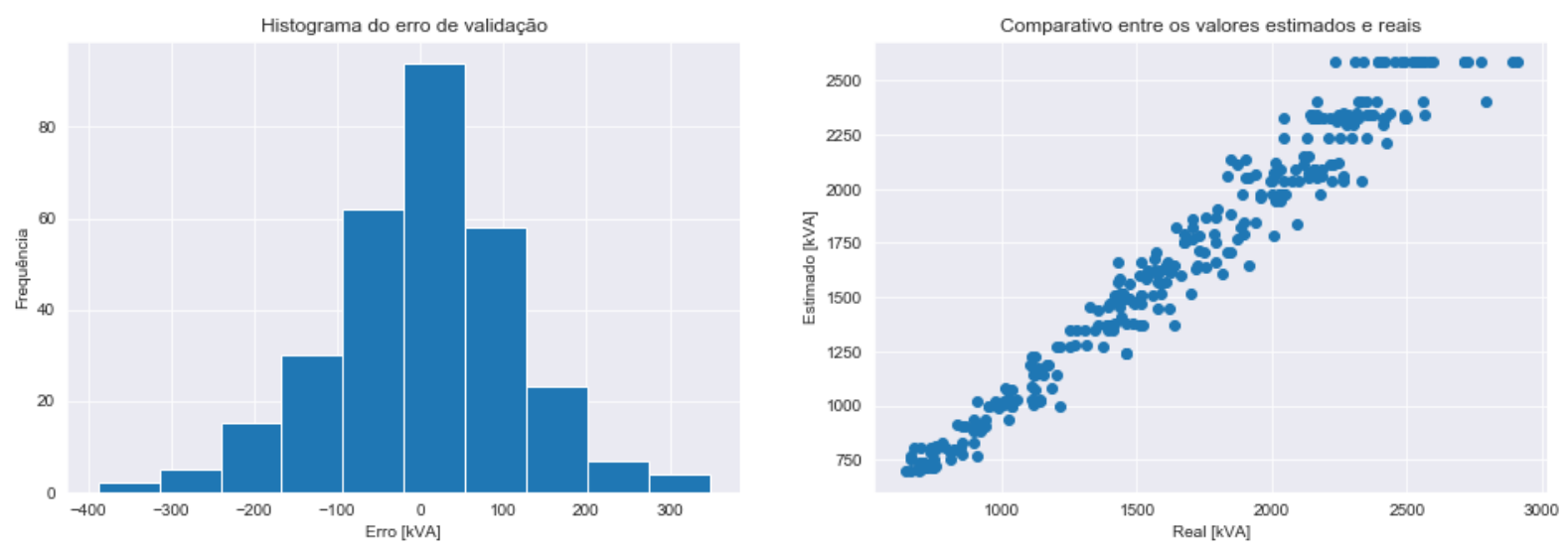

Fonte: Autor

Retomando os resultados apresentados na figura 43, é possível observar que, para todos os cenários onde o coeficiente de determinação foi praticamente igual a 100\%, coincidem as ocorrências das variáveis $M L, S T$ e $E T$. Isso ocorre pelo fato que, a partir destas três variáveis, é possível calcular a quantidade de tempo em que cada máquina fica nos estados de consumo de energia (i.e., estados operando e ocioso). O tempo de operação é a própria variável $M L$ para cada máquina. Já o tempo de ociosidade pode ser obtido a partir da diferença entre o tempo 
Figura 47 - Erros de estimação para o Grupo 2 Individual $(F P)$
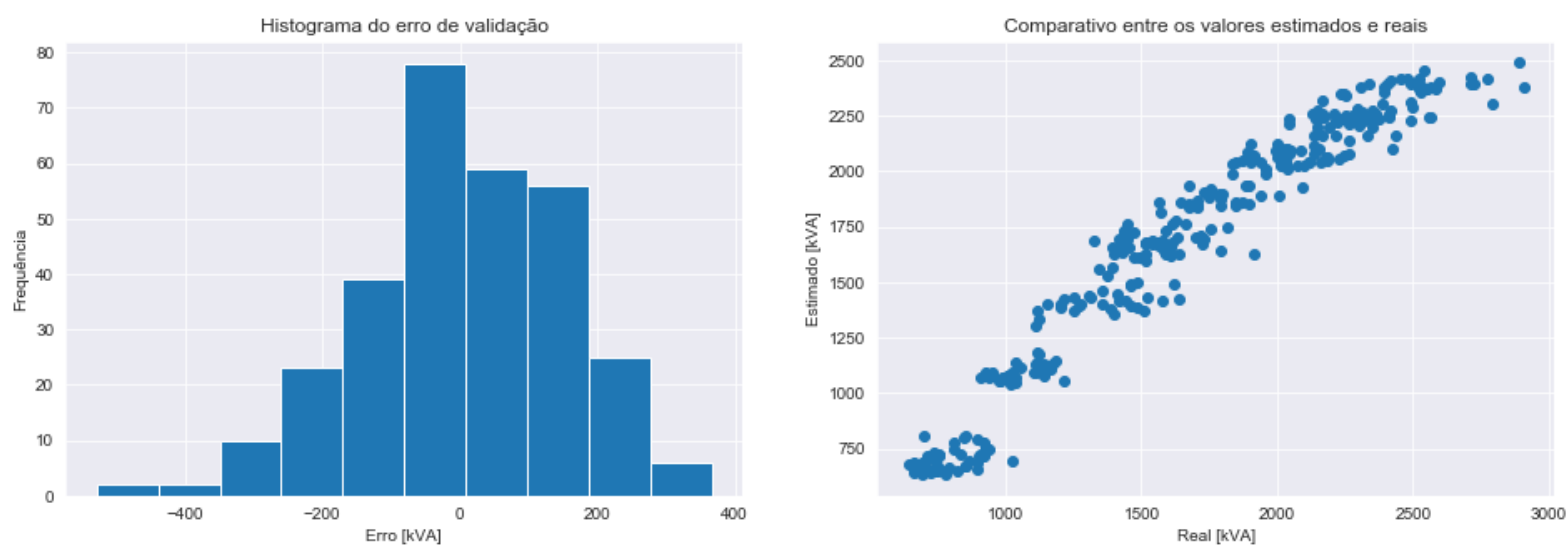

Fonte: Autor

Figura 48 - Erros de estimação para o Grupo 3 Individual $(S T+E T)$
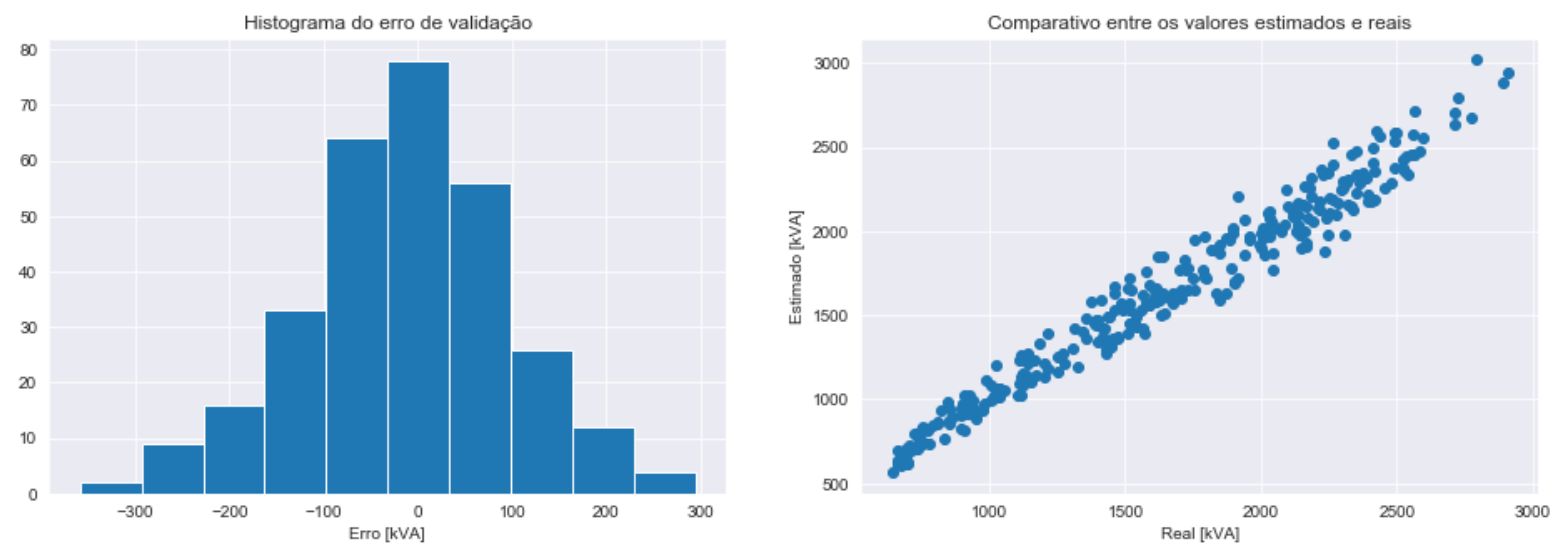

Fonte: Autor

Figura 49 - Erros de estimação para o Grupo 1 Acumulado (ML+NumJobs)
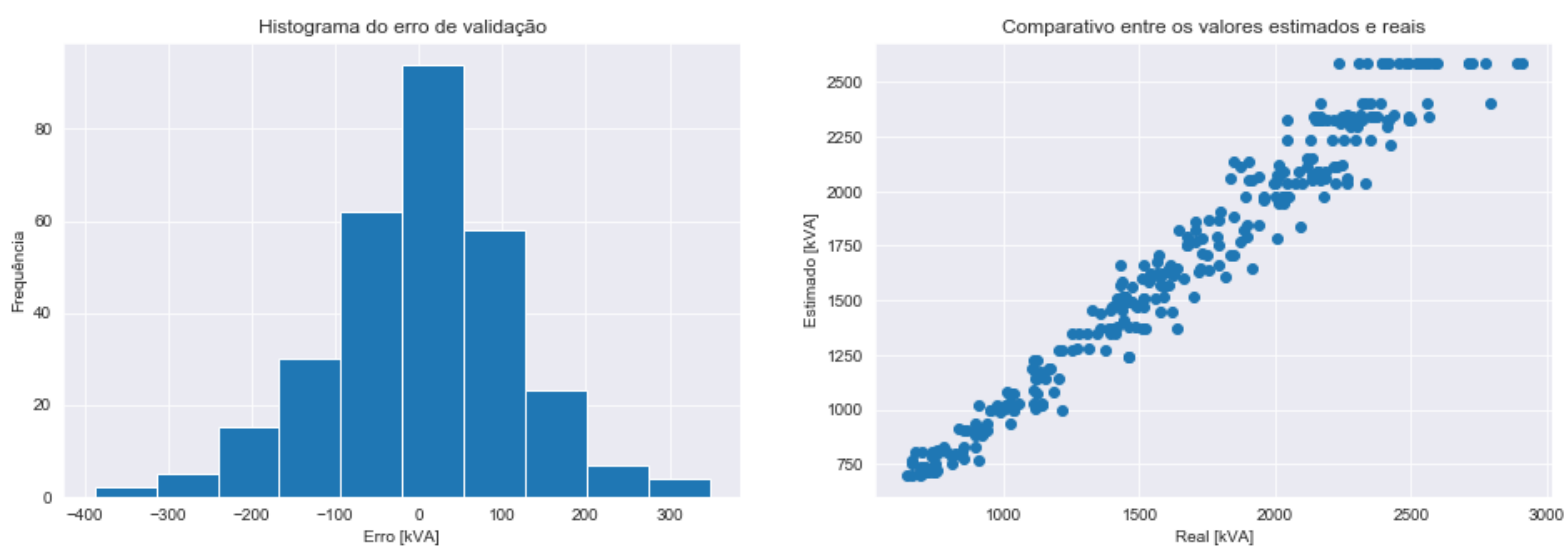

Fonte: Autor 
Figura 50 - Erros de estimação para o Grupo 2 Acumulado $(F P+M L)$
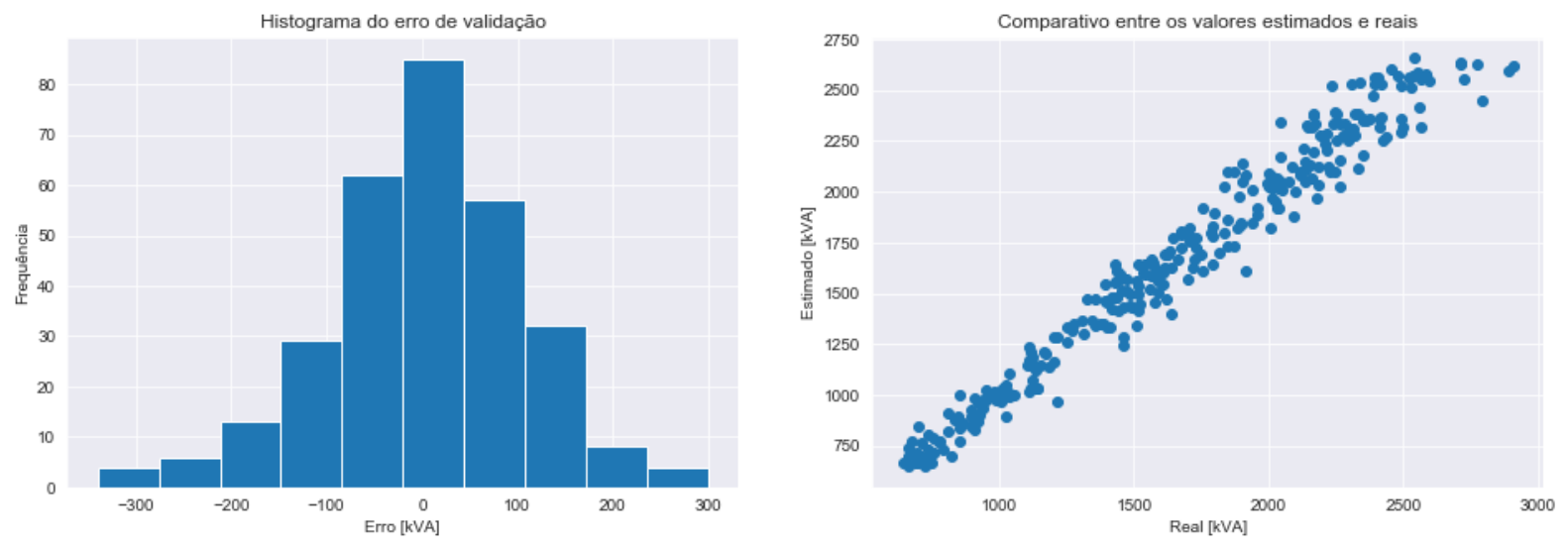

Fonte: Autor

Figura 51 - Erros de estimação para o Grupo 3 Acumulado $(F P+M L+N u m J o b s+S T+E T)$
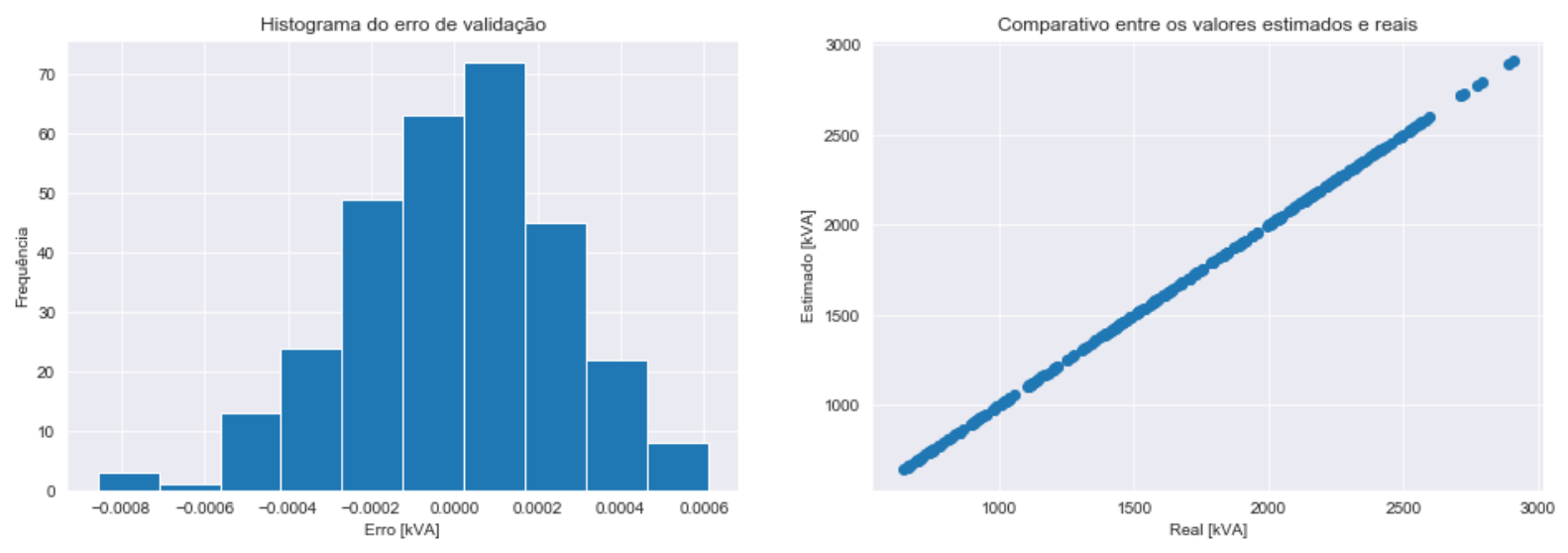

Fonte: Autor

total no qual a máquina está ligada (i.e., $E T-S T$ ) e o respectivo tempo de operação $(M L)$. Desta forma, temos:

$$
\mathrm{t}_{\text {idle }_{m}}=\left(\mathrm{ET}_{m}-\mathrm{ST}_{m}\right)-\mathrm{ML}_{m}
$$

onde $\mathrm{t}_{i d l e_{m}}$ é o tempo de ociosidade da máquina $m$.

Sabendo que a máquina assume os estados de consumo de energia operando e ociosa, consequentemente temos duas potências elétricas associadas a cada um deles: Potência em Operação $\left(\mathrm{P}_{\text {working }}\right)$ e Potência em Ociosidade $\left(\mathrm{P}_{\text {idle }}\right)$. Com isso, temos que a energia total consumida por cada máquina é igual a:

$$
\mathrm{E}_{m}=\mathrm{t}_{\text {idle }_{m}} \times \mathrm{P}_{\text {idle }_{m}}+\mathrm{ML}_{m} \times \mathrm{P}_{\text {working }_{m}}
$$


onde $E_{m}$ é a energia total consumida pela máquina $m$.

Logo, o consumo total de energia $\left(E_{\text {Total }}\right)$ que a RNA busca estimar, pode ser descrito analiticamente por:

$$
\begin{gathered}
E_{\text {Total }}=\sum_{m=1}^{M}\left(E_{m}\right) \\
E_{\text {Total }}=\sum_{m=1}^{M}\left(\mathrm{t}_{\text {idle }_{m}} \times \mathrm{P}_{\text {idle }_{m}}+\mathrm{ML}_{m} \times \mathrm{P}_{\text {working }_{m}}\right)
\end{gathered}
$$

Para a forma analítica descrita na equação 15, é possível verificar que apenas as variáveis $\mathrm{P}_{\text {idle }}$ e $\mathrm{P}_{\text {working }}$ não compõem o conjunto de treinamento da RNA. Desta forma, para os casos onde a RNA apresentou acertos próximos à 100\%, a rede foi capaz de absorver os valores destas potências e combina-las com as variáveis de tempo apresentadas. Para os outros casos onde as variáveis do cálculo analítico não foram contempladas no conjunto de treinamento, a RNA precisou realizar a abstração dos dados faltantes, extraindo padrões a partir das variáveis para realizar a estimação do consumo de energia. 


\section{CONCLUSÕES}

Este trabalho apresenta uma aplicação das RNAs, como ferramenta de apoio para a estimação do consumo de energia elétrica em sistemas de produção do tipo job shop. Tal aplicação permite contribuir com a redução da lacuna existente na literatura quanto ao estudo destes sistemas, a partir da perspectiva energética, descrevendo uma metodologia para a criação da ferramenta de suporte ao processo de tomada de decisão com base no aspecto decisório da sustentabilidade.

Em particular, este trabalho busca utilizar as RNAs como ferramenta para a estimação do consumo total de energia elétrica de um sistema job shop, considerando diferentes combinações de ordens de produção. Desta forma, o modelo proposto poderá auxiliar os tomadores de decisões no planejamento das ordens de produção, a partir de uma perspectiva sustentável onde, por exemplo, poderá ser avaliado previamente aspectos relacionados à demanda de energia necessária em um dado período.

Outra importante contribuição está na possibilidade de substituição das ferramentas de simulação para estimar o consumo de energia. Com base na acurácia apresentada pelo modelo, o consumo de energia poderia ser estimado a partir da RNA, facilmente empregadas em software gratuitos ou linguagens de programação open source disponíveis no mercado, reduzindo os custos com a aquisição e manutenção destes tipos de ferramentas.

A modelagem realizada parte da representação cromossômica de permutação com repetição, onde as operações dos jobs que compõem o sistema são adicionadas a um vetor de prioridade, decomposto por um algoritmo de sequenciamento das operações. Durante o desenvolvimento do modelo apresentado, foi observado que o comprimento deste vetor é um ponto crítico para a modelagem. Sistemas job shop reais possuem flexibilidade para processar diferentes combinações de jobs, implicando em diferentes ordens de produção, que podem ter comprimentos variáveis. Com isso, o vetor de entrada também poderia ter diferentes dimensões, impossibilitando o uso de uma mesma rede para diferentes combinações de jobs.

Para contornar esta questão, a modelagem é realizada a partir da perspectiva das máquinas, já que, tipicamente, o número de máquinas em uma fábrica não costuma ser alterado. Com isso, a quantidade de variáveis independentes é estabelecida a partir do número de máquinas que compõem o sistema. Esta restrição permite fixar o número de variáveis do vetor de entrada 
e, consequentemente, o número de neurônios da camada de entrada da RNA, de tal forma que a mesma rede seja capaz de realizar a estimação para diferentes ordens de produção.

A partir dos dados de entrada, cinco diferentes conjuntos de variáveis relacionadas ao vetor de entrada são utilizados. As variáveis mapeadas para cada máquina são o fator de prioridade de entrada em operação, o instante inicial de energização, o instante final de desenergização, o tempo total de processamento previsto para cada máquina e a quantidade de jobs que compõe o vetor de entrada. A relevância de cada variável é explorada individualmente, e também em grupo, permitindo avaliar as combinações que melhor representam a variável de saída (i.e., energia total consumida). Vale ressaltar que a escolha das variáveis de entrada para o modelo foi o ponto que demandou maior esforço para a elaboração do modelo, uma vez que sua determinação foi feita de forma empírica e não identificada em trabalhos anteriores.

Como sugestão para trabalhos futuros, este estudo poderia ser expandido a partir da análise de desempenho da RNA proposta frente a diferentes políticas energéticas empregadas no sistema, como o desligamento de máquinas ociosas ou a introdução de estágios energéticos transitórios durante a energização e desenergização dos equipamentos. Outra frente de estudo possível seria a utilização de diferentes técnicas de aprendizado de máquina, como as redes de aprendizado extremo (Extreme Machine Learning), redes com funções de bases radiais (Radial Basis Function) e máquinas de suporte vetorial (Support Vector Machines).

Por fim, este trabalho contribui de forma direta com o aspecto da sustentabilidade no contexto da Indústria 4.0, uma vez que é proposta a utilização de técnicas de aprendizado de máquina no processo decisório da manufatura. A RNA proposta, uma vez treinada, poderia atuar de forma online e direta com o sistema de planejamento e programação da produção, de tal forma que a escolha entre diferentes programações poderia ser tomada com base no aspecto da eficiência energética. 


\section{REFERÊNCIAS}

ADAMS, Joseph; BALAS, Egon; ZAWACK, Daniel. The shifting bottleneck procedure for job shop scheduling. Management science, INFORMS, v. 34, n. 3, p. 391-401, 1988.

ANTONIOL, R. L.; LIMA, F. Digital manufacturing tools applied to energy analysis and decision in manufacturing systems. In: 2016 Portland International Conference on Management of Engineering and Technology (PICMET). [S.1.: s.n.], set. 2016. p. 721-729.

APOSTOLOS, Fysikopoulos et al. Energy Efficiency of Manufacturing Processes: A Critical Review. Procedia CIRP, v. 7, p. 628-633, 2013.

ARAZ, Özlem Uzun; SALUM, Latif. A multi-criteria adaptive control scheme based on neural networks and fuzzy inference for DRC manufacturing systems. International Journal of Production Research, Taylor \& Francis, v. 48, n. 1, p. 251-270, 2010.

ARRIANDIAGA, A. et al. Downsizing training data with weighted FCM for predicting the evolution of specific grinding energy with RNNs. Applied Soft Computing Journal, Elsevier B.V., v. 61, p. 211-221, 2017. Disponível em: <http://dx.doi.org/10.1016/j.asoc.2017.07.048>.

AZIMI, Parham; SOOFI, Parham. An ANN-based optimization model for facility layout problem using simulation technique. Scientia Iranica. Transaction E, Industrial

Engineering, Sharif University of Technology, v. 24, n. 1, p. 364, 2017.

AZMI, Saipul; MOHD, Bin; FADLI, Mohd. Simulation for reducing energy consumption of multi core low voltage power cable manufacturing system. Journal on Technical and Vocational Education, v. 1, n. 2, p. 1-10, 2016.

BANGSOW, Steffen. Tecnomatix Plant Simulation: Modeling and Programming by Means of Examples. [S.1.]: Springer Publishing Company, Incorporated, 2015.

BENEDETTI, Miriam; CESAROTTI, Vittorio; INTRONA, Vito. From energy targets setting to energy-aware operations control and back: An advanced methodology for energy efficient manufacturing. Journal of Cleaner Production, v. 167, p. 1518-1533, 2017.

BENEDETTI, Miriam et al. Energy consumption control automation using Artificial Neural Networks and adaptive algorithms: Proposal of a new methodology and case study. Applied Energy, v. 165, p. 60-71, 2016.

BENYOUCEF, Lyes; GRABOT, Bernard (Ed.). Artificial Intelligence Techniques for Networked Manufacturing Enterprises Management. [S.1.]: Springer London, 2010. (Springer Series in Advanced Manufacturing).

BIEL, Konstantin; GLOCK, Christoph H. Systematic literature review of decision support models for energy-efficient production planning. Computers \& Industrial Engineering, v. 101, p. 243-259, 2016.

BIERWIRTH, Christian. A generalized permutation approach to job shop scheduling with genetic algorithms. Operations-Research-Spektrum, v. 17, n. 2, p. 87-92, jun. 1995. 
BORNSCHLEGL, Martin; BREGULLA, Markus; FRANKE, Jörg. Methods-Energy Measurement - An approach for sustainable energy planning of manufacturing technologies. Journal of Cleaner Production, v. 135, p. 644-656, 2016.

BRAGA, Antônio de Pádua; CARVALHO, André Ponce de Leon F. de; LUDERMIR, Teresa Bernarda. Redes neurais artificiais: teoria e aplicações. 2. ed. Rio de Janeiro: LTC, 2014. p. 226.

BRUNDTLAND, Gro H. Our Common Future: Report of the World Commission on Environment and Development. United Nations Commission, v. 4, n. 1, p. 300, 1987. eprint: arXiv:1011.1669v3.

CHAE, Young Tae et al. Artificial neural network model for forecasting sub-hourly electricity usage in commercial buildings. Energy and Buildings, v. 111, p. 184-194, 2016.

CHEN, Zhengjie et al. Artificial neural network modeling for evaluating the power consumption of silicon production in submerged arc furnaces. Applied Thermal Engineering, v. 112, p. 226-236, 2017.

CHOI, S.H.; WANG, K. Flexible flow shop scheduling with stochastic processing times: A decomposition-based approach. Computers \& Industrial Engineering, v. 63, n. 2, p. 362-373, 2012.

CHRYSSOLOURIS, George. Manufacturing Systems: Theory and Practice. Edição:

Lin Frederick F. 2. ed. [S.1.]: Springer-Verlag New York, 2006. p. 606. (Mechanical Engineering Series).

DEB, K. et al. A fast and elitist multiobjective genetic algorithm: NSGA-II. IEEE

Transactions on Evolutionary Computation, v. 6, n. 2, p. 182-197, abr. 2002.

DEBNATH, Kumar Biswajit; MOURSHED, Monjur. Forecasting methods in energy planning models. Renewable and Sustainable Energy Reviews, v. 88, p. 297-325, 2018.

DRATH, R.; HORCH, A. Industrie 4.0: Hit or Hype? [Industry Forum]. IEEE Industrial Electronics Magazine, v. 8, n. 2, p. 56-58, jun. 2014.

DUFLOU, Joost R. et al. Towards energy and resource efficient manufacturing: A processes and systems approach. CIRP Annals, v. 61, n. 2, p. 587-609, 2012.

FYSIKOPOULOS, Apostolos et al. On a generalized approach to manufacturing energy efficiency. The International Journal of Advanced Manufacturing Technology, v. 73, n. 9, p. 1437-1452, ago. 2014.

GENG, ZhiQiang et al. Energy saving and prediction modeling of petrochemical industries: A novel ELM based on FAHP. Energy, Elsevier, v. 122, p. 350-362, 2017.

GIL, A.C.G.I.L. Como elaborar projetos de pesquisa. [S.1.]: Atlas, 2010.

GIRET, Adriana; TRENTESAUX, Damien; PRABHU, Vittal. Sustainability in manufacturing operations scheduling: A state of the art review. Journal of Manufacturing Systems, v. 37, p. 126-140, 2015. 
HENNING, Kagermann; WOLFGANG, Wahlster; JOHANNES, Helbig. Recommendations for implementing the strategic initiative INDUSTRIE 4.0. [S.1.], 2013. p. 82.

HERRMANN, C. et al. Energy oriented simulation of manufacturing systems - Concept and application. CIRP Annals, v. 60, n. 1, p. 45-48, 2011.

HOLLAND, John H. Genetic Algorithms. Scientific American, v. 267, n. 1, p. 66-72, jul. 1992. Disponível em:

<http://www.nature.com/doifinder/10.1038/scientificamerican0792-66>.

HOPFIELD, J J. Neural networks and physical systems with emergent collective computational abilities. Proceedings of the National Academy of Sciences, National Academy of Sciences, v. 79, n. 8, p. 2554-2558, 1982. eprint:

http://www.pnas.org/content/79/8/2554.full.pdf.

HUANG, S. H.; ZHANG, Hong-Chao. Neural networks in manufacturing: A survey. In: PROCEEDINGS of 15th IEEE/CHMT International Electronic Manufacturing Technology Symposium. [S.1.: s.n.], out. 1993. p. 177-190.

IEA. Energy Technology Perspectives 2017. [S.1.]: IEA, 2017. p. 1-82. (Energy Technology Perspectives).

INDÚSTRIAS ROMI S.A. Linha ROMI Centur. 2018. Disponível em: $<$ http://www.romi.com/produtos/linha-centur/>. Acesso em: 16 ago. 2018.

JIN, Mingzhou et al. Impact of advanced manufacturing on sustainability: An overview of the special volume on advanced manufacturing for sustainability and low fossil carbon emissions. Journal of Cleaner Production, v. 161, p. 69-74, 2017.

KALOGIROU, Soteris A. Applications of artificial neural-networks for energy systems. Applied Energy, v. 67, n. 1, p. 17-35, 2000.

KARATASOU, S.; SANTAMOURIS, M.; GEROS, V. Modeling and predicting building's energy use with artificial neural networks: Methods and results. Energy and Buildings, v. 38, n. 8, p. 949-958, 2006.

KIALASHAKI, Arash; REISEL, John R. Development and validation of artificial neural network models of the energy demand in the industrial sector of the United States. Energy, v. 76, p. 749-760, 2014.

KIDD, Charles V. The evolution of sustainability. Journal of Agricultural and Environmental Ethics, v. 5, n. 1, p. 1-26, mar. 1992.

KOUKI, Meriem et al. Input data management for energy related discrete event simulation modelling. Journal of Cleaner Production, v. 141, p. 194-207, 2017.

KUO, Ping-Huan; HUANG, Chiou-Jye. A High Precision Artificial Neural Networks Model for Short-Term Energy Load Forecasting. Energies, v. 11, n. 1, p. 213, jan. 2018. 
LE, Cao Vinh et al. Classification of energy consumption patterns for energy audit and machine scheduling in industrial manufacturing systems. Transactions of the Institute of Measurement and Control, v. 35, n. 5, p. 583-592, 2013.

LI, Xiaoling et al. Total energy consumption optimization via genetic algorithm in flexible manufacturing systems. Computers \& Industrial Engineering, v. 104, p. 188-200, 2017.

LIU, Ying et al. A multi-objective genetic algorithm for optimisation of energy consumption and shop floor production performance. International Journal of Production Economics, v. 179, p. 259-272, 2016.

LIU, Ying et al. An investigation into minimising total energy consumption and total weighted tardiness in job shops. Journal of Cleaner Production, v. 65, p. 87-96, 2014.

LIU, Ying et al. Reducing environmental impact of production during a Rolling Blackout policy - A multi-objective schedule optimisation approach. Journal of Cleaner Production, v. 102, p. 418-427, 2015.

MAY, Gökan; KIRITSIS, Dimitris. Business Model for Energy Efficiency in Manufacturing. Procedia CIRP, v. 61, p. 410-415, 2017. The 24th CIRP Conference on Life Cycle Engineering.

MAY, Gökan et al. Energy management in production: A novel method to develop key performance indicators for improving energy efficiency. Applied Energy, v. 149, p. 46-61, 2015.

MELLO, Carlos Henrique Pereira; MARTINS, Roberto Antonio; TURRIONI, João Batista. Fundamentação Teórica. In: GUIA para Elaboração de Monografia e TCC em Engenharia de Produção. 1. Ed. São Paulo: Editora Atlas SA, 2013. cap. 3, p. 224.

MICHALEWICZ, Zbigniew. Genetic Algorithms + Data Structures = Evolution Programs. Berlin, Heidelberg: Springer Berlin Heidelberg, 1996. Disponível em: $<$ http://link.springer.com/10.1007/978-3-662-03315-9>.

MORALES, Sergio Gomez; RONCONI, Débora Pretti. Formulações matemáticas e estratégias de resolução para o problema job shop clássico. pt. Production, scielo, v. 26, p. 614-625, set. 2016.

MURALITHARAN, K.; SAKTHIVEL, R.; VISHNUVARTHAN, R. Neural network based optimization approach for energy demand prediction in smart grid. Neurocomputing, Elsevier B.V., v. 273, p. 199-208, jan. 2018.

MUTH, J.F.; THOMPSON, G.L. Industrial Scheduling. [S.1.]: Prentice-Hall, 1963. (International series in management).

NEGAHBAN, Ashkan; SMITH, Jeffrey S. Simulation for manufacturing system design and operation: Literature review and analysis. Journal of Manufacturing Systems, v. 33, n. 2, p. 241-261, 2014. 
NETO, Alberto Hernandez; FIORELLI, Flavio Augusto Sanzovo. Comparison between detailed model simulation and artificial neural network for forecasting building energy consumption. Energy and Buildings, v. 40, n. 12, p. 2169-2176, jan. 2008.

OGLIARI, E. et al. Neural forecasting of the day-ahead hourly power curve of a photovoltaic plant. In: 2016 International Joint Conference on Neural Networks (IJCNN). [S.l.: s.n.], jul. 2016. p. 654-659.

OLANREWAJU, Oludolapo Akanni; MBOHWA, Charles. Comparison of artificial intelligence techniques for energy consumption estimation. In: IEEE. ELECTRICAL Power and Energy Conference (EPEC), 2016 IEEE. [S.1.: s.n.], 2016. p. 1-5.

ONS. Sobre o SIN O Sistema em Números. 2018. Disponível em: $<$ http://www.ons.org.br/paginas/sobre-o-sin/o-sistema-em-numeros $>$. Acesso em: 28 jun. 2018.

PALOMINO, RC. Planejamento da produção em sistemas flexíveis do tipo job shop usando redes de petri. XXIV Encontro Nacional de Engenharia de Produção:

ENEGEP/ABEPRO, v. 3, 2004.

PEDREGOSA, F. et al. Scikit-learn: Machine Learning in Python. Journal of Machine Learning Research, v. 12, p. 2825-2830, 2011.

PEREIRA, M. S.; LIMA, F. A Machine Learning Approach Applied to Energy Prediction in Job Shop Environments. In: IECON 2018 - 44th Annual Conference of the IEEE Industrial Electronics Society. [S.1.: s.n.], out. 2018. p. 2665-2670.

PINEDO, M.L. Scheduling: Theory, Algorithms, and Systems. [S.1.]: Springer International Publishing, 2016.

R. SULE, Dileep. Production planning and industrial scheduling. Examples, case studies and applications. 2nd ed, jan. 2007.

RATHORE, K.; CHAUHAN, N. R. FMS scheduling using Neural networks: A review. In: 2015 International Conference on Soft Computing Techniques and Implementations (ICSCTI). [S.1.: s.n.], out. 2015. p. 39-44.

REIM, Wiebke; PARIDA, Vinit; ORTQVIST, Daniel. Product-Service Systems (PSS) business models and tactics - a systematic literature review. Journal of Cleaner Production, v. 97, p. 61-75, 2015. Special Volume: Why have 'Sustainable Product-Service Systems' not been widely implemented?

RUMELHART, David E.; HINTON, Geoffrey E.; WILLIAMS, Ronald J. Learning representations by back-propagating errors. Nature, v. 323, n. 6088, p. 533-536, out. 1986.

SALIDO, Miguel A. et al. Rescheduling in job-shop problems for sustainable manufacturing systems. Journal of Cleaner Production, v. 162, s121-s132, 2017. Innovative Products and Services for Sustainable Societal Development. 
SALONITIS, Konstantinos; BALL, Peter. Energy Efficient Manufacturing from Machine Tools to Manufacturing Systems. Procedia CIRP, v. 7, p. 634-639, 2013. Forty Sixth CIRP Conference on Manufacturing Systems 2013.

SCHMIDT, Peter-Michael. A short introduction to embedded optimization. [S.1.: s.n.], jun. 2016. Tecnomatix Plant Simulation Worldwide User Conference.

SHROUF, Fadi; ORDIERES-MERÉ, Joaquin; MIRAGLIOTTA, G. Smart factories in Industry 4.0: A review of the concept and of energy management approached in production based on the Internet of Things paradigm. In: 2014 IEEE International Conference on Industrial Engineering and Engineering Management. [S.1.: s.n.], dez. 2014. p. 697-701.

SHROUF, Fadi et al. Optimizing the production scheduling of a single machine to minimize total energy consumption costs. Journal of Cleaner Production, v. 67, p. 197-207, 2014.

SIEMENS, Siemens Product Lifecycle Management Software Inc. Tecnomatix Plant Simulation Visão Geral do Produto. 2018. Disponível em:

$<\mathrm{https} / / / \mathrm{www}$.plm.automation.siemens.com/pt/products/tecnomatix/manufacturingsimulation/material-flow/plant-simulation.shtml>. Acesso em: 2 jun. 2018.

SIMON, Foo Yoon-Pin; TAKEFUJI, T. Integer linear programming neural networks for job-shop scheduling. In: IEEE 1988 International Conference on Neural Networks. [S.l.: s.n.], jul. 1988. 341-348 vol.2.

SMITH, Jeffrey S. Survey on the use of simulation for manufacturing system design and operation. Journal of Manufacturing Systems, v. 22, n. 2, p. 157-171, 2003.

SRIVASTAVA, Nitish et al. Dropout: a simple way to prevent neural networks from overfitting. The Journal of Machine Learning Research, JMLR. org, v. 15, n. 1, p. 1929-1958, 2014.

TANG, Lixin; LIU, Wenxin; LIU, Jiyin. A neural network model and algorithm for the hybrid flow shop scheduling problemin a dynamic environment. Journal of Intelligent Manufacturing, v. 16, n. 3, p. 361-370, jun. 2005.

THIEDE, Sebastian. Energy Efficiency in Manufacturing Systems. [S.1.: s.n.], jan. 2012.

UZLU, Ergun et al. Estimates of energy consumption in Turkey using neural networks with the teaching-learning-based optimization algorithm. Energy, v. 75, p. 295-303, 2014.

VAN HULLE, M.M. A GOAL PROGRAMMING NETWORK FOR MIXED INTEGER LINEAR PROGRAMMING: A CASE STUDY FOR THE JOB-SHOP SCHEDULING PROBLEM. International Journal of Neural Systems, v. 02, n. 03, p. 201-209, 1991.

VAZ, A.G.R. et al. An artificial neural network to assess the impact of neighbouring photovoltaic systems in power forecasting in Utrecht, the Netherlands. Renewable Energy, v. 85, p. 631-641, 2016.

WANG, S. et al. A systematic approach of process planning and scheduling optimization for sustainable machining. Journal of Cleaner Production, v. 87, p. 914-929, 2015. 
WANG, Shuang-Xin et al. Short-term wind power prediction based on improved small-world neural network. Neural Computing and Applications, fev. 2018.

WEINERT, Nils; CHIOTELLIS, Stylianos; SELIGER, Günther. Methodology for planning and operating energy-efficient production systems. CIRP Annals, v. 60, n. 1, p. 41-44, 2011.

WILLEMS, T. M.; BRANDTS, L. E. M. W. Implementing heuristics as an optimization criterion in neural networks for job-shop scheduling. Journal of Intelligent Manufacturing, v. 6, n. 6, p. 377-387, dez. 1995.

XU, J.; XU, X.; XIE, S.Q. Recent developments in Dual Resource Constrained (DRC) system research. European Journal of Operational Research, v. 215, n. 2, p. 309-318, 2011.

YAHYAOUI, A.; FNAIECH, N.; FNAIECH, F. A Suitable Initialization Procedure for Speeding a Neural Network Job-Shop Scheduling. IEEE Transactions on Industrial Electronics, v. 58, n. 3, p. 1052-1060, mar. 2011.

YAO, A. W. L.; PAN, Y. M. A Petri nets and genetic algorithm based optimal scheduling for job shop manufacturing systems. In: 2013 International Conference on System Science and Engineering (ICSSE). [S.1.: s.n.], jul. 2013. p. 99-104.

YU, Jian-bo; XI, Li-feng. A neural network ensemble-based model for on-line monitoring and diagnosis of out-of-control signals in multivariate manufacturing processes. Expert Systems with Applications, v. 36, n. 1, p. 909-921, 2009.

ZHANG, H.-C.; HUANG, Samuel H. Artificial neural networks in manufacturing: concepts, applications, and perspectives. IEEE Transactions on Components, Packaging, and Manufacturing Technology: Part A, Vol. 17, No. 2, pp. 212-228, 1994.

ZHANG, Rui; CHIONG, Raymond. Solving the energy-efficient job shop scheduling problem: a multi-objective genetic algorithm with enhanced local search for minimizing the total weighted tardiness and total energy consumption. Journal of Cleaner Production, v. 112, p. 3361-3375, 2016.

ZHOU, Lirong et al. Energy consumption model and energy efficiency of machine tools: a comprehensive literature review. Journal of Cleaner Production, v. 112, p. 3721-3734, 2016. 

APÊNDICE A - ALGORITMO PARA O CÁLCULO DOS INSTANTES DE INÍCIO E TÉRMINO DE USO DAS MÁQUINAS 
O algoritmo abaixo foi empregado para o cálculo das nuances 2 e 3 apresentadas na Subseção 4.3.2 e Subseção 4.3.3, respectivamente.

Figura 52 - Algoritmo para o cálculo dos instantes de início e término das máquinas

1 Entrada: vetor de entrada $C$

2 Entrada: matriz de sequenciamento de máquina $S$

3 Entrada: matriz de tempos de processamento $T$

4 Saída: conjunto de instantes de início $S T$

5 Saída: conjunto de instantes de término ET

$6 S T \leftarrow \infty$

7 ET $\leftarrow 0$;

8 para cada $i \leftarrow 1$ até $C$.length faça

9

/* Identifica a operação

$j o b \leftarrow C[i]$

op $\leftarrow$ próximaOperação[job];

máquina $\leftarrow S[j o b, o p]$;

$t \leftarrow T[j o b$, máquina $]$;

se (ocupaçãoMáquina [máquina] > ocupaçãoJob[job]) então

/* Identifica início da operação corrente * operações $[j o b, o p] \leftarrow$ ocupaçãoMáquina [máquina];

/* Incrementa a ocupação da máquina * / ocupaçãoMáquina $[$ máquina $] \leftarrow$ ocupaçãoMáquina $[$ máquina $]+t$; $o c u p a c ̧ a ̃ o J o b[j o b] \leftarrow o c u p a c ̧ a ̃ o M a ́ q u i n a[$ máquina $] ;$

\section{senão}

/* Identifica início da operação corrente * $o p e r a c ̧ \tilde{e} e s[j o b, o p] \leftarrow o c u p a c ̧ a ̃ o J o b[j o b]$;

/* Incrementa o makespan do job *

$o c u p a c ̧ a ̃ o J o b[j o b] \leftarrow o c u p a c ̧ a ̃ o J o b[j o b]+t ;$

ocupaçãoMáquina $[$ máquina $] \leftarrow o c u p a c ̧ a ̃ o J o b[j o b]$;

\section{fim}

I* Atualiza valor de $S T(m)$

se $(($ ocupaçãoMáquina $[$ máquina $]-t)<S T[$ máquina $])$ então

| ST $[$ máquina $] \leftarrow$ ocupaçãoMáquina $[$ máquina $]-t$;

\section{fim}

/* Atualiza valor de $\operatorname{ET}(\mathrm{m})$

se ((ocupaçãoMáquina[máquina] $)>S T[$ máquina $])$ então

| ST $[$ máquina $] \leftarrow$ ocupaçãoMáquina $[$ máquina $]$;

\section{fim}

I* Incrementa a operação do job

30 fim

Fonte: Autor 
APÊNDICE B - ALGORITMO PARA O CÁLCULO DO FATOR DE PRIORIDADE 
Este algoritmo foi empregado para o cálculo da nuance 1 apresentada na Subseção 4.3.1, referente ao Fator de Prioridade de cada máquina.

Figura 53 - Algoritmo para o cálculo do Fator de Prioridade

1 Entrada: vetor de entrada $C$

2 Entrada: matriz de sequenciamento de máquina $S$

3 Saída: conjunto de fatores de prioridade $F P$

/* Inicializa Fator de Prioridade *

$4 F P \leftarrow 0$;

/ Inicializa ponteiro das operações *

$\mathbf{5}$ op $\leftarrow 0$;

I* Varre o vetor entrada $C$ * /

6 para cada $i \leftarrow 1$ até $C$.length faça

/* Identifica o job da posição $i$

$7 \quad j o b \leftarrow C[i]$;

/ Identifica a máquina associada à posição $i$ * /

$8 \quad$ máquina $\leftarrow S[j o b, o p]$;

/* Incrementa o valor do Fator de Prioridade *

$9 \quad F P[$ máquina $] \leftarrow F P[$ máquina $]+\frac{1}{i}$;

I Atualiza operação corrente do job * /

$10 \quad o p[j o b] \leftarrow o p[j o b]+1$;

11 fim

Fonte: Autor 